\section{Introduction and Overall Assessment}

A visit to China of an American seismological delegation which took place October 5 to November 5 , 1974 , is covered in this report. The Americans were sponsored by the Committee on Scholarly Com. munication with the People's Republic of China (CSCPRC), and the hosts in China were the Scientific and Technical Association and the State Seismological Bureau. The CSCPRC is sponsored jointly by the National Academy of Sciences, the Social Science Research Council, and the American Council of Learned Societies.

The visit had its origins in an invitation extended in January 1973 by Carl Kisslinger, as President of the Seismological Society of America, to the Chinese Academy of Sciences to send representatives to a Symposium on Earthquake Pre. diction Research. Although the Chinese declined to participate, this invitation was one step towards a reciprocal exchange of seismologists between the United States and the People's Republic of China. Several months after Kisslinger's letter the CSCPRC visited Peking. Their purpose was to arrange an exchange program with the Chinese Scientific and Technical Association. Prompted by Kisslinger, the committee's proposals for American delegations included seismology. Not only was

This report was prepared by the following members of the American Seismology Delegation. Part 1: Frank Press, Massachusetts Institute of Technology, Cambridge, Massachusetts; Mary Bullock, Committee on Scholarly Communication with the People's Republic of China, Washington, D. C. Part 2: Robert M. Hamilton, U.S. Geological Survey, Reston, Virginia. Part 3: William F. Brace, Massachusetts Institute of Technology, Cambridge, Massachusetts; Carl Kisslinger, University of Colorado, Boulder, Colorado. Part 4: Carl Kisslinger, University of Colorado, Boulder, Colorado. Part 5: Manuel G. Bonilla, U.S. Geological Survey, Menlo this particular exchange accepted, but the Chinese in turn suggested that a Chinese seismology group visit the United States.

The Chinese Seismology Delegation visited the United States in the spring of 1974, and our group traveled to China in October of the same year. The reciprocal nature of this exchange made personal continuity possible. Members of the American delegation were hosts for the Chinese visit, and while we were in China, we met most members of the Chinese group. Ku Kung-hsu, chairman of the Chinese group, was closely involved with our program in Peking. Ting Kuo-yu, deputy head of the Chinese delegation, accompanied us throughout our stay in China.

We traveled in China by airplane, train, and automobile and visited a total of nine cities. Our longest stay (12 days) was in Peking, where several major research institutesthe Institute of Geophysics and the Institute of Geology-are located. Other locations visited were Tientsin, Harbin, Hsingt'ai, Sian, Kun. ming, Kweilin, Canton, and Hoyuan (the site of the Hsinfengkiang Dam). We were the first delegation sponsored by the CSCPRC to visit Kunming, Kweilin, and Harbin.

We listened to over 40 lectures by our Chinese colleagues in institutions as varied as the Institute of Geophysics in Peking and the Red

Park, California; Clarence R. Allen, California Institute of Technology, Pasadena, California. Part 6: Clarence R. Allen, California Institute of Technology, Pasadena, California. Part 7: Lynn R. Sykes, Columbia University, New York, New York; C. Barry Raleigh, U.S. Geological Survey, Menlo Park, California. Part 8: Leon Knopoff, University of California, Los Angeles, California. Part 9: William F. Brace, Massachusetts Institute of Technology, Cambridge, Massachusetts. Part 10: Ray W. Clough, University of California, Berkeley, California. Part 11: Roy Hofheinz, Jr., Harvard University, Cambridge, Massachusetts. 
Mountain Seismograph Station near Hsingt'ai. We in turn each gave a formal lecture to an audience of professors and students. Informal sessions were sometimes held in the evenings with smaller groups. Our itinerary included tours of standard seismograph stations as well as a number of field trips. A detailed description of each center visited together with a list of scientists we met can be obtained from the CSCPRC.

Our delegation arrived in China with few expectations. When the Chinese visited the United States, they gave no lectures and declined to discuss their work in seismology. Their position was that they had come to the United States to learn; we could obtain information about their methods and techniques when we paid a return visit. Moreover, little information on Chinese earthquakes has appeared in print. It was only about a year ago that the restrictions imposed during the Cultural Revolution were lifted and Chinese scientists again began to publish their work; since that time, only a few papers relating to earthquake prediction research have appeared.

The research institutes play a major role in Chinese science. For example, the Geophysical Institute in Peking, founded in 1949, originally included the fields of meteorology, seismology, and mineral explora. tion, among others, but in subsequent years as the academy was reduced in size, work in many of these areas was transferred to government ministries, and the institute's role is now centered primarily on earthquake prediction. It maintains modern electronics laboratories using solid state circuitry, a computer on the order of our IBM 7094 of about 10 years ago, and an excellent library of over 30,000 volumes with 600 current publications.

Centers such as the Geophysical Institute are responsible for all serious research as well as all graduate education that takes place in China today. When the universities reopened after the Cultural Revolution, they were transformed to schools which provided $3^{1 / 2}$-year training programs. Those students pursuing advanced scientific careers are employed by the institutes where they receive their scientific education on the job in a one-to-one relationship with a researcher. In addition to graduate education, technical on-the-job training is made available to middle-school graduates. Typically, about $300-400$ people are employed at these institutes.

Basic data for the advanced research conducted by the institutes are gathered in the field by the socalled provincial seismological brigades. A typical brigade will have its own central observatory (there are now 17 dealing with earthquake prediction) and serve as a regional center for accumulating data from a major province or group of provinces. In many cases there are also outlying stations. The library facilities are relatively poor, and the workers are mostly young and specialized.

There appears to be a trend toward the decentralization of science in China: while Peking is the source of funding for scientific programs and the large city institutes form the major intellectual centers, the data are largely collected in the provinces. A sign that the academy is becoming less monolithic is the fact that the provincial teams compose their own research programs and submit them directly to the central authorities in Peking for ratification and funding. This dual level of leadership has advantages and disadvantages; the absence of critical evaluation can result in a lack of quality control: the central authorities often accept without review the claims of the provincial brigades. In addition, communication between the different laboratories needs to be improved, and the work is extremely uneven.

A typical briefing at a provincial brigade illustrates some of the characteristics of Chinese science today. The briefing begins with an account of the advances made since the advent of the Cultural Revolution presented by the Chairman of the Revolutionary Committee (administrative director of the labora- tory), who is often a nonscientist, after which the local scientific workers describe the experiments in which they are engaged. Discussing their work in this manner is apparently an unusual experience for many of these young scientists, and when we questioned or disagreed with them they seemed unaccustomed to the give-and-take of scientific criticism which is so characteristic of the American scientific establishment.

It was in the course of these discussions that we found, to our considerable surprise, that a large-scale well-supported program in earthquake prediction is currently under way in China. Until about 10 years ago, geophysics in China was highly theoretical, and there were few workers in the field. Some very specialized papers were produced, but there was little experimental work. Major changes, however, have occurred in the last decade, and China is now embarked on a major program of earthquake research involving several hundred scientists and thousands of technicians and skilled workers, about 250 seismic stations, and approximately 5000 observation points (the latter might consist of an observatory or simply of a well where radon content is monitored). At the present time this is the main thrust of geophysical research being carried out in China with the possible exception of oil and mineral exploration efforts conducted under the auspices of government ministries.

The Chinese program in earthquake prediction encompasses every prediction method that has ever been suggested in any part of the world. Chinese scientists have kept abreast of the current literature on new techniques, and they are developing their own experiments and measurements using instruments of their own manufacture. Their seismographs are modern, and they have radon detectors in large numbers (a systematic field program of monitoring the radon content of water has yet to be established in the United States). Laser geodimeters capable of determining distances to one part in a million over a distance of $20 \mathrm{~km}$ and 


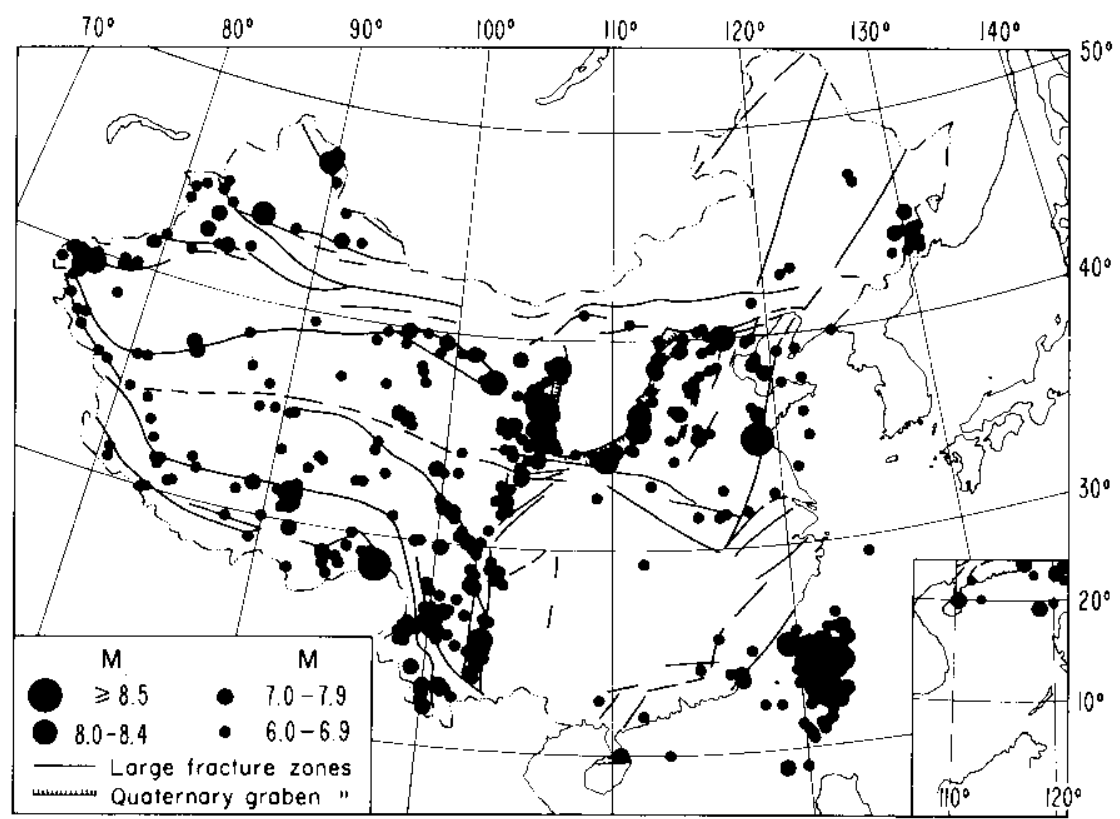

Fig. 1. Seismicity map of China, based on Shih et al. [1974b, Figure 1].

nuclear precession magnetometers are also in operation in China. (The Chinese told us that they first attempted to purchase the latter in the United States but when they were unsuccessful, proceeded under the principle of self-reliance to build such instruments themselves.) At the same time the Chinese program suffers considerably from lack of modern computers; we observed only one computer dedicated to geophysics and one to earthquake engineering throughout our tour, whereas there should be one in every laboratory to process the large number of data being accumulated. Moreover, the Chinese are not yet experienced in handling large arrays in the telemetry of data, and they lack some of the newly developed sensors now in use in the United States. However, their recent progress is amazing and bodes well for the future.

The emphasis on earthquake research in China stems in large part from the great loss of life suffered as a result of earlier quakes (Figure 1). Close to a million people perished in the Huahsien earth. quake in 1556; more recently, 180,000 people were killed in the 1920 Kansu earthquake; and last year at the time of the visit of the Chinese delegation to the United States thousands of casualties may have occurred in a single earth- quake in Yunnan Province. This high casualty rate is due partly to the nature of housing in rural villages, which is as susceptible to earthquake damage today as it was in the sixteenth century. To rebuild with stronger structures would be economically infeasible; it may be better policy to allow these houses to be demolished at the time of an earthquake and then to rebuild. Therefore the most beneficial strategy for China would be to develop accurate methods of earthquake prediction so that people can be evacuated from their homes before the quake occurs.

The immediate impetus for an intensive program in earthquake prediction came as a result of the 1966 earthquake in Hopeh Province, in which many casualties may have occurred. (The Chinese make it a practice not to reveal such statis. tics.) Chou En-lai visited the area and immediately directed that earthquake research be given the highest priority. To the Chinese government, earthquake prediction manifests the concept of science for the people: like the elimination of famine and the control of disease, protecting the people from the great scourge of earthquakes that has afflicted them for centuries is seen as an appropriate concern of the state.

The Chinese claim that they have predicted 11 earthquakes to date. Unlike an earthquake prediction in the United States, which merely takes the form of one scientist's indicating to another the possibility of the occurrence of a quake at a particular time and place, a prediction in China is a public announcement which results in evacuating people from their homes. Thus the Chinese have already had some experience with the social aspects of prediction: the problem of how to communicate this information to the public, the consequences of such warnings, and the reaction to false alarms. Since they believe that the act of predicting is in itself as important as finding the technical base for prediction, they have made public announcements and sought to evacuate people even at an elementary stage of prediction technology. If an actual quake does not take place, it is felt that the people will understand that the state is acting in their behalf and accept a momentary disruption in their normal lives. Of course, there have been a number of failures in prediction, and it is likely that a greater attempt will be made in the future to avoid false alarms.

There can be no doubt that China's program is significant and merits international attention. The Chinese have essentially doubled the earth's data base with respect to actual premonitory changes; in radon and well level measurements they have compiled more data than everyone else combined. However, their approach (like ours) has several serious drawbacks. As was mentioned, a massive empirical methodology has been adopted: the Chinese are trying everything that has been suggested without discrimination in the belief that by examining each possible technique they will find the formula for prediction. It is as if one embarked on a cancer research program in which every chemical agent was tested to determine if it would work in terms of chemotherapy, without having a conceptual model in mind and without employing the recent discoveries of molecular biology. There is no effort as yet to establish experimental design or confirm statistical validity. Perhaps as the program 
matures one might be able to challenge a worker on the statistical validity of his experiment (i.e., how does he know that the signal is greater than the noise by a certain number of standard deviations and what is the previous time history of his record before this anomalous signal appeared) and receive a proper response.

It will be interesting to see if the changes in education following the Cultural Revolution will serve to redress or increase the present imbalance between theory, statistical analysis, and experimental design on the one hand and massive experimentation on the other. Will it be possible to provide a sound education in the physical sciences. emphasizing advanced mathematics and theory, under a system in which there is a gap of up to 3 years between high school and the university, which in any case only provides a $31 / 2$-year training program, after which the student learns research on the job? The world of science will eagerly follow the unique Chinese experiment in the training of scientists. If earthquake prediction turns out to be comparatively simple, the Chinese will probably discover the successful techniques more rapidly than anyone, since they are gathering so many data with modern instruments, but if nature does not reveal her secrets easily, they may have to redesign their program.

Another puzzling factor in Chinese science that we saw is the uncritical acceptance of the claims of co-workers. For example, colleagues at the same institute may present two scientific papers at the same time. One may be a brilliant analysis and the other a document of absolutely no scientific merit; apparently it is not usual procedure to point out the inadequacies of a colleague's work. The reason for this lack of critical evaluation is unclear: it may be that in China criticism is considered elitist in that the critic establishes himself above the one being criticized, or perhaps it derives from the fact that during the Cultural Revolution there was a lack of scientific meetings, peer review, and publication, which would have provided workers with this kind of experience. On the other hand, our opinions and criticisms were frequently solicited.

Tens of thousands of amateurs are working on earthquake prediction; they may monitor professional instruments or they may participate in public education campaigns by reporting to their communes the latest results and information relating to appropriate procedures in case of an earthquake. This is a highly original development which we may wish to copy. However, there is a potential shortcoming in this procedure: since it is important for the scientists to consider the wisdom of the masses, fanciful claims may not be disputed; if a zoo keeper reports that a tiger is ill and an earthquake occurs 3 days later, that report might be included in the relevant data despite the fact that it was not based on a controlled experiment.

Ultimately, one cannot evaluate the Chinese earthquake prediction program in terms of the American experience. From a base level of essentially zero in geophysical science, the Chinese embarked on a large-scale effort involving massive data gathering with sound instruments and skilled technicians. Their program in terms of commitment and technology ranks with the best. Our own research was developed on the basis of an advanced geophysical science, employing techniques for the detection of nuclear explosions which provided experience in the use of arrays and large computers and led to the development of modern sensors and their deployment in remote areas. We view the Chinese program as being in a transitional stage with strengths and weaknesses; if shortcomings are present, the Chinese may well recognize them and take corrective measures. In any case, we think that our visit had a profound influence on us and on the Chinese. The great potential power of Chinese science was demonstrated to us. We probed, questioned, criticized, and were frank with our praise and criticism, as we are with each other. Our Chinese hosts appeared to take this in terchange of ideas seriously.

Considerable benefit might be derived if the Chinese and the
Americans were to launch a cooperative earthquake research effort. The Chinese are predicting earthquakes now. Their latest success, according to news dispatches, was the prediction of the destructive magnitude 7.3 shock of February 4, 1975, in Liaoning Province. Knowledge of their procedures and results would be invaluable to us. We in turn could help Chinese scientists establish programs in rock mechanics, provide them with sensors not yet in their arsenal of equipment, and give access to our precursory data and to computers. We could help with experimental design and provide insight to the physical basis of their research; they could furnish us with a data base substantial enough to progress more rapidly to earthquake prediction than we could under our own program as well as provide us with information on the public response to earthquake prediction. The Chinese earthquake catalog, extending back 2500 years, is a gold mine of data for researchers interested in earthquake statistics, recurrence rates, 'flow' of seismicity, etc. Chinese seismicity and tectonics await an interpretation in the context of plate tectonics. Perhaps the idea of continental mini-plates will find its verification in China. These are but a few examples of possible areas of cooperation and joint research. Unfortunately, the problem of Taiwan may make it politically infeasible for the scientific communities of the two countries to join forces in the near future; however, in our enthusiasm for the potential of a joint effort, our delegation submitted a proposal to the Chinese detailing the advantages of a cooperative program. If a pooling of the knowledge and expertise of international scientific communities could be accomplished, there is little doubt that accurate earthquake prediction would become a reality in the foreseeable future.

\section{National Program}

The earthquakes of magnitude 6.8 and 7.2 that struck Hopeh Province on March 8 and 22, 1966, added to a long history of seismic disasters in China: the world's largest death toll from an earthquake occurred 
there in 1556 , when at least 820,000 people were killed in Shensi Province, and an earthquake in Kansu Province in 1920 killed 180,000 people. The devastation wrought by the 1966 earthquakes brought governmental attention to the earthquake threat and led to the current national program in earthquake studies. Earthquake studies in China now rank very high in priority compared with other scientific programs, a situation that can be envied by American scientists engaged in earthquake studies.

The current concern about earthquakes in China contrasts sharply with past attitudes. Our delegation was told on numerous occasions that the immense suffering from earthquakes was not alleviated significantly by earlier governments. Indeed, until the mid-1960's, earthquake research was not a high priority subject. The Communist government's attitude of concern for the people was demonstrated by Premier Chou En-lai's visit to the area stricken in 1966, and the subsequent research program provides visible evidence of the government's dedication to reducing the impact of such disasters in the future.

The emphasis given to the earthquake program derives in part from the fortuitous circumstance that the 1966 earthquake occurred as the Great Proletarian Cultural Revolution was beginning. A criticism leveled during the Cultural Revolution was that science does not serve the people and that scientists live in an ivory tower and are not concerned with the nation's problems. The program to predict earthquakes could well be intended to demonstrate how scientists can combine with workers, peasants, and soldiers to solve a problem of great national concern.

\section{Program Goals}

The main thrust of geophysical and geological studies under the Chinese earthquake program is to predict the location, magnitude, and time of future earthquakes. Capabilities throughout the earth sciences are centered on this goal in an effort that is impressive because of its sharp focus. The largest activity in earthquake studies not aimed at prediction is earthquake engineering, which has the goal of evaluating the earthquake performance of structures. Considering relative personnel levels, however, the earthquake engineering goal ranks below the earthquake prediction goal in priority.

The Chinese and American na. tional earthquake programs differ markedly. In the United States, expenditures for earthquake engineering in fiscal year 1974 ( $\$ 8$ million) represented more than a third of the total earthquake funds and more than twice the expenditure on earthquake prediction. In addition to prediction and engineering, the U.S. earthquake program has goals of earthquake hazard mapping, which is funded at about the same level as earthquake prediction, seismic risk assessment, and earthquake control. Seismic risk assessment is, in fact, included in the Chinese program as a technique of long-range prediction or a means of identifying areas for intensive study. Earthquake control in the United States is funded at such a low level that it ranks as a secondary objective.

A logical explanation can be offered for the difference between the Chinese program with its emphasis on earthquake prediction and the American program which ranks earthquake hazard mapping and seismic risk zoning, both for land use planning, on a par with prediction. In China, mud and masonry houses with heavy tile or mud roofs are common and are vulnerable to collapse in earthquakes. In the United States, wooden frame houses with light roofs are widely used and stand up well in earthquakes. Evacuation of housing, which is made possible by earthquake prediction, is consequently much more important in China. Cultural differences with respect to land use are additional factors in shaping Chinese and American earthquake goals. About $80 \%$ of the Chinese population are engaged in food production and live mostly in small villages scattered over the arable land. China has about the same acreage of arable land as the United States but 4 times the population, so virtually all usable land is cultivated. Many traditions and beliefs are associated with the land. These several factors make American ideas such as setting aside earthquake-prone land for a golf course or cemetery or zoning land for population density based on seismic risk irrelevant solutions for China's earthquake hazard.

\section{Program Management}

When China's earthquake predic. tion program was launched in 1966, no provision was made for central direction. Each organizational group with a capability to conduct earthquake studies organized and carried out its own program. It was later recognized that the resulting program was too scattered and needed more coordination, so in 1971 the situation was significantly changed with the creation of the State Seismology Bureau (SSB). The SSB was formed within the Chinese Academy of Sciences, a cabinet level agency under the State Council that is responsible for scientific research throughout China.

The SSB has overall responsibility for the earthquake program. Its tasks include (1) preparation of a comprehensive budget proposal for submission to the Academy of Sciences, (2) allocation of funds, (3) distribution of instruments (the SSB funds the Peking Seismograph Factory), (4) establishment of personnel levels (the assignment of individuals is done through discussions between the SSB and the provincial Party and Revolutionary committees), (5) organization of conferences (e.g., to coordinate the operation of the network of standard seismograph stations), (6) distribution by cable of data (not much being done in this area now), and (7) compilation of predictions made by the provincial seismological brigades.

The SSB does not train seismological workers. Training is done by the various research groups, by univer. sities, and by provincial brigades, groups, and teams through shortterm courses.

The SSB is responsible for leadership of the Institute of Geophysics and the Institute of Geology in Peking, the Institute of Engineering Mechanics in Harbin, and the Seis- 
mological Survey Brigade in Tientsin. It manages the personnel in all these groups; however, in the program area the SSB is responsible only for their earthquake-related studies. Other groups similar to the SSB in the Academy of Sciences develop programs for the other studies, except in the field of geology, which is also handled by the SSB because there is no other group in the Academy of Sciences to do the job. Geologic mapping, exploration geology, and many other geologic studies are carried out in another government ministry, the Bureau of Geology.

The SSB is also responsible for the earthquake studies carried out by provincial seismological brigades, groups, or teams, but the SSB is not directly responsible for their leadership. The leadership for these units comes from the local organizations. Each provincial unit submits an annual proposal to the SSB which is reviewed in relation to the national goals, and a grant of funds is made. The annual proposal for funding to the SSB includes ideas on how to distribute earthquake information to the people and how to organize the people to combat earthquakes, suggestions for new instrumentation, and studies and information about accomplishments. The provincial units are responsible for the conduct of all aspects of their studies. These studies are organized at the provin. cial, regional, and county level and are overseen by the Party and Revolutionary committees.

The role of the provincial units is to conduct earthquake studies within each province, organize the participation of the people, and disseminate earthquake information to the people. The responsibilities include (1) operation of a standard seismograph station (not all provinces have one), (2) operation of a regional seismograph network, (3) operation of various other types of geophysical instrumentation, (4) determination of provincial seismicity, (5) construction and distribution of indigenous instruments, such as ammeters for detecting telluric currents, and tiltmeters, and (6) issuance of earthquake predictions.
As provincial teams and groups are smaller than brigades, their tasks may not include all of the above.

The universities have no direct relationship with the SSB and play only a minor role in the earthquake program.

Although the main task of the SSB is program management, it also carries out research. A section is being established to keep abreast of the earthquake program all over China, to be informed of results from principal stations, and to evaluate proposed predictions of large shocks.

Personnel of the SSB presently number about 70 , including about 20 research scientists. The staff was drawn mostly from the Institutes of Geophysics and Geology of the Academy of Sciences and from the Geodetic Survey Brigade at Tientsin. It is planned to rotate SSB personnel with tenures of 3-5 years.

The role of the SSB is evolving rapidly. Only recently its responsibilities were such that Boll [1974] made only brief reference to a new 'Earthquake Bureau.' Further changes are expected.

\section{Scope and Strategy \\ of the Program}

Ten thousand workers participate in China's earthquake program. They include all types of personnel: scientific, technical, and clerical workers, laborers, etc. At first our delegation was skeptical that the number could be so large, but as we learned about the activities at the various centers, the numbers began to add up. (See preceding section.) In addition to the trained people, there are many thousands of amateur workers assisting in the program. This is a truly unique aspect of the Chinese program and one that appears to be very useful in guiding public response to earthquake prediction: because the people are active participants in the program, they are somewhat familiar with the evidence used for predictions, and when predictions fail they are not as given to recriminations.

Trained personnel associated with earthquake studies in the United States number of the order of one thousand, one tenth the Chinese personnel. (This disparity is offset somewhat by the extensive use of telemetry in the United States.)

The overall strategy of the Chinese program is to detect longand short-term geophysical and other anomalies that will warn of impending earthquakes. The phenomena observed include (1) seismicity patterns-migrations and temporal variations in activity; (2) seismic wave velocities-variations in $P$ and $S$; $(3)$ radon in well water; (4) telluric currents; (5) geomagnetic field; (6) earth tilt; (7) earth strain; (8) vertical land deformation-leveling surveys; (9) horizontal land deformation--triangulation and trilateration surveys; (10) ground temperature; (11) water level in wells; (12) bubbling, muddling, and swirling of water; and (13) animal behavior. Thus the Chinese program includes virtually every type of observational study conducted for earthquake prediction elsewhere.

The observational program is most advanced in the installation of seismographs. The network of 17 standard stations is of high quality and ranks with the World-Wide Network of Standardized Seismograph Stations. The 250 regional stations, although they do not utilize telemetry to facilitate recording and analysis, produce excellent photographic and ink records. Other instrumentation is not as extensively deployed, but tiltmeters, various types of strain measuring devices, and magnetometers are common. Leveling, triangulation, and trilateration surveys are well organized and are apparently conducted often. The excellent deformation data obtained for the 1966 earthquakes indicate the high quality of the survey activities.

The approach of the Chinese earthquake program is mainly em. pirical in that installation and operation of instruments and surveys dominate the activities. Although theoretical and laboratory studies are underway, the balance compared with other national earthquake programs is clearly toward instrumental and other field observations. For example, theoreti- 
cal studies of earthquake source mechanism and laboratory studies on conditions of rock failure receive much more attention in the United States. Perhaps as more workers are trained in China, theoretical and laboratory studies will have more emphasis.

The earthquake studies are geographically dispersed with important centers of study in or near Peking, Tientsin, Hsingt'ai, Harbin, Sian, Kunming, Hoyuan, Lanchow, and probably many other cities. Our delegation was continuing to learn of additional places even toward the end of our visit. The places visited are listed below; detailed information about each place is given later in this report.

Peking: State Seismological Bureau, Institute of Geophysics, Institute of Geology, Peking University, Tsinghua University, Paichiat'an Seismological and Geomagnetic Station (Peking Station), Seismograph Factory, Tahuich'ang Crustal Deformation Observatory.

Harbin: Institute of Engineering Mechanics.

Tientsin: Geodetic Survey Brigade for Earthquake Research.

Hsingt'ai: Red Mountain Observatory.

Sian: Chihwuchen Seismograph Observatory (Sian Station).

Kunming: Kunming Station.

Canton: Hsinfengkiang Sam Station.

\section{Chinese Universities and Institutes}

We visited those universities and research institutes (with the exception of the Science and Technology University) where essentially all of the seismological studies go on. We inspected laboratories and shops, met most of the leading researchers and teachers, and listened to accounts of some current research. We summarize below the factual information gained on the research programs, as well as our impressions of the general climate of scientific research and higher education today in China. Details of specific programs will be found in later sec tions.

Research and formal teaching are almost evenly divided between the institutes and universities, although the institutes perform extensive onthe-job training, and some undergraduate research is carried out in the universities.

\section{Universities}

Two major Chinese universities are in Peking. Peking University is the older and has departments in many sciences. Engineering is taught exclusively at Tsinghua University.

\section{Peking University}

Peking University, founded in 1898 , is located on a beautiful campus in the northwestern part of the city. It offers programs in 75 specialties, organized in three main branches: liberal arts, foreign languages, and science. As was observed during visits to the various seismological brigades, the Geophysics Department of Peking University is the primary source of college-trained seismologists in the country. The university was profoundly affected by the Cultural Revolution and began accepting students again only in 1970 .

The present enrollment is 7000 , a maximum of 8000 undergraduates being planned. No graduate programs are offered, as a result of the decision evolving from the Cultural Revolution to emphasize undergraduate instruction. The changes that have occurred at Peking University are typical of the revolu. tion in education that has taken place throughout China and illustrate the consequences of implementing Mao Tse-tung's policy: 'Education must serve proletarian politics; education must be combined with productive labor.'

With emphasis on simplifying and concentrating the subject matter, most programs have been reduced to $3^{1 / 2}$ years. Some specialties, such as foreign languages, go for 4 years. The faculty expressed its satisfaction that the quality of the recent graduates is high. All students are required to participate in a graduation research project for 6 months at the end of their program. They work in teams, in close cooperation with a faculty member. The topics are chosen on the basis of their practical applicability to real problems. As part of the effort to integrate teaching, research, and production, seven factories are now operated within the university.

With no graduate training or advanced degrees offered, teàchers are trained on the job. This year 300 graduating students were retained to be trained as teachers, 'to learn war by fighting the war.' The 300 were selected on the basis of proletarian background, political reliability, good grades, and good health. Of this number, three were in geophysics.

The policy on admitting students is described under the description of Tsinghua University. There are currently 70 students enrolled in geophysics, 80 in astrophysics, and 100 in meteorology. Instruction has been reorganized to reduce the size of introductory course classes greatly. For example, each science department has its own first-year physics class, so that there are about 20 students in a class. Undergraduate mathematicians take an introductory course in mathematical physics, including some work in special functions.

During the brief visit it was possible to see only a small part of the facilities. The computer, used by faculty and students, was designed and built at the university. The 130,000 twenty-four bit word machine executes 150,000 operations per second. Remote terminals to be installed around the campus are now being debugged.

The Geophysics Department has a well-instrumented seismograph pier dedicated to instructional use. The rock mechanics laboratory has a 100 -ton press which is currently being used to study electrical properties of rocks as described in section 9 . We met five faculty members of the Geophysics Department.

\section{Tsinghua University}

Tsinghua University was founded in 1911 with the help of Boxer indemnity funds returned by the United States. It has the following 11 departments, with some representatives whom we met: architectural engineering (Ch'en Tan), hydraulics (Liu Kuang-t'ing), electronics, radio, automation, electric 
power, mechanics (Liu Hsin-sheng), precision instruments, engineering chemistry, engineering (nuclear) physics, and engineering mechanics (Tu Ch'ing-hua). Most departments have associated laboratories or workshops. Many workshops are small factories employing permanent workers (1500 in the whole university) who manufacture various items on a production basis. For example, in the mechanical manufacturing workshop, some 75 machinists worked together with students and teachers in the production of a computer-controlled vertical miller.

Nearly 2000 students graduated in March 1974 out of a student body of 7000 (one third female) and a teaching staff of 2000 . All students require $3^{1 / 2}$ years to complete their studies; a year has only 5 weeks of vacation. Typically, a student's time is divided as follows: $80 \%$ professional (a third in shop or laboratory), $15 \%$ political theory, and $5 \%$ physical labor. The final 6 months is devoted to a 'graduation exercise,' a cooperative effort of several students, teachers, and shop or laboratory technicians. The main objective is to solve some immediate practical problem. Some tasks may be suggested to the university by the State Planning Commission.

Research at Tsinghua seems to be limited to graduation exercises. There are no graduate students as such. Publication is restricted to short reports in the Tsinghua Journal. The library contains 1.3 million books, a third of which are in foreign languages, and 2000 periodicals. We noticed that fewer books circulate now than prior to 1966 .

The educational background of the teachers varies. A few older ones, often called 'professors,' obtained advanced degrees in China or abroad. Many others have had the 6-year undergraduate program in existence at Chinese universities before the Cultural Revolution. Still others, including 120 new teachers from this year's graduating class, have had only the present $3^{1 / 2}$-year training.

Admission to Tsinghua University is based both on the country's needs in certain fields and on an individual's ability and political con- sciousness. Following high school an aspiring student must spend 2-3 years in military training or in farm or factory work. His application must have both the approval of the commune, factory, or military leadership and the approval of the university. He is thus drawn in fact from the ranks of the workers, soldiers, and peasants. Graduates of Tsinghua University enter industry, various engineering businesses, or institutes or remain to teach.

The Cultural Revolution had a profound effect on Tsinghua University in general leadership, in admission procedure, and in curriculum. Direction of the university, previously in the hands of faculty, now rests in the hands of a committee of workers, teachers, and political cadre or advisors. Admission, previously on the basis of examinations, now follows the procedure outlined above. The ideal student must be both a political activist and one who can grasp and solve practical immediate problems. The curriculum previously extended over 6 years; learning occurred through contact with teachers and books. Now a $3^{1 / 2}$-year period is required, and as much as half a student's training occurs in the laboratories, shops, or departmental factories. He has extensive contact with the technicians and workers.

\section{Research Institutes}

The organization of seismological research underwent a major change in 1971 with the founding of the State Seismological Bureau. Prior to that time, earthquake-related research was carried out in various organizations. A Ministry of Geology and a Ministry of Petroleum existed prior to the Cultural Revolution, both of which employed personnel doing work in seismology. The Geology Ministry is now a department of the State Planning Commission; after our visit the existence of the Petroleum Ministry was announced for the first time since the Cultural Revolution. How much seismological research these units perform is unknown.

A complete list of Chinese research institutes was not available to us, so some relevant studies may have been overlooked in fields such as fracture mechanics. We learned quite by accident while we were at Harbin of the existence of the Institute of Rock and Soil Mechanics at Wuhan. A visit there could not be scheduled at that late date; we were told that the senior researcher there is Tan Chen.ko. Rock excavation and slope stability, tunneling, and rheology of rock and soil are some of the topics under investigation at Wuhan.

\section{Institute of Geology}

The original mission of the Institute of Geology was to carry out studies in structural geology and mineral exploration. The institute's scope expanded rapidly following the Great Leap Forward of 1958 , with the development of programs in igneous petrology, sedimentology, isotope geology, engineering geology, and mineral resources. Following the Cultural Revolution a further reorganization took place, with some activities transferred to the Bureau of Geology (formerly the Ministry of Geology), and the establishment of the following units, called research rooms: (1) structural geology, (2) neotectonics and Quaternary geology, (3) subsurface geology, (4) mathematical geology, (5) engineering geology, (6) minerals and igneous petrology, (7) sedimentology and stratigraphy, (8) isotope geology, (9) chemical analysis. In addition, there is a wellequipped machine shop. At the present time, primary emphasis is directed to seismogeologic problems. There is no computer facility at the institute; presumably that at the Institute of Geophysics is available.

The radiocarbon laboratory has been in existence since 1972. The gas method (conversion to $\mathrm{C}_{2} \mathrm{H}_{2}$ ) is employed, yielding ages up to 50,000 years. A typical precision for intermediate ages was stated to be $\pm 4 \%$. Some use of the laboratory is made to date Holocene faulting.

Older ages are determined in the isotope laboratory using both $\mathrm{Rb} / \mathrm{Sr}$ and K/Ar. About 30-40 Rb/Sr analyses per year are made with Russian-made equipment of 1959 vintage. The region of greatest interest is northeast China in predominantly Precambrian terrain. 
The oldest rocks so far dated (2.7 billion years) are found in Kirin Province. The K/Ar method has been used since 1970 primarily for whole rock ages of Mesozoic volcanic rocks.

The mass spectrometer used was made in China in 1964. Isotopes with mass numbers $1-80$ can be determined to a precision stated to be a part in $10^{9}$. The vacuum system is capable of $10^{-8}$ torr.

The high pressure-high temperature laboratory is used exclusively for rock mechanics, and details of the equipment and research program are given in a later section on that subject.

The geothermal laboratory is devoted at present to thermal conductivity determinations in order to interpret a large backlog of measured temperature gradients. A standard divided bar method is used for the conductivity measurement on samples extracted largely from oil wells in the plains of northern China. A group, whom we did not meet, at Peking University is measuring heat flow in western China. A small geothermal pilot plant is also in operation, but we were given no details.

A program of magnetotelluric deep sounding begun in 1970 is directed at both crust and upper mantle structure and at interpretation of earthquake precursors observed throughout China. In this work a five-channel recording is made, including three components of the magnetic field and two of the electric field. The records are hand digitized and interpreted using standard Cagniard theory. Amplifiers and filters used seem particularly well designed and constructed.

A photoelastic laboratory, previously used for engineering ap. plications, is now directed at twodimensional analysis of tectonic problems. We were shown one plate of photoelastic material in which the elastic stress distribution was displayed around a system of faultlike fractures and other discontinuities.

Some 300 scientific workers are currently employed at the Institute of Geology. Many of the new staff are drawn from university gradu- ates in both the earth sciences and the engineering field. On-the-job training is widespread since the Cultural Revolution, particularly for high school students. Nearly 100 are now at work in the institute; they are being trained in the scien. tific laboratories and machine shops.

We were not shown a library at the Institute of Geology. Most publications appear in Acta Geologica Sinica or Acta Geophysica Sinica.

\section{Institute of Geophysics}

The Institute of Geophysics of the Chinese Academy of Sciences has major responsibility for carrying out the program of seismological research that has been developed by the State Seismology Bureau. Chang Chin, responsible person of the Revolutionary Committee of the Institute, greeted our study group, and $\mathrm{Ku}$ Kung-hsu, vice director of the institute, provided a general briefing on the program. The group heard 2 full days of presentations on recent research in the institute. These results are incorporated elsewhere in this report.

The institute was founded in 1949 with four branches:meteorology, geomagnetism, seismology, and geophysical prospecting. Subsequently, meteorology and geophysical prospecting were transferred. Major adjustments in the research programs have been made since the Cultural Revolution, with increased emphasis on providing better service to societal needs. Earthquake prediction is established as the top priority goal.

Prior to 1949 , only two seismological stations and two geomagnetic observatories were operated in all of China, with fewer than 10 people engaged in work in these disciplines. Presently the staff of the Institute of Geophysics consists of 400 persons; there are 17 standard seismograph stations distributed through the country, 250 regional and local stations, and 8 geomag. netic observatories, as mentioned earlier.

The scientific program of the institute is organized into four sections devoted to seismology and general geophysics and one section of geomagnetism. One section works on characteristics of regional seismicity, with the task of searching for regularities in seismicity. The second section does seismic risk analysis for all of China. One of their tasks is the selection of places for short-range prediction studies. The work proceeds primarily on the basis of the statistical analysis of the historical record of earthquakes, with the purpose of establishing patterns of earthquake occurrence with respect to time, place, and magnitude.

The third section studies the structure of the crust and earth's interior. It is a new activity, without much yet accomplished. The fourth section works on seismic instruments and observation techniques. Current studies are directed to improved telemetry systems and automation of data processing.

The section on geomagnetism is now engaged in making a groundbased magnetic survey of the entire country. Geomagnetic methods for earthquake prediction are also under investigation. Observations of electrical conductivity for studies of crustal and upper mantle struc. tures are also the responsibility of this section.

Instrumentation laboratories that were inspected included the magnetometer laboratory, in which work on both an alkali vapor instrument and flux-gate sensors is in progress. Current work in the telemetry laboratory is on an improved hard wire system for transmitting long-period signals by telephone line. A borehole seismometer that is in the testing stage is described in a later chapter on instrumentation. The electronics laboratory is dedicated primarily to the development of new amplifiers for use in observatory seismographic systems.

The data from the 17-station standard network are sent to the institute, where hypocenters are determined and an annual sum. mary of Chinese earthquakes is prepared. The 1972 issue of this summary has just been published. Data from the International Seismological Center and the U.S. National Earthquake Information Service 
are used in the Chinese hypocenter determination work.

The institute operates an eightstation regional network around Peking and is responsible for fast determination of nearby events. The recording room for this telemetered network is manned 24 hours a day. A magnetic tape recording capability has been developed recently, and computer programs for automatic processing of the data from the network have been written.

The computer facility of the institute is built around a DJS- 6 solid state computer installed in 1971 . The core memory is 32,000 fifty-bit words, including sign and parity. In the floating point full-word mode the processor executes 50,000 operations per second, with an increase to 70,000 per second in the fixed point half-word mode. Additional memory of 60,000 words is provided by four magnetic drums. An $X$ - $Y$ plotter, a line printer capable of fifteen 160-character lines per second, a five-track paper tape reader, and a teleprinter are among the accessory units. An analog/ digital converter for processing the data from the eight-station network is capable of handling 30 signal channels.

The institute has an excellent library. A good collection of important works in English, Japanese, and Russian is available to the research staff. Complete sets of many important scientific journals, including very recent issues, are held. Research results by institute workers are published in Acta Geophysica Sinica.

The institute has an active program of training scientists. The older, experienced personnel train the young people in a planned way. The persons receiving this training are generally not university graduates but those that have come to the institute from middle school. In addition to this program of basic scientific education, there is also a program to raise the professional level of the scientists on the staff. Along with the scientific training, there is emphasis on learning foreign languages, especially English and Japanese.

The main method of training is through practice. After completing experiments the trainees summarize their experience and contemplate what they have learned and where they have failed in a continuing effort to improve their technical level. This method of training is used throughout China. There is no system of examinations or degrees. As Ku Kung-hsu said, 'The work is the examination.'

\section{Instilute of Engineering \\ Mechanics}

This is described more fully in section 10 . We note simply that current work here, under the direction of Liu Hui-hsien and $\mathrm{Hu} \mathrm{Yu-hsien,}$ consists of investigation of damaging earthquakes; study of strong earthquake motion and development of strong motion instruments; studies of foundation problems and factors influencing site intensities; design of earthquake-resistant bridges, dams, industrial buildings and housing; and preparation of design codes for construction in seismic areas. Unlike earthquakerelated studies elsewhere in China, the Harbin effort has been in full swing since 1954 , well before the Cultural Revolution.

\section{Dissemination of \\ Research Results}

The Acta Geophysica Sinica and Acta Geologica Sinica are the most important media for publication of research results in seismology. Papers to be submitted for publica. tion in these journals are first subjected to internal review and criticism within the author's own organization and then further reviewed by an editorial board made up of senior scientists. The most recent issues of these journals carry as lead articles papers relating research in the earth sciences to the current vigorous campaign of criticism of the philosophy of Confucius and of Lin Piao. This campaign is an integral part of the follow-up to the Cultural Revolution and is intended to further remold Chinese society. Although the inclusion of such material in a scientific journal is startling to an American observer, it is understandable within the context of contemporary Chinese life.

The State Seismology Bureau organizes conferences on seismolo- gy and especially earthquake prediction. These conferences are aimed at the usual transmittal of research results and sharing of research experiences as well as at discussions of methodology and adoption of uniform standards for instrument operation and data han. dling. No details of the frequency of these conferences or their publications were given.

The Chinese Geophysical Society, of which $\mathrm{Ku}$ Kung-hsu is president, embraces many fields in geophysics, including exploration geophysics and atmospheric science. It does not now publish a journal but holds meetings in various parts of China. Scientists join the society as individuals and pay no dues. The Chinese Geophysical Society is also responsible for participation of its members in international meetings.

In addition to regular serial publications, we also saw research reports published in offprint form. These are locally produced and distributed by the sponsoring institute to other interested research workers in the country.

\section{General Scientific and \\ Academic Climate}

It is difficult to appraise China's scientific and academic climate on the basis of a visit as short as ours. One or two aspects are fairly clear; however, our other conclusions must be regarded as little more than personal impressions. Hopefully, they hold for students wiser than we some clues as to directions China will take in the near future.

First, two events in 1966 had a profound effect both on geologic research and on university life. The Hsingt'ai earthquake and the reaction it produced on China's leadership caused an abrupt change of emphasis in the earth sciences. The change could hardly have been more strongly felt than in the Geological Institute, for which earthquake prediction suddenly became the major task. The Geophysical Institute was also strongly affected; it doubled and intensified its seismological studies.

The second event, the beginning of the Cultural Revolution, resulted in profound changes in China's universities. Some detailed effects 
were noted above. In general, university training became much more practical, more closely coupled to actual production and immediate problem solving, and accessible only to students who were physically strong and both mentally and politically active. Curricula have been completely revised, and the relations between faculty and students totally altered. Libraries, lectures, and books now share a major portion of a student's time with routine laboratory or factory production work. The university product is expected to be 'Red and expert.'

\section{Geophysical Instrumenta- tion and Observatories}

During visits to research institutes, universities, observatories, and the principal Chinese seismograph factory we were able to view a variety of geophysical instruments in use now and to gain some insight as to work in progress on new instruments. Only instruments used for specifically geophysical measurements will be reported on, and descriptions of general purpose laboratory equipment, such as signal generators and oscilloscopes, will be omitted. The mass spectrometers used in the Institute of Geology for age determinations and the two computer facilities visited are described briefly in section 3 .

'Self-reliance' is the cornerstone of the contemporary Chinese approach to problem solving, and the impact of this philosophy on the development and production of scientific instrumentation is readily apparent. Older observatory seismographs, either made in the USSR or made in China from Soviet designs, are being replaced with new instruments of Chinese design and manufacture. The only important modern foreign-made equipment seen in use was a Japanese digitizer used in Harbin for processing strong motion seismograms.

As a result of the high priority that has been given to earthquakerelated research, laboratories for the development and testing of new or improved instruments and a factory for mass production are very active now. Although no real in- novations or new principles for instrument design were seen, it is clear that the Chinese are producing first-class equipment that functions well and is made to high professional standards.

In addition to descriptions of the instruments seen, the several observatories visited will be briefly described. No equipment for use in exploration geophysics was seen.

\section{Seismological Instruments}

Strong motion instruments. Sixty permanent strong motion stations are now installed in the most seismically active areas of China, and some mobile units are available to be moved in for observations of aftershocks of major earthquakes. The instruments have been designed by the Institute of Engineering Mechanics in Harbin, and most of the strong motion stations were established by that organization. However, the operation and maintenance of most of the stations is the responsibility of provincial seismological brigades or other local or regional groups, and the Harbin group is directly responsible for the operation of only the network of some 19 stations around Peking. Although local groups keep their records, copies of strong motion records are sent to Harbin for analysis, and between 200 and 300 clear records have been obtained. Regular maintenance visits are made every 1-2 months.

Only one system will be described in detail, the RDZ-1-12-66 strong motion accelerograph, which is now the standard equipment for the strong motion program. Older instruments were seen in a few places, but they are gradually being replaced. The RDZ-1-12-66 was designed in 1965, and the prototype was completed in 1966 at the Institute of Engineering Mechanics in Harbin. It is now manufactured by the Peking Geological Instrument Factory.

The system is based on a 12-channel oscillograph, with a normal complement of eight horizontal and four vertical pickups (Figure 2), to be distributed throughout a structure as desired. Two mechanical triggers are provided. The system is powered by a $24-\mathrm{V}$ nickel-cadmium battery. The important system parameters are as follows:

1. Trigger: natural frequency, $1.5-2.0 \mathrm{~Hz}$; damping, 0.1 critical; maximum triggering sensitivity, 0.5 Gal; normally operated at 5-10 Gals.

2. Pickups: natural frequency, $4.0 \mathrm{~Hz}$ (horizontal), $4.5 \mathrm{~Hz}$ (vertical); coil constant $57 \mathrm{~V} \mathrm{~s} / \mathrm{m}$; coil resistance, $43 \Omega$.

3. Galvanometers: natural frequency, $120 \mathrm{~Hz}$; current sensitivity,

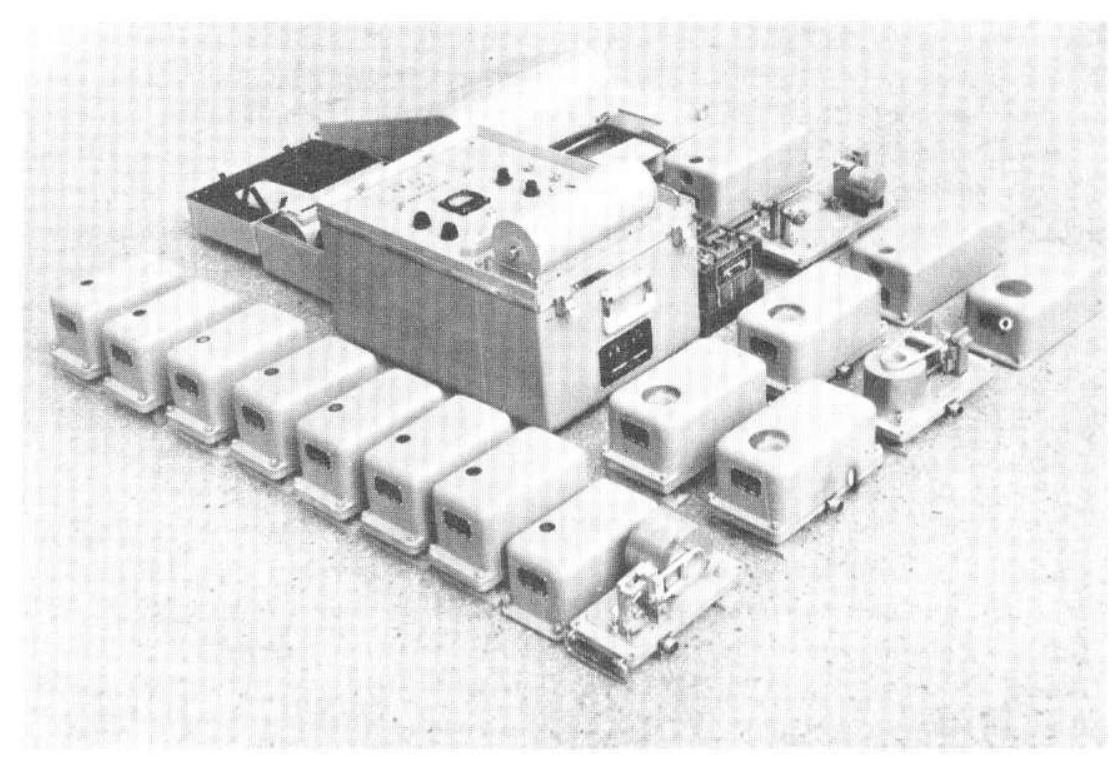

Fig. 2. The 12-component RDZ-1-12-66 strong motion accelerograph (Peking Geological Instrument Factory). 
$2700 \mathrm{~mm} / \mathrm{mA} / \mathrm{m}$; coil resistance, 50 $\pm 10 \Omega$; resistance of external circuit, $180 \pm 50 \Omega$.

4. Amplifier: flat from 0.7 to 20 $\mathrm{Hz}$; down $10 \%$ at 0.5 and $35 \mathrm{~Hz}$.

5. Oscillograph: recording paper, $20 \times 2000 \mathrm{~cm}$; chart speeds, 2.1 , 4.8 , or $11.3 \mathrm{~cm} / \mathrm{s}$; time marks, $20 \mathrm{~Hz}$ $\pm 1 \%$; dimensions, $49 \times 35.8 \times 35.3$ $\mathrm{cm}$; weight, $35 \mathrm{~kg}$.

6. System: frequency response, 0.5-35 Hz; dynamic range, 5-1000 Gals.

Results with this system have been good. The principal problem encountered is that weight of the oscillograph is excessive, and work on a lighter weight model is underway.

At the Hsinfengkiang Dam two complete systems are installed, providing 24 data channels. The triggers for the two systems are set at different levels, so one will turn on for any local event greater than magnitude 2 , but a magnitude 3 or greater is required to activate both systems. The two triggers for one system are positioned orthogonally, as each has a single degree of freedom. The system at the Kunming Seismograph Station is operated at a sensitivity of $1 \mathrm{~mm} / \mathrm{Gal}$.

Another, older instrument, known as the model 513 intermediate strong motion instrument, is a mechanical two-component horizontal, with a free period of $4 \mathrm{~s}$, recording on smoked paper at a magnification of 50 . This was seen in the permanent seismological observatories, and apparently a fairly large number of these are deployed around the country.

Short-period observatory instruments. The most recent standard short-period seismographic system used in permanent observatories is designated the DD1. The prototype of this system was produced in 1971 , and after a period of field testing and modification, the Peking Seismograph Factory went into full production, turning out 100 sets in the past 3 years. A batch run of this system was in progress during our visit to the factory.

The system records three components, with flat response in the range $0.1-1 \mathrm{~Hz}$. Recording is on a well-designed three-channel ink recorder, the first such recorder to be put into use in China. System

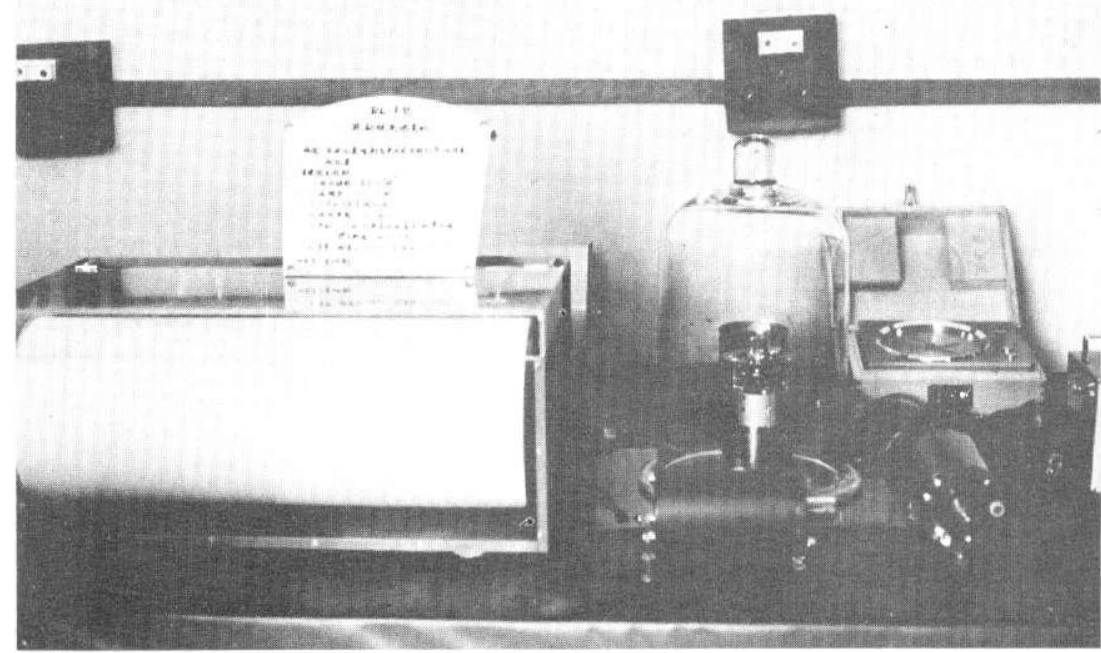

Fig. 3. The DL-1 mobile seismograph station. The three-component pen and ink recorder is to the left, the three pickups to the right, and the quartz crystal clock to the rear (Peking Seismograph Factory).

magnifications ranged from 20 to 30,000 at the Peking Station to 380,000 at the Sian Station. The Chinese will sell a complete DD1 system for $\$ 6000$.

A variety of other short-period systems are still in use, even in those places in which the DD1 has been installed. An instrument similar to the unit known as SKM in the USSR was seen in some places. A system called type 62 , consisting of a 1.5-s seismometer and a $0.4-\mathrm{s}$ galvanometer was seen at Peking and Kunming stations (50,000 magnification). Another short-period system, designated type 64 , is based on a 1.5-s seismometer and a 0.1 -s galvanometer. One system operating at 60,000 magnification was seen on a pier in the Kunming Station.

Portable seismograph stations. A new mobile system to be used to establish temporary stations, designated the model DL-1 (Figure 3), is being developed, and a few units were produced by the Peking Seismograph Factory during 1974. The equipment provides a high-gain recording in the $10-$ to $15-\mathrm{Hz}$ frequency range, through a pen-andink recorder. Either $220 \mathrm{~V}$ ac or 10 $\mathrm{V}$ dc can be used to power the unit. Apparently, the principal intended use is for aftershock recording.

Borehole seismometer. An experimental borehole seismometer has been developed in the laboratories of the Institute of Geophysics and is now undergoing field testing. Because of the thick sedimentary cover and dense population, the sensitivity at which short-period equipment can be operated in north China is severely limited. The new instrument measures the vertical component in the band from 0.05 to $1.2 \mathrm{~Hz}$ and has been successfully operated at a magnification of about 200,000 at a depth of $270 \mathrm{~m}$ in an irrigation well near Hsingt'ai.

The instrument employs an electromagnetic transducer and integrating amplifier, and the output is recorded on the standard ink recorder. A sidewall clamp is used to anchor the sensor in the borehole. The instrument has not yet been tested in a noisy urban environment. The instrument was described by Li Feng-chieh.

Long-period observatory instrumenls. The Kirnos long-period system, which is flat from 0.1 to 10 $\mathrm{s}$, is the standard instrument in the observatories. A model SD-70, with magnification of 2000 in the band from 0.1 to $11 \mathrm{~s}$, was seen at the Kunming Station.

An instrument designated as the DK-1 and described as an intermediate-period seismograph, for which no specifications were given, has recently been developed. The 


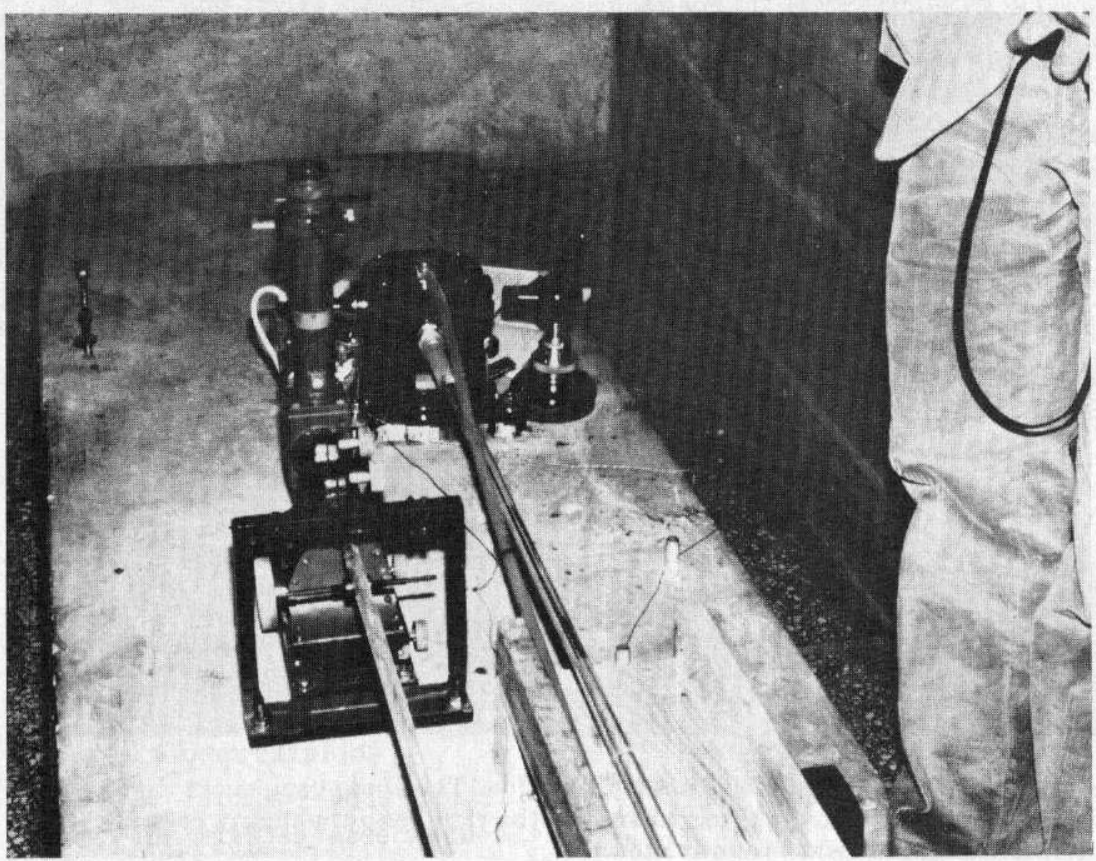

Fig. 4. End sections of the quartz bar extensometer and water tube tiltmete (Tahuich'ang Crustal Deformation Observatory).

Peking Seismograph Factory will turn out 15 sets this year.

Research on long-period seismographs in the Institute of Geophysics was described by Chin Chaochin. The objective of the program is to develop an instrument with wider bandwidth and greater dynamic range than the ones now in use in the standard stations. The instrument currently under development will provide magnification of about 1000 in the 20 - to 30 -s range.

The designs displayed are conventional. The horizontal component seismometer incorporates a $10-\mathrm{kg}$ mass and is intended to be operated at a period between 10 and $50 \mathrm{~s}$. On a good pier, stable operation at $60-70 \mathrm{~s}$ has been achieved. The vertical component seismometer is of the LaCoste type. The zero-length springs are made locally from a nickel alloy similar to invar. The temperature coefficient of the spring constant is $10^{-6} /{ }^{\circ} \mathrm{C}$. The best springs will yield a period of $60 \mathrm{~s}$ in the new vertical.

The galvanometer for the system has its free period in the 90 - to $100-\mathrm{s}$ range. The suspension now used is made from beryllium copper, but platinum is to be used in the future. The current sensitivity of the is being tested at the Peking Seismograph Factory.

\section{Strain and Tilt Measurements}

Quartz bar extensometer. A simple quartz bar extensometer was seen at the Tahuich'ang Crustal Deformation Observatory (Figure 4). The bar is $24 \mathrm{~m}$ long and approximately $15 \mathrm{~mm}$ in diameter. It is not insulated and is suspended along its length by wire supports. The horizontal extension parallel to the bar is read by means of a scale and microscope, with a maximum range of $5 \mathrm{~mm}$ available.

The bar is installed in an underground room $28 \mathrm{~m}$ long, in which the stated temperature variation is $\pm 0.2^{\circ} \mathrm{C}$, and the relative humidity is less than $80 \%$. The Papaoshan fault, the major fault near Peking on which recent movements have been observed, runs through the center part of the room, the purpose of the observatory is to monitor motions on this fault.

Another technique for measuring horizontal crustal deformation was observed in an observatory near the Hsinfengkiang Dam. An invar wire loaded to a standard amount of tension crosses a known fault, downstream from the dam, at $45^{\circ}$. This wire, which is slackened between measurements, is used to measure the distance between two reference points some $20 \mathrm{~m}$ apart. The currently observed rate of deformation is a shortening of $1.85 \mathrm{~mm} /$ year.

Water tube tiltmeter. Water tube tiltmeters of standard design were observed at the Tahuich'ang Crustal Deformation Observatory (one component parallel to the extensometer, Figure 4) and at the Kunming Seismological Station (northsouth and east-west). The base length of the tiltmeter is approximately $20 \mathrm{~m}$.

Similar tiltmeters will be installed in the newly completed vault of Chihwuchen (Sian) Observatory.

Quartz pendulum tiltmeter. The model SQ-70 quartz horizontal pendulum tiltmeter (Figure 5) is the standard instrument now being deployed in China. The instrument, very similar to the VerbaandertMelchior tiltmeter, is manufactured at the Peking Seismograph Factory. 
It is a nicely constructed and finished instrument and is operated at a sensitivity of $0.01 / \mathrm{mm}$. The instrument was observed at Tahuich'ang Observatory, Peking Station, Sian Station, and Kunming Station. A number of tiltmeters were operating side by side at Kunming as part of the calibration procedure before deployment in other places in Yunnan Province.

\section{Tidal Gravity Meter}

An Askania tidal gravity meter was installed in 1972 in the Kunming Station. The records seen are of excellent quality. One worker in Kunming is doing the tidal studies based on these data. This is one of the very few geophysical efforts we saw that is not related to earthquake prediction.

\section{Laser Geodimeter}

A very interesting new instrument is the model JCY-2 laser geodimeter, developed and demonstrated by personnel of the Wuhan Seismological Brigade. The instrument is based on a $2-\mathrm{mW}$ heliumneon laser. The stated range is $15 \mathrm{~m}$ to $20 \mathrm{~km}$, with accuracy of $5 \pm 1$ $\mathrm{mm} / \mathrm{km}$. Tests of the instrument over various ranges, as measured with an invar tape, gave accuracies from 5 parts in $10^{7}$ to 2 parts in $10^{6}$. Atmospheric corrections are based on temperature measurements made at ground level at the ends of the line.

All components of the instrument, including the laser and the reflectors, are made by the Wuhan group. Five units have been produced.

\section{Geomagnetic Instrumentation}

Eight geomagnetic observatories are operated by the Institute of Geophysics. The one at Paichiat'an (Peking Station) was observed in some detail. The instrumentation is conventional. A proton precession magnetometer, made in Peking, working into a digital frequency meter, made in Nanking, is used for measuring the total field and the vertical component to $0.5 \gamma$. Two sets of instruments for absolute determination of the horizontal component of the field, the declina-

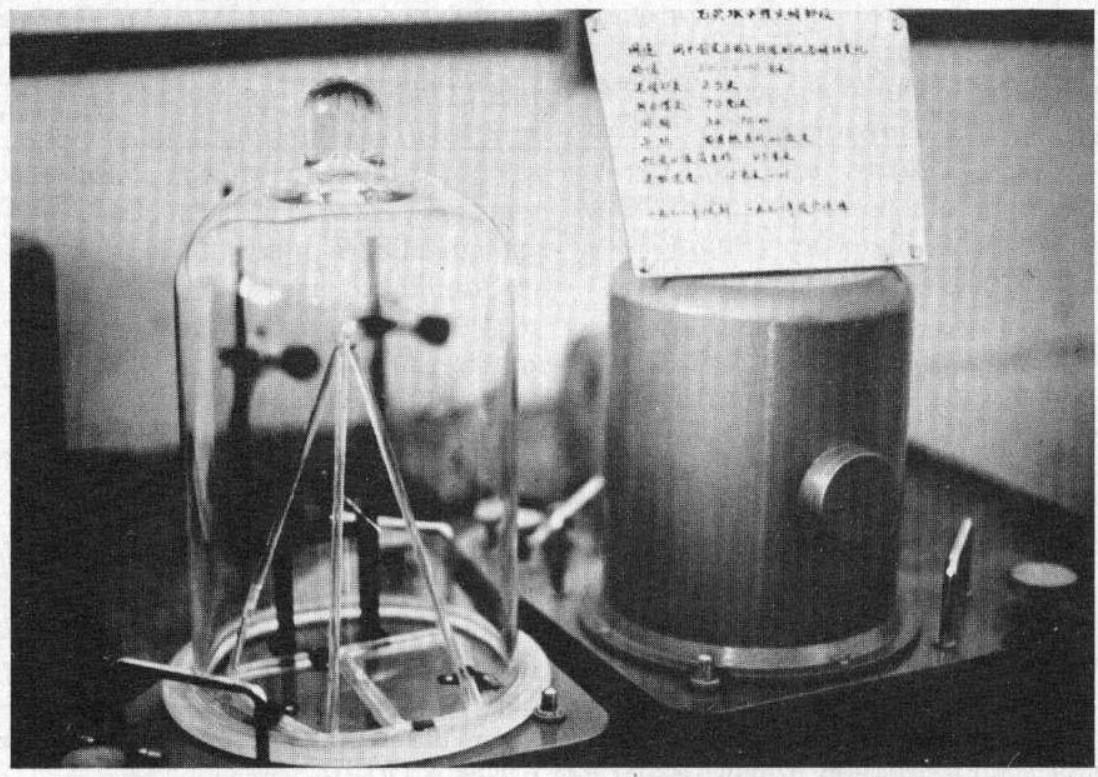

Fig. 5. Model SQ-70 quartz tiltmeter (Peking Seismograph Factory).

tion, and the inclination are also operated.

Variometers, made in the German Democratic Republic, record relative values of the vertical component of the field (to $2 \gamma$ ), the inclination (to $0.8^{\prime}$ ), and the declination. These instruments were installed in 1953.

This station serves as a primary calibration point for instruments being used currently in compiling geomagnetic charts of China.

Similar variometers are being operated at the Kunming Station, as well as a balance-type magnetometer for vertical component variations. The equipment for absolute value determinations has not yet been installed in the new vault.

The magnetotelluric equipment developed by the Institute of Geology (see section 3) incorporates a set of three induction coils in the form of elongated cylinders with mu-metal cores as magnetic field sensors and two sets of electrodes to measure orthogonal horizontal components of the electrical field. The signals are low-pass filtered, with the corner period at $40 \mathrm{~s}$.

\section{Brief Description of \\ Observatories}

The system of seismological stations consists of the 17 standard stations and 250 regional stations ( $\mathrm{Ta}$ ble 1$)$. The decision as to which sta- tions are to be equipped as standard stations is made jointly by the local leadership and the State Seismology Bureau.

Eight geomagnetic observatories are operated. At least some of these are attached to seismological observatories.

Paichiat'an Seismological and Geomagnetic Station (Peking Sta(ion). This station, located about $20 \mathrm{~km}$ northwest of Peking, is operated by the Institute of Geophysics. Construction was started in 1953 and completed in 1954 . The facility has gradually developed into a comprehensive geophysical observatory, with seismological, geomagnetic, telluric, and tilt measurements. The staff of 20 includes 18 scientific or technical personnel.

Two buildings, one for geomagnetism and the other for seismology, house the instruments. The instruments have been described above. The seismograph piers are placed 2 $\mathrm{m}$ deep in soil, not a very good situation.

Tahuich'ang Crustal Deformation Observatory. The facility was created in 1969 during the Cultural Revolution. Located in the southwestern part of Peking Municipality, the station is operated by the Peking Seismological Team. The observatory consists of an elongated building crossing the $\mathrm{Pa} \mathrm{Pao}$ Shan fault. The tiltmeter and strain 
TABLE 1. Chinese Standard Seismograph Network as of 1973

\begin{tabular}{|c|c|c|c|c|c|}
\hline $\begin{array}{c}\text { Station } \\
\text { Name }\end{array}$ & $\begin{array}{l}\text { Chinese } \\
\text { Code }\end{array}$ & $\begin{array}{c}\text { International } \\
\text { Code }\end{array}$ & $\begin{array}{l}\text { North } \\
\text { Latitude }\end{array}$ & $\begin{array}{c}\text { East } \\
\text { Longitude }\end{array}$ & $\begin{array}{c}\text { Elevation, } \\
\mathrm{m}\end{array}$ \\
\hline Peking & BJI & PEK & $40^{\circ} 02^{\prime} 25^{\prime \prime}$ & $116^{\circ} 10^{\prime} 30^{\prime \prime}$ & 43 \\
\hline Paotow & BTO & PAO & $40^{\circ} 35^{\prime} 54^{\prime \prime}$ & $110^{\circ} 10^{\prime} 06^{\prime \prime}$ & 1120 \\
\hline Chengtu & CDU & $\mathrm{CNU}$ & $30^{\circ} 39^{\prime} 37^{\prime \prime}$ & $104^{\circ} 00^{\prime} 40^{\prime \prime}$ & 506 \\
\hline Changchun & CNH & & $43^{\circ} 49^{\prime} 45^{\prime \prime}$ & $125^{\circ} 18^{\prime} 48^{\prime \prime}$ & 236 \\
\hline Kweiyang* & GYA & & $26^{\circ} 27^{\prime} 31^{\prime \prime}$ & $106^{\circ} 39^{\prime} 50^{\prime \prime}$ & 1162 \\
\hline Canton (Kwangchow) & GZH & CNT & $23^{\circ} 05^{\prime} 13^{\prime \prime}$ & $113^{\circ} 20^{\prime} 38^{\prime \prime}$ & 11 \\
\hline Kunming & KMI & KUN & $25^{\circ} 07^{\prime} 24^{\prime \prime}$ & $102^{\circ} 44^{\prime} 24^{\prime \prime}$ & 1945 \\
\hline Kuhsi & KSH & & $39^{\circ} 27^{\prime} 19^{\prime \prime}$ & $75^{\circ} 58^{\prime} 48^{\prime \prime}$ & 1286 \\
\hline Lhasa & LSA & & $29^{\circ} 42^{\prime} 00^{\prime \prime}$ & $91^{\circ} 09^{\prime} 00^{\prime \prime}$ & 3658 \\
\hline Lanchow & $\mathrm{LZH}$ & $\mathrm{LCC}(?) \dagger$ & $36^{\circ} 05^{\prime} 12^{\prime \prime}$ & $103^{\circ} 50^{\prime} 40^{\prime \prime}$ & 1560 \\
\hline Nanking & $\mathrm{NJI}$ & NAN & $32^{\circ} 03^{\prime} 48^{\prime \prime}$ & $118^{\circ} 47^{\prime} 00^{\prime \prime}$ & 10 \\
\hline Ch'uan-chou & $\mathrm{QZH}$ & & $24^{\circ} 56^{\prime} 35^{\prime \prime}$ & $118^{\circ} 35^{\prime} 30^{\prime \prime}$ & 21 \\
\hline Shanghai (She-shan)* & SSH & & $31^{\circ} 05^{\prime} 48^{\prime \prime}$ & $121^{\circ} 11^{\prime} 11^{\prime \prime}$ & 90 \\
\hline Taian & TIA & & $36^{\circ} 12^{\prime} 41^{\prime \prime}$ & $117^{\circ} 07^{\prime} 28^{\prime \prime}$ & 300 \\
\hline Wuhan* & WHN & WUC & $30^{\circ} 32^{\prime} 37^{\prime \prime}$ & $114^{\circ} 21^{\prime} 01^{\prime \prime}$ & 26 \\
\hline Urumchi & WMQ & & $43^{\circ} 49^{\prime} 16^{\prime \prime}$ & $87^{\circ} 41^{\prime} 42^{\prime \prime}$ & 970 \\
\hline Sian & XAN & SIA & $34^{\circ} 02^{\prime} 22^{\prime \prime}$ & $108^{\circ} 55^{\prime} 17^{\prime \prime}$ & 630 \\
\hline
\end{tabular}

${ }^{*}$ Before 1973, the names of these stations were different. Kweiyang (GYA) was Huachi (HXI); Shanghai She-shan (SSH) was She-shan (SSH); and Wuhan (WHN) was Wuchang (WCH).

†There are two nearby stations in the U.S.G.S. list: LAN (Lanchow) and LCC (Liang-chow). The coordinates of this station, called Lanchow by the Chinese, agree more closely with those for LCC.

meter in the underground room are described above. In the center of the upper room a high-precision level is mounted on a pier. Observations of reference marks at opposite ends of the room provide an independent measurement of tilt. Tilts as obtained by leveling agree closely with those from the tiltmeter in the room below.

Chihwuchen Seismograph Observatory (Sian Station). This station, operated by the Shensi Province Seismological Team, was established in 1953 as the first in the province. There are now three comprehensive stations and seven observatories in addition to the standard station. The original station was at Northwest University in Sian City. The installation was moved south a few miles to Chihwuchen in December 1966, at which time tiltmeters and short-period seismographs were added to the mechanically recording instruments previously used.

A new vault has been constructed but not yet equipped. It is located in a hillside and is in the form of a cross. Two seismograph piers are at the end of the main chamber, and a water tube tiltmeter will extend across the vault. The plan calls for construction of a small building at the entrance to act as a buffer against atmospheric disturbances.

Kunming Station. The Kunming
Standard Station was established in 1957. A fine new underground vault, with many pier rooms connected by a well-lighted system of corridors, is almost in full operation. Twenty-seven workers are associated with the station. The instrumentation includes seismographs, magnetic variometers, and water tube and horizontal pendulum tiltmeters, all described above.

The old standard station was still in operation in October 1974, the change to the new station, some 2.5 $\mathrm{km}$ north, being planned for the near future.

Red Mountain Hsingt'ai Observalory. This comprehensive earthquake prediction facility is $60 \mathrm{~km}$ north of Hsingt'ai City. Seismographic equipment is a three-component DD1 short-period system (200,000 magnification) and a Kirnos intermediate-period system. Six auxiliary stations at which shortperiod vertical motion is recorded are operated by the observatory.

Geomagnetic observations are made with variometers and a proton precession magnetometer. Radon concentration is being measured in water from four wells $50-200 \mathrm{~m}$ deep. Water levels are being monitored in over 70 shallow (10-20 $m$ ) wells and in eight drilled for scientific studies $(150-300 \mathrm{~m})$.

Hsinfengkiang Dam S/ation. In addition to the strong motion in- stallation at the dam, a short-period station, recording in the band 0.1-1 $\mathrm{Hz}$ on smoked paper, is operated. The invar wire strain gage used at this station is described above.

A small network of short-period seismographs was set up around the reservoir in 1961 and is still in use as a means of monitoring local activity.

\section{Peking Seismograph Factory}

A first-rate facility for manufacturing seismic instruments has been developed in Peking since the Cultural Revolution. The factory started as a seismograph repair shop with a few workers. There are now 270 workers who produce all components of instrument systems except the crystal clocks. The DD1 short-period, DK1 intermediateperiod, DL-1 mobile station, and SQ-70 quartz tiltmeters are the principal products.

The factory is complete in itself, and all castings for seismometer frames and all small parts, like screws and snaps for instrument cases, are made in the plant. The main machine tool areas are clean and well lighted.

Development of new instrument designs is a closely coordinated effort of technical personnel from the factory and users in the field. Cooperation with the Institute of Geophysics is close, and the in- 
stitute occasionally proposes instrumentation problems to the factory for solution.

\section{Seismotectonics in China}

In keeping with the great concern over earthquake hazards in China, seismotectonic studies are among those being vigorously pursued. However, we were somewhat more exposed to the seismological aspects of these studies than to those bearing on geology, inasmuch as the systematic geologic mapping on which these studies depend is carried out by governmental organizations that we did not visit. The Bureau of Geology is evidently responsible for the systematic preparation of geologic maps, whereas the State Seismological Bureau, through its Institutes of Geophysics and Geology, carries out most of the research in seismotectonics. We saw essentially no detailed geologic maps, although it is clear that the generalized seismotectonic maps depended on such detailed information for many of the individual faults and other seismotectonic features that were shown. We had no reason to question the validity or accuracy of the basic geologic data, but neither were we in a position to see it and criticize it.

of the more than 40 technical papers that we heard in China, nearly 20 related earthquakes to tectonics. These 20 or so talks were given by individuals representing eight different organizations and ranged from broad syntheses covering all of China to detailed studies of small areas. An idea of the scope and content of these studies can be gained from the following partial list of the individuals and their topics, arranged by organization and location.

1. Institute of Geophysics, Peking: S.H. Hsu, seismicity of the Peking area; K.T. Wu, Chinese historical earthquakes; Y.T. Chen, source parameters, of the 1966 Hsingt'ai earthquakes derived from ground surface deformation data; Huan Wen-lin, relation between seismicity and tectonics, and various other features of the seismicity of China; Yao Che'n-hsing, seismicity of Lin-Fen basin, Shansi.
2. Institute of Geology, Peking: P.C. Chang, development of basic tectonic features in China; Li Chi$h-i$, seismogeologic features and seismic zoning in China; Teng Ch'itung, seismic intensity zonation in China; Li P'ing, seismogeologic features in Western Szechuan and eastern Yunnan.

3. Geodetic Survey Brigade for Earthquake Research, Tientsin: T'an Tung-ch'iu, crustal deformation associated with the 1966 Hsingt'ai earthquake; Hsieh Hsiang-wei, crustal defprmation associated with the 1970 'T'unghai earthquake; Ch'e Chao-hung, earthquake prediction based on crustal deformation in southern Tienshan mountains.

4. Shensi Province Seismic Team, Sian: Li Yung-shan, structural background of strong seismicity in Guan Chung region; Li Ming-hua, the Taiyuan earthquake of 1920 .

5. Hsinfengkiang Seismic Team, Hoyuan: Huang Li-sheng, geologic structure and earthquakes near Hsinfengkiang Reservoir.

6. Kunming Seismic Station, Kunming: Chang Ssu-ch'ang, the T'unghai earthquake of 1970; Chu Cheng-nan, the Yungshan-Takwan earthquake of 1974.

The relationship between major active faults and large shallow earthquakes seems to be well accepted in China. Active faults are generally defined as those with a history of Quaternary displacements, and such faults are recognized as the source of most current seismic activity. In the Shansi graben as well as elsewhere in China it has been demonstrated that the areas with the largest Quaternary displacements, vertical or horizontal, are the areas of most intense current seismicity. Time and time again, in the discussion of individual historic earthquakes, our Chinese colleagues referred to specific surficial faults and fault zones as being responsible for the earthquakes. There is obviously a considerable effort to tie together the seismological evidence from epicentral locations and focal mechanisms with the geological evidence of the location and nature of active faults. For example, it was reported to us by Li Chih-i of the Institute of Geology that in a study of recent earthquakes in Yunnan and west. ern Szechuan provinces, $61 \%$ of all earthquakes of intensity 7 and greater had occurred 'along or near' geologically mapped 'big, active faults'; $80 \%$ of those equal to or greater than intensity 9 were so located, and $100 \%$ of those equal to or greater than intensity 10 .

We heard comparatively little reference to Soviet seismotectonic methodology, which places primary emphasis upon older geologic structures and the boundaries of blocks with differing geologic histories. It was clear from a number of presentations that zones of Quaternary faulting in China in many places followed older geologic boundaries, but the primary emphasis in seismotectonic studies was on their recent histories. Also unlike some Soviet approaches, most recent faulting in China was said to be strike slip.

One interesting attempt was being made by Liu Chen-yung in a part of the Shansi graben to use archeological evidence to determine rates of vertical displacement and recurrence rates of large earthquakes. Although our group found it difficult to accept some of the arguments of uniform deposition of alluvial and eolian materials over fairly wide areas, there is nevertheless a tremendous opportunity for utilizing the rich and long archeological record in deciphering past rates of deformation and in pinpointing areas of recent faulting. Chinese scientists are obviously attempting to take advantage of this opportunity.

One of the greatest and most disastrous earthquakes of Chinese history, the 1668 Tanch'eng event (event 4, Figure 6) that occurred roughly halfway between Peking and Shanghai, took place in a region that neither before nor since has been one of continuing intense activity, and it was preceded by more than 150 years of almost total seismic quiescence in the epicentral area. Nevertheless, the area is recognized as being athwart a major throughgoing fault with abundant evidence of Quaternary faulting, based primarily on drilling records 


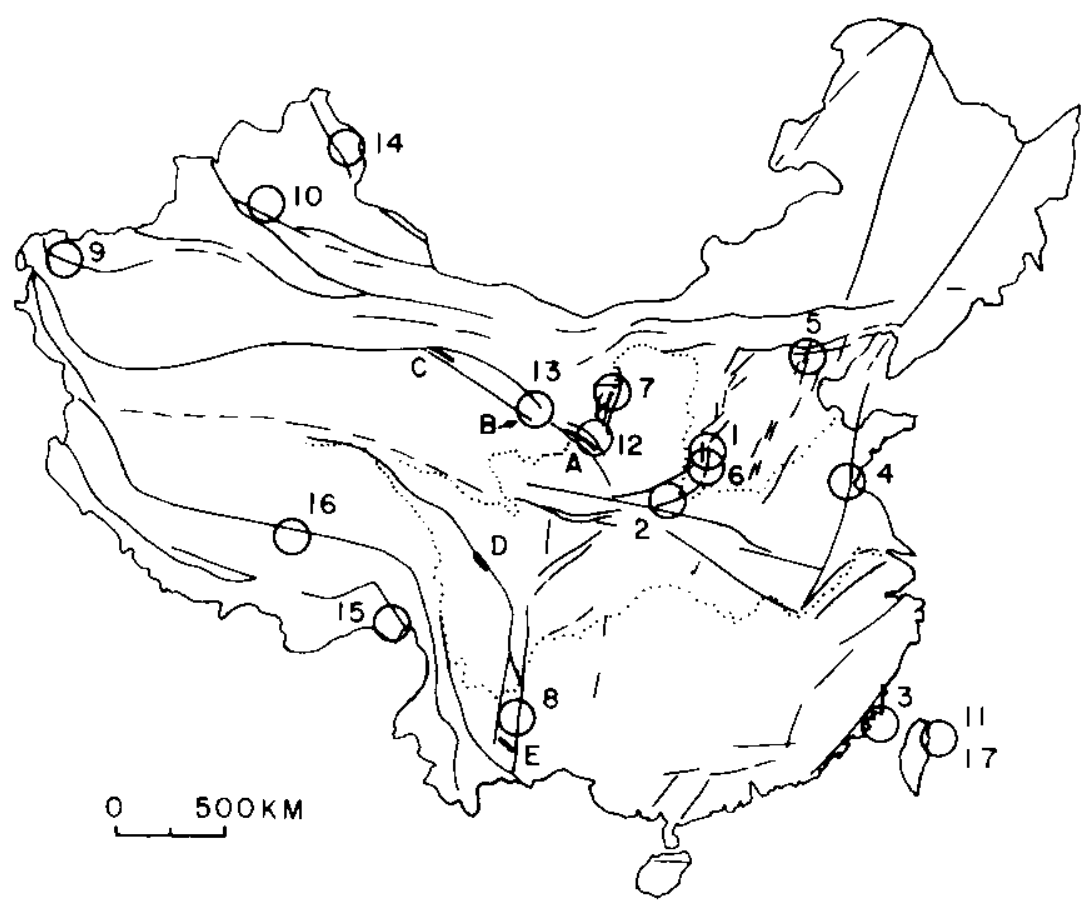

Fig. 6. Map of China showing major fracture belts, sites of historic surface faulting (indicated by short wide lines and letters A-E) and epicenters of earthquakes with $M$ $\geqslant 8$. The dates of occurrence of these great earthquakes are as follows: (1) September 17, 1303; (2) January 23, 1556; (3) December 29, 1604; (4) July 25, 1668; (5) September 2, 1679; (6) May 18, 1695; (7) January 3, 1739; (8) September 6, 1833; (9) August 22, 1902; (10) December 23, 1906; (11) June 5, 1920; (12) December 16, 1920; (13) May 23, 1927; (14) August 11, 1931; (15) August 15, 1950; (16) November 18, 1951; and (17) January 25, 1972. Fracture belts and epicenters from Shih et al. $[1974 b$, Figure 1].

and geophysical studies. In seismic zoning considerations in China, such geologic evidence seems to be given fully as much weight as that of the historic earthquake record.

It was not clear to us whether vertical aerial photographs were being systematically used in the study of active faults, but our Chinese colleagues were intensely interested in the ERTS images covering all of China which we presented to them as a gift of the American group, and probably the greatest interest and discussion concerned those images showing active faults. Perhaps no area in the world more dramatically displays active faults on aerial coverage than China does (Figure $7)$.

The mainland of China can be divided into seismic and tectonic zones in several different ways. The simplest division is into two major parts consisting of eastern and western China, with the boundary approximately along the $100^{\circ} \mathrm{E}$ meridian. Eastern China is commonly subdivided into 3 parts: tween major fracture belts and the great earthquakes is evident on Figure 6; this relation generally holds true also for earthquakes as small as magnitude 6 (Shih el al., $1974 b$; Shih et al., 19731. A few of the fracture belts in northeast, southeast, and northwest China apparently have not been associated with historic earthquakes of $M \geqslant 6$, but the pattern of some earthquakes in southwest China suggests that one fracture belt extends farther west than is shown on Figure 6 and that additional unmapped east-west fracture belts exist. Moderately detailed maps that we saw demonstrated that the Chinese are aware of many more fracture belts and faults than are shown on Figure 6.

We know of several historic surface fault ruptures in continental China; others not known to us have probably occurred. In response to a question we were told that the old historic records contain descriptions that can be interpreted as surface faulting, but the earliest rupture known to us was associated with the great Haiyuan, Kansu, earthquake of 1920 (event 12, Figure 6). Although previous accounts of the earthquake did not mention surface faulting, a reexamination of the data by the Chinese has led them to conclude that surface ruptures occurred in a zone more than $200 \mathrm{~km}$ long. According to M.L. Li, evidence for the left lateral sense of displacement included a change in a stream course and offset of a tomb, but the amount of displacement is not known. The location of the rupture as shows by a heavy line on Figure 6 (at A) is based on a small-scale map in a preprint of M.L. Li's talk coupled with ERTS imagery which shows a distinct linear feature along that line. The lack of exact coincidence with the long fracture belt on Figure 6 is probably the result of plotting errors.

The $M=8$ earthquake of 1927 (event 13, Figure 6) was reported by Ambraseys [1969] to have been accompanied by $60 \mathrm{~km}$ of surface faulting. We did not have an opportunity to verify this rupture, but a prominent structure zone visible on ERTS imagery is apparently coincident with the fracture belt shown on 


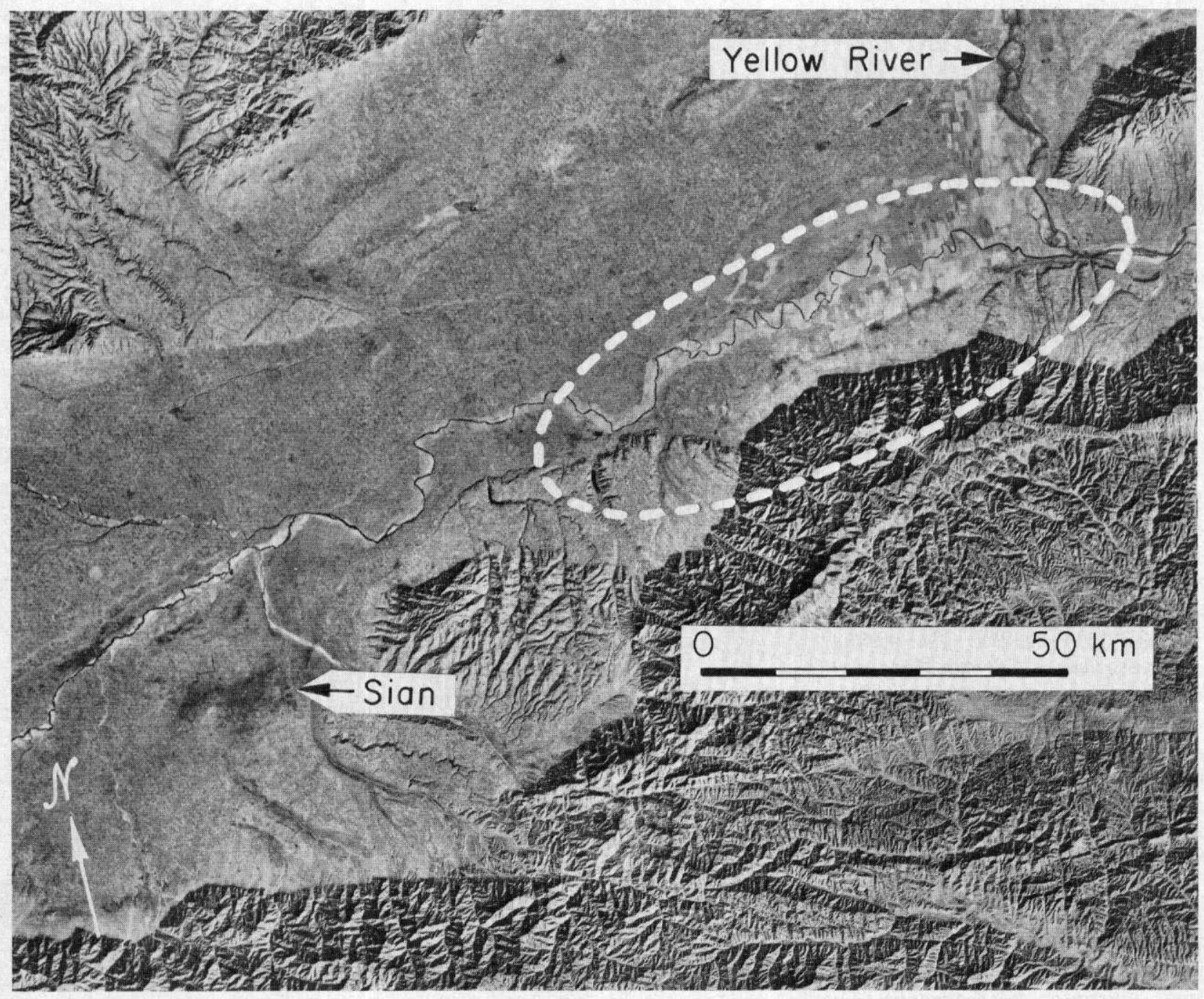

Fig. 7. ERTS image (1525-02461) of Sian region, Shensi Province. White dashed line is outline area of shaking greater than intensity 11 during great 1556 earthquake.

Figure 6 (at B). This locality is about $30 \mathrm{~km}$ southwest of the epicentral coordinates of the 1927 earthquake as given in the Academia Sinica earthquake catalog.

On December 25, 1932, an $M=$ 7.6 earthquake damaged the Changma, Kansu, area. A recently published report [Shih et al., 1974a; Huan el al., 1974l describes $116 \mathrm{~km}$ of surface faulting that accompanied the earthquakes (C, Figure 6 ). The displacement was reverse with a vertical component of $4 \mathrm{~m}$ and a small right slip component. In that area of low precipitation and low population the faulting was still clearly evident in 1964, when the field investigation was done.

Many moderate to large earthquakes have occurred along the prominent fracture belt that ex- tends northwest and southeast of Luho and Taofu (near D, Figure 6). Ground ruptures found after the $1923 M=7.3$ earthquake, described by Heim [1934], very likely included surface faulting that was at least 15 $\mathrm{km}$ long and possibly was much longer. An informal oral report of surface faulting in the $1967 M=6.8$ earthquake in that area has not yet been confirmed by us. More than 70 $\mathrm{km}$ of left lateral faulting in the same general area occurred in 1970 [Bolt, 1974]. The magnitude of the associated earthquake was 7.75 according to Bolt and 7.9 according to the Academia Sinica catalog. No report describing the faulting has been published by the Chinese, and the rupture as shown at $D$ on Figure 6 assumes $70 \mathrm{~km}$ of faulting, along the prominent fracture zone, bi- laterally symmetrical with respect to the epicenter listed by Academia Sinica.

The T'unghai faulting of January 5, 1970, was described to us by S.C. Chang. The earthquake of $M=7.7$ resulted in isoseismal lines elongated $\mathrm{N} 60^{\circ} \mathrm{W}$, parallel to the $50-\mathrm{km}$ surface rupture (E, Figure 6 ) which had a steep northeast dip. Right slip of as much as $2.5 \mathrm{~m}$ offset things such as a footpath, a line of shrubs, and a tree. Vertical displacement of as much as $0.5 \mathrm{~m}$, generally up on the north side, was consistent with prequake movements up on the north inferred from the recent geologic history and measured by leveling. The faulting occurred along one of several strongly arcuate structural zones which are convex southward. According to the 
Chinese, the stress field, inferred from geology, geodesy, and $P$ wave focal mechanism, locked the northeast-trending segments of the arcuate system but resulted in rupture of one of the favorably oriented northwest-trending segments.

We were told that the Great Wall has been offset in Ningsia Hui

Autonomous Region, and we got a glimpse, in a motion picture, of a right lateral offset in the wall; however, we have no definite information about dimensions or time or whether the offset was of tectonic origin.

Although some aspects of China's seismicity and tectonics can be related to movement of neighboring plates, the relationship is complex and not yet fully understood. In southwestern China the arcuate fracture belts shown on Figure 6 and associated folds are clearly related to the northward or northeastward movement of the India plate, but consistent right lateral slip, which one might expect on the east and northeast edge of this system, does not occur. Instead, left slip predominates, as is shown by the historic faulting at localities $\mathrm{A}$ and $D$, and geologic and seismologic evidence of left slip [Shih el al., 1973) along the north-south fracture belt near epicenter 8 (Figure 6). The reverse faulting at $\mathrm{C}$ is quite consistent with northward movement of the India plate, but the other slip directions seem to require a southeastward and southward movement of material near the east edge of the system. Geologic and seismic evidence has led the Chinese to conclude that the block from the vicinity of epicenter 8 to the vicinity of the Burma border is indeed moving southward with respect to the adjacent blocks, producing left slip on the east and right slip on the west. Complex interaction of the India plate with the Pacific plate has been invoked by Shih et al. $|1973|$ to explain the stress system and distribution of earthquakes in the eastern China and Taiwan regions. One clear and certain conclusion from the geology, seismology, and surface faulting is that the China mainland is not behaving as a single rigid plate.

\section{Historic Records of}

\section{Chinese Earthquakes}

A major Chinese contribution to modern seismology is the truly remarkable catalog of Chinese earthquakes that extends back almost 3000 years, more than a quarter of the entire Holocene epoch. No other part of the world has a record this complete, and in no other area has the history been as carefully worked over in recent years by both seismologists and historians. The implications of the long Chinese record for studies of seismicity and seismic hazard throughout the world are profound, because the catalog shows significant and surprising temporal variations that are barely hinted at in the much shorter seismic histories that characterize most other parts of the world. Two of the Chinese historic events (1556 Shensi and $1920 \mathrm{Kan}$ su) are among the most gigantic natural disasters of world history. It is little wonder that the historic records of early seismic events in China have come under such close scrutiny in the effort to plan intelligently for the future.

The first comprehensive modern catalog of Chinese earthquakes seems to have been prepared in the mid-1950's in response to the need for seismicity information on economic developments such as new mining districts. A revised catalog was printed in 1970 , and even further corrections and revisions have been issued since that time. The principal effort has been by the Academia Sinica, the Institute of Geophysics, and the Institute of History: and the principal source materials have been the local gazetteers and records of local historians. Ever since the time of the Yin dynasty (1532-1028 B.C.), official historians wrote not only of political affairs but also of natural phenomena which could be regarded as portents. The first earthquake on record is that of 1831 B.C., although regular listings in the 1970 catalog commence with the event of 1177 B.C. Epicentral coordinates and magnitudes have been assigned to some 1323 individual earthquakes from that time to the present, apparently selected from a list of more than 9000 documented events. The impressive wealth of data available on distribution of damage is indicated by the fact that 146 isoseismal maps are shown in the 1970 catalog, including events as early as a damaging earthquake in 138 A.D. near Lanchow, Kansu. Some 629 earthquakes in the catalog are thought to be of magnitude 6.0 or greater, 95 events between 7.0 and 7.9 , and 18 of magnitude 8.0 and greater.

No claim is made for the complete statistical homogeneity of the catalog, especially in the early years. This is particularly obvious in the case of western China; the historical data prior to 1900 show almost no epicenters of large events in the Tibet and Sinkiang regions, and yet the post-1900 instrumental record shows the great bulk of current activity occurring in this region, with almost none in the area of eastern China that is the primary focus of much of the earlier historic records. Although it is possible that the locus of seismicity has changed with time, a far more logical conclusion is simply that the extremely low population density in western China is responsible for the apparent quiescence in the historic seismicity.

On the other hand, the area of north China that has been the cradle of Chinese civilization, par ticularly in the Fen and Wei River valleys, has a remarkably complete record of large earthquakes back to about 466 B.C. The linearity of the recurrence curve for all of north China suggests that the record for that region is homogeneous down to about magnitude 5 since 1484 . By way of contrast, that claim can be made for southern California only since about 1930 , and there is no continuous record of even great California earthquakes prior to about 1850 .

The volume of work in compiling the catalog is suggested by the fact that more than 5600 individual local gazetteers had to be collected and studied. Four principal dif ficulties were encountered by the Chinese researchers, and these are not unlike the problems that have been faced elsewhere: (1) Partly because of changes in calendar systems in the various dynasties, ac 
curate dates are hard to establish, and duplications are difficult to avoid. (2) Locations are often hard to pin down because of obscure or changed place names. Partly because of this, there is an unfortunate tendency to place earthquakes at prefectural capitals or other major cities. (3) Some records obviously have gross exaggerations. (4) Many earthquakes simply have inadequate descriptions.

The type of information that is contained in the catalog is best indicated by briefly describing five of the important earthquakes of Chinese history:

1. The great 1303 Hung-tsao (Shansi) earthquake (event 1 , Figure 6), occurred in the Fen River valley between Sian and Taiyuan, an area that has had much recurring seismicity throughout the historic record. Forty-seven counties recorded the 1303 event, 34 with destruction. A very detailed isoseismal map can even now be made from the reports, and its 'dumbbell' shape suggests to Chinese scientists that the faulting was bilateral. On the basis of the distribution of isoseismal lines, the fault length is thought to be about $140 \mathrm{~km}$. The magnitude is given as 8 on the basis of Chinese formulas (which vary from region to region) relating intensity to magnitude.

2. The 1556 Huahsien (Shensi) earthquake (event 2, Figure 6), mentioned above, may qualify as the greatest natural disaster in history. Well-documented deaths reportedly exceeded 820,000 , and the destructive area was some 870 $\mathrm{km}$ long. It was reported in 212 counties (98 with destruction) in 8 provinces. In the 6 counties within the most heavily shaken area, the average death rate in villages was $60 \%$, almost all due to collapsing houses (at night) and not because of collapsing loess caves, as has sometimes been reported. East-trending tension cracks appeared over wide areas of the Wei River Valley in the epicentral area, but none of these is now interpreted as due to primary faulting. A marked asymmetry of the isoseismal lines is related to contrasts between bedrock and alluvium. The magnitude is thought to be between 8.0 and 8.3 , and the depth of focus is calculated as 24 $\mathrm{km}$. The hundred years prior to the event was generally marked by high to moderate seismic activity in the epicentral region, except that a quiet period immediately preceded the earthquake for about 13 years. There was only one damaging aftershock, in 1558. The American delegation visited the epicentral area of the 1556 earthquake and was particularly impressed with two things: (a) the Holocene faulting in the area is truly spectacular, both on the ground and on ERTS images, and certainly the area would easily be recognized as earthquake prone along with the rest of the Shansi graben, even in the absence of historic earthquakes, and (b) the density of population in the Wei River valley and the construction practices of homes are such that a repetition of the 1556 event would again be a major disaster unless it were accurately predicted and appropriate measures taken.

3. The great Tanch'eng or Lienshui (Shantung) earthquake of 1668 (event 4, Figure 6) was unusual and disconcerting in that it occurred in a part of eastern China, about halfway between Shanghai and Peking, that has neither before nor since been one of continuing high activity. And it was preceded by a period of more than 150 years of almost total quiescence in the epicentral region. The earthquake was recorded in 379 counties, 29 of which had 'heavy destruction'; three county seats were completely destroyed. Following the earthquake until 1900, the epicentral region was the locus of a modest number of small earthquakes, but there is now some concern that since 1900 the area has again become one of almost total seismic quiescence. As is mentioned elsewhere in this report, the 1668 earthquake was located along a major regional fault zone showing abundant Quaternary displacement, so that even in the light of the aberrant historic seismic record, the region could have been (and is) regarded as one with significant seismic hazard from large shocks. It is perhaps significant that the epicenter of the very recent destructive earthquake of February 1975 , which occurred subsequent to the visit of the American delegation, was located in Liaoning Province some $700 \mathrm{~km}$ farther north and apparently along the same Quaternary fault system as that of the 1668 event. Similarly, the area of the 1975 earthquake does not appear to have been characterized by major preceding historic seismic ac. tivity.

4. In 1679 , Peking was severely shaken by a great earthquake centered some 50-60 km from the city (event 5, Figure 6). Contemporary poems hint at numerous fissures within the city. Peking was also damaged by smaller but destructive shocks in 1057, 1337, 1484, 1536, 1658,1665 , and 1730 , but none since. A dense telemetered seismic network in operation since 1966 shows that numerous small earthquakes ( $M=1.8-3.5$ ) tend to occur in roughly the same places as the earlier larger shocks, but it is interesting to note that a history as short as that of the United States would have included none of the eight destructive earthquakes. What kind of seismic zoning map would have resulted from a history this short?

5. The 1920 Haiyuan (Kansu) earthquake (event 12, Figure 6) of magnitude 8.5 is the largest earthquake in contemporary China and has been the subject of several articles in the modern literature. The great loss of life was in part associated with massive soil failures in the thick loess that blankets the Kansu region. A $200 \mathrm{~km} \cdot \mathrm{long}$ left lateral fault associated with the earthquake has recently been reported. Perhaps the most significant aspect of the earthquake is that the region outlined by aftershocks had been almost totally quiescent for 280 years prior to 1920 , although it clearly lines within a broad zone of longer historic activity.

The great significance of the historic record of Chinese earthquakes lies in its implications for the use of historic records in seismic zoning and in statistical extrapolations of expected future activity. Briefly, the principal lesson to be learned is that even a 3000-year record must be used with extreme 
caution in extrapolating into the future, inasmuch as it is clearly statistically inadequate in many ways. For other parts of the world, where the length of the record is often less than a tenth that of China, the lesson is clear that even greater caution must be used. The basic problem is simply that seismicity is not uniform in time and space even during periods as great as 3000 years and in regions as large as China itself.

The difficulty in extrapolating from the historic record is perhaps best illustrated by the study of Mei Shih-jung on seismic activity in China. In the highly active Kansu and North China regions, an area some 4 times larger than that of California and Nevada combined, the record of large shocks is relatively complete from 466 B.C. to the present day. The seismic activity during the first and last parts of that period is relatively high, but there was an 800-year period from 200 to 1000 A.D. during which activity in large shocks was almost nil. Although considerable further historic investigation has been carried out since Mei first reported these data in the 1950 's, she informed us during our recent visit that the basic 'gap' still remained.

Other parts of China have been subject to similar secular variations. Mei reported that southeastern China, which is now relatively quiet, has experienced prolonged periods of very weak activity lasting for 300-500 years, interrupted by periods of high activity. Teng Ch'i-tung reported that in north China three major active periods separated by relatively quiescent interludes occurred from 1209 to 1368,1485 to 1724 , and 1812 to the present. There is, of course, some suggestion of cyclical periodic variations in these data, and this topic seems to be the subject of lively debate among Chinese scientists. All agree that there have been dramatic changes and variations, but not all agree that the variations are periodic.

Major secular changes in seismicity are, of course, not unknown elsewhere in the world. Ambraseys has pointed out that the fault system extending southwest from eastern Turkey into Syria, Lebanon, and Israel was the locus of many disastrous earthquakes up until about 1200 A.D. but has been relatively quiescent ever since. And high seismic activity in Korea terminated abruptly about 3 centuries ago. But the Chinese record is so well documented and extends over such a long time period that it is truly unique.

In addition to the secular variations, the Chinese history also points up some other worrisome problems. Some parts of China seem to have experienced only small earthquakes and no large shocks at all, at least over the 3000-year history. But other parts of China with relatively few continuing small shocks nevertheless have infrequent great earthquakes, as exemplified by the 1668 event.

Lest the reader get the impression that most destructive Chinese earthquakes are aberrant events, a glance at the seismicity map (Figure 6) will show that most historic earthquakes have indeed occurred in a few well-defined zones and that these zones have generally become better defined with more and more years of record. Nevertheless, the history is sufficiently long to include enough aberrant events to be worrisome, and the secular variations in activity even within the well-defined zones are surprising and perplexing. Suffice it to say that some reference of the Chinese earthquake history should be required reading for scientists any. where in the world who are faced with problems of constructing seismic zoning maps or of making statistical extrapolations based on historic seismic activity.

\section{Premonitory Effects of Earthquakes}

\section{Nalure of Program and Overall Results}

The scale of this program and nearly all of the results on precursory phenomena that we learned about were almost completely unknown to us before we visited China. Field programs to detect possible precursory effects have been underway for the past few years at provincial centers at Kunming (Yunnan), Chengtu (Szechuan), and Lanchow (Kansu) within the zone of high seismic activity that crosses China from south to north as well as in the Peking area, in the region of the damaging Hsingt'ai earthquakes of 1966, and near the Hsinfengkiang Dam in Kwangtung Province.

The very high level of seismic activity and the relative accessibility of many of the active regions of China to monitoring (the most active zone in the United States is located almost entirely offshore along the Aleutian trench) are two factors that have led to the rapid accumulation of premonitory data and which can be expected to be important in the rapid accumulation of precursory data on large earthquakes in the future. A wide variety of types of precursory phenomena-the existence of which has been reported previously in Japan, the USSR, and the United States-are being studied in China largely from an empirical point of view. Relatively little thought appears to have been given thus far to designing field or laboratory experiments with theories or models, such as the dilatancy-fluid diffusion hypothesis, in mind.

Most of the Chinese scientists we talked with are convinced that a wide range of precursory phenomena do occur before earthquakes and that they occur in a variety of tectonic environments. Changes in the following variables have been reported prior to earthquakes and are being studied actively by extensive field programs: crustal movements, seismic velocities, frequency of occurrence of small earthquakes, seismic attenuation, the flux of radon from water in deep wells and springs, water level and temperature in wells, geomag. netic field, natural geoelectric field using telluric currents, and earth resistivity using an applied poten. tial. Chinese scientists generally distinguish precursory phenomena by their duration as either long term (years), intermediate term (months or weeks), or short term (days to minutes).

While we did not examine original data, our preliminary assessment is 
that several of the reported changes in radon flux, seismic velocity, tilt, and frequency of occurrence of small earthquakes appear to represent valid premonitory phenomena. Some of the other reported anomalies may well result from other causes and hence may represent a chance association in time with earthquakes. Although precursory effects were reported hundreds of kilometers from magnitude 4 to 5 shocks, most of the anomalies with a high signal to noise ratio do not occur at such great distances but are limited to within a few fault (rupture) lengths of the epicenter. Several of the better examples of precursory phenomena have a time duration $t$ that falls close to the line

$$
\log \tau=a+c M
$$

discussed by Scholz et al. [1973| and others, where $a$ and $c$ are constants and $M$ is the magnitude. In addition, various short-term effects, which fall well below the line defined by (1), were also found prior to the occurrence of moderate and large earthquakes.

Among Chinese scientists we found attitudes about the validity of precursory effects that range from the acceptance of nearly all reported anomalies as being related to earthquakes to the view that a large body of data should be accumulated before certain techniques are chosen as the more reliable premonitory indicators. Generally, the latter view is held by the more senior scientists. Particularly at the provincial and county level, where a great amount of the monitoring and data analysis is now being done, attempts are being made to use a variety of types of anomalies to predict earthquakes on a routine basis. Chinese scientists claim to have predicted several earthquakes successfully. Nevertheless, they emphasize that they have failed in some cases; not estimated the time, place, or size very accurately in other instances; and made predictions that turned out to be false alarms in others. They were not prepared at present to tabulate these results in terms of a false alarm ratio or a successfailure percentage. (We were told that such tabulations had been made in the early stages of prediction work 5 years ago but had been abandoned as meaningless during the present phase of work.) Most of the scientists we talked with believe that observations with a multiplicity of techniques rather than reliance on a single method will be necessary for successful and reliable prediction.

\section{Siles of Multiple Observalions}

Monitoring programs using a variety of techniques for predicting earthquakes are presently underway in the Peking area, in the Hsingt'ai region of Hopeh Province, and in central China along the seismically active parts of Yunnan, Szechuan, and Kansu provinces. We visited the Red Mountain Seismological Center, which is located about $60 \mathrm{~km}$ north of the city of Hsingt'ai, facilities for seismic monitoring and for studies of crustal deformation in the Peking area, the Yunnan Seismological Brigade at Kunming, and the Hsinfengkiang Dam in Kwangtung, where premonitory effects of reservoir-induced earthquakes IShen et al., 1974] are being studied. The Lanchow Seismological Brigade described their work on changes in seismic velocity, earth resistivity, and acoustic noise to us in Sian. The Wuhan (Hupeh Province) and Tientsin geodetic brigades are studying crustal movements associated with earthquakes in various parts of China.

The most complete series of observations that we saw are being carried out at the Red Mountain Observatory near Hsingt'ai and at Kunming. These include changes in seismic velocity, radon flux, water level in wells, telluric currents, geomagnetic field, crustal deformation, and frequency of occurrence of small earthquakes. Monitoring in the Hsingt'ai area includes the fault zone that ruptured in the damaging earthquakes of 1966. The occurrence of those shocks was one of the main factors leading to the initiation of a Chinese program of earthquake prediction. Although the Hsingt'ai region is not as active as several other areas of China, a num- ber of moderate-size aftershocks were available for studying precursory effects that have led to predictions of earthquakes or could have been so used.

\section{Elecirical-Magnelic Anomalies}

More data on magnetic and electrical field changes than on any other method were shown to our delegation. In part, this reflects the ease with which telluric currents and self-potential can be measured by volunteer personnel, but the professional workers also put a considerable effort into such observations. Of the anomalies shown us, only in one case had a statistical treatment of the data been conducted in the detail required to establish it as a valid signal beyond the noise. In this case, the anomaly in the vertical component of the magnetic field preceded a $M=5.2$ event near Hsingt'ai in 1972 by 5 months. The anomaly was only slightly above the noise, and the probability that it represented an event was not very high.

Prior to an earthquake of $M=4.8$ in a county in Yunnan Province on July 17,1972 , telluric meters $20 \mathrm{~km}$ from the earthquake showed anom alous drops in the current a few days prior to the earthquake. Over the time span of the data shown, about 20 days, the changes appeared quite anomalous. A longerterm data set would have helped to show whether such changes were expectable. However, these data, combined with changes in water wells, tilting, radon anomalies, and anomalous behavior of animals, were used to make a prediction. The prediction was for $M=5$ within a few days of July 15, when the announcement was made.

A few days prior to the $M=7.1$ Yunshan-Takuan earthquake near Chaot'ung on May 11, 1974, an indigenous (amateur) telluric meter at a distance of $90 \mathrm{~km}$ showed a drop of about $70 \mu \mathrm{A}$. The noise level for the 2 months preceding this drop was a few microamperes. There was little change following the earthquake for 1 month until, after an aftershock of $M=6$, the current rose by about $50 \mu \mathrm{A}$ and remained relatively constant for the succeed. 
ing 30 days on the record shown us. On two other indigenous meters, apparently anomalous changes in telluric currents were recorded prior to both earthquakes. No statistical analysis was presented of the data from these records, so that evaluation of the significance of these anomalies is not possible. Nevertheless, the second of these events was predicted publicly on June 12 as an earthquake of $M=5$ on June 13 or 14 . The shock occur. red on June 15 after precautionary measures had been taken in the counties affected. In this case as well, the prediction was based on anomalies in other observations also, notably changes in the quality of well water and unusual behavior of animals.

Observations of the vertical component of the magnetic field are made at the 17 principal seismological observatories and also at a closely spaced net of stations near Peking. Differences between the measurements are taken, and the daily means of the differences plotted. At the Red Mountain Observatory near Hsingt'ai, one analyst, Ma Shen-ling, reported anomalies in the differences between Hung shan and Peking preceding two earthquakes of $M=4.4$ and 5.2. He considers that deviations of the differences from the running mean which are of the same sign for 5 days consecutively constitute an anomaly.

The group at Red Mountain issued a public prediction of an earthquake of $M=4.9$ which occurred on June 6,1974 . The prediction was based on a variety of observations which included an anomalously large increase in the differential magnetic field 2 days before the event. Also, apparent resistivity is monitored through joint measurements of telluric currents and the magnetic field at the observatory. A decrease in the apparent resistivity had been in progress for 2 to 3 months prior to the earthquake. Such decreases had occurred previously without earthquakes following, however, and the geophysicists at Red Mountain did not attach much significance to the resistivity anomaly.

A Schlumberger array using a dc current source was used to make repeated measurements of earth resistivity in Kansu Province by the Lanchow Seismological Brigade. While many of the anomalies thought to be related to moderatesize shocks involve changes in resistivity of about $1 \%$, a figure that is comparable to the size of the errors in similar measurements elsewhere, in one example, resistivity started to increase at an epicentral distance of $50 \mathrm{~km}$ about 13 months before a shock of magnitude 7.8, reached a peak $9 \%$ above the previous level about 7 months later, and subsequently decreased to near its previous.level just before the earthquake.

\section{Crustal Deformation}

Measurements of tilt and strain using geodetic methods and continuously monitoring instruments constitute a large fraction of the Chinese earthquake prediction effort. The geodetic work is carried out under the direction of the SSB, and technical guidance is provided by the Geodetic Survey Brigade at Tientsin. The instrumentation for the triangulation, trilateration, and leveling is comparable to that used in the United States. The number of people involved in carrying out the field measurements was not given but probably exceeds 900 . For example, we were told that 'dozens' of people were involved in field measurements in Kwangtung Province alone. The tiltmeters, present at all the observatories visited, are quartz fiber pendulums using an optical lever and photographic recording, but water tube tiltmeters are also in use at several localities. Strain meters are used but have relatively poor resolution and thermal stability.

The geodetic measurements have been used chiefly for retrospective predictions and studies of the earthquake source. The most interesting of these data are from level and tilt changes prior to several intermediate to large earthquakes.

In March 1971 an earthquake of $M=6.8$ took place $35 \mathrm{~km}$ downstream from Tosu Lake in Tsinghai Province. The lake level at the reservoir had dropped $41 \mathrm{~cm}$ over a period of 1 month prior to the shock, a rate of decline which was unusually rapid and in the opposite sense from the rise normally experienced at this time of the year. Twenty-four hours before the quake the level began to rise, an increase of $21 \mathrm{~cm}$ being attained before the earthquake took place. An additional rise of $17 \mathrm{~cm}$ was recorded 1 hour later, and a total rise of $81 \mathrm{~cm}$ was recorded before the level stabilized 1 week after the earth. quake. The streamflow would have had to increase by a factor of 7 to account for the rise, and therefore the level changes may be attributed to tilting of the land surface. Tilts of about $3 \times 10^{-5} \mathrm{rad}$ before and $6 \times$ 10.5 after the earthquake would account for the observed changes.

A $25-\mathrm{cm}$ change in sea level was detected by a tide gage on the Shantung Peninsula before the Po Hai Gulf earthquake of magnitude 7.4 on July 18,1969 . The change in sea level is a bay-shaped curve which started to rise about 8 years before the shock, reached a maximum, and then decreased before the earthquake.

Instrumental tilt records tend to be noisy due to the location of the instruments in vaults inside build. ings. However, two records were shown us which recorded anomalous tilts prior to two earthquakes. In 1971 an earthquake of $M=6.0$ near Mapien, Szechuan Province, was preceded by an increase in tilt of $7 \times 10^{6} \mathrm{rad}$ over a period of 3 days before the event. The tilt began to decrease on the day preceding the earthquake and continued to decrease following the event, recovering to the previous value within about 1 week. Only about 30 days of record was displayed, but within that time the anomalous tilt was about 10 times the amplitude of the other excursions on the record

The July 17, 1972, earthquake of magnitude 4.8 in Yunnan Province, which was predicted publicly, was preceded by anomalous tilting. For a period of 15 days prior to the event, the daily tilt vectors were directed almost due south and had a nearly constant amplitude. Three days before the earthquake the orientation changed to NNW but continued at the same daily amplitude. The orientation rotated toward the east 
the day before the earthquake occured.

Precise leveling loops or lines of about $1 \cdot \mathrm{km}$ length have been used as long base line tiltmeters in several localities. Apparently anomalous excursions in the levels were reported to have occurred prior to two earthquakes. However, the excursions, when translated into tilt, were only around 1 or $2 \mu \mathrm{rad}$, which is about the precision of the method. Longer lines in the vicinity of the Hsingt'ai earthquakes of 1966 showed a pronounced divergence from the long-term level change beginning about 2 years before the first of the large earthquakes. The number of repeats over the interval of 40 years prior to 1966 was too few to establish the length of time over which the reversal in the subsidence direction took place. Another similar example of a reversal and acceleration of the rate of uplift preceded the Fengnan earthquake of 1970 in Hopeh Province. In this case there was an increase in the rate of uplift for 1 year, followed by subsidence for a year prior to the earthquake. However, the repeat interval between levelings was long, and the long-term trend to which the anomalous period is compared is established by only two points.

\section{Radon Flux}

Some of the work in China on radon emanation as a precursory effect is to our knowledge as good as that being done anywhere in the world. An electrometer is used to measure the flux of alpha particles (and hence of radon) from water samples taken from wells and springs near fault zones. We saw these instruments in use at Red Mountain, Kunming, a middle school located near a hot spring along an active fault zone about 50 $\mathrm{km}$ east of Kunming, and the Ts'unghua hot spring about $100 \mathrm{~km}$ north of Canton (Kuangchow). This technique is simple enough that amateur observers can easily learn to make the appropriate measurements. Water samples are normally taken for analysis once or twice a day. A scintillation counter is also used to monitor radon flux on a continuous basis from a well $270 \mathrm{~m}$ deep near Kunming.
A large number of wells $(10<N$ $<$ 100?) are being sampled or monitored continuously for variations in the radon content of the waters. Several anomalies preceding moderate to large earthquakes were reported, principally by seismologists from the Red Mountain Observatory. They have observed six cases in which earthquakes between $M=4.3$ and $M=7.9$ have been preceded by anomalous increases, generally, in radon content. The time span between anomaly and shock is a few days to a few tens of days. For five of the events in the magnitude range 4.3-5.0, the anomalies were recorded at distances of less than $110 \mathrm{~km}$ from the shock. For the larger quake of magnitude 7.9 in the Pohai Gulf, the wells showing the anomalies were located at distances of $250-300 \mathrm{~km}$. The anomaly time is related to magnitude but by an empirical equation with parameters which vary depending on the particular well. The relation is

$$
M=a \log h t+b
$$

where $h$ is the amplitude and / is the time. Prior to the Yunshan Takuan earthquake of May 11, 1974, a strong decline in radon content was noted 3 months before the event in a well $160 \mathrm{~km}$ distant.

Most of the data reported were shown on a time scale too short to permit an assessment of the significance of the anomalies. The radon content of the wells lay between 1 and $10 \times 10^{10} \mathrm{Ci} / \mathrm{l}$, with variations of 5 to $10 \times 10^{-10} \mathrm{Ci} / 1$ constituting the anomalies. The anomalies exceeded the background variation in amplitude by about a factor of 10 .

Some of the best examples of precursory effects involving radon that we have seen come from four wells 50-200 m deep near the Red Mountain Observatory. Before several shocks the radon flux increased 2-3 times the normal background level. One of these examples was the magnitude 4.9 earthquake of June 6 , 1974 , for which the precursor lasted about 15 days at an epicentral distance of $49 \mathrm{~km}$. For this same event premonitory changes in the ratio of seismic velocities $v_{p} / v_{s}$ of about 3.5 month duration and an anomalously quiet period for small shocks of about 2-month duration were detected by the network of seismic stations near Red Mountain.

\section{Changes in Seismic Velocities}

We were shown about 16 examples-about 10 from the area of the Peking eight-station seismic network, about 5 from the Lanchow (Kansu and Szechuan) seven-station net, and 1 from the Red Mountain seven-station net-of premonitory changes in the seismic velocity ratio $v_{p} / v_{s}$, which occurred before earthquakes of magnitude 3.5-6.3. this more than doubles the number of examples of velocity changes that have been reported thus far. No false alarms were found in the Peking area for events of magnitude greater than 3.5. The deepest event for which a precursor was observed occurred at a depth of about $25 \mathrm{~km}$. These and the other changes in $v_{p} / v_{s}$ appear to fit closely the precursor duration-magnitude relationship of Scholz et al. [1973|.

Feng [1974] and Fenget al. [1974] published two papers on changes in $v_{l} / v_{s}$ and on variations in the amplitude ratio of $P$ and $S$ waves for earthquakes in the Lanchow area. Feng also showed us several additional unpublished examples. He did not find any false alarms for events of magnitude greater than 5. Most of his examples as well as those from the Peking net involve predominantly strike-slip faulting. $\mathrm{He}$ also computed changes in $v_{p}$ and $v_{s}$ individually.

Feng finds that when $v_{p} / v_{s}$ returns to normal it tends to overshoot to values of about 1.8 both before the earthquake occurs and for a short time thereafter. This is compatible with the idea that newly opened or newly elongated cracks become filled with water prior to the shock but do not close until the water is squeezed out after the earthquake in response to the stress drop accompanying the shock.

Many Chinese investigators indicated that they believe the size of precursory anomalies for a given shock varies azimuthally in accordance with the focal mechanism. Anisotropic variations in physical properties, in fact, can be expected to be associated with dilatancy, since cracks are expected to have a 
preferred orientation. Nevertheless, Feng reports that the maximum and minimum changes in $v_{p} / v_{s}$ are found along the axes of maximum and minimum principal stress, respectively, rather than along the axes of minimum and maximum stress, respectively, which are predicted for dilatancy models.

Four portable seismographs were operated in the Lin Fen basin of the Shansi graben from December 1971 to October 1973. During this period no significant variations in $v_{p} / v_{s}$ were found, and no moderate or large shocks occurred in the area.

Earthquakes triggered by the filling of the Hsinfengkiang Dam in $\mathrm{K}$ wangtung have been monitored by a seismic network since 1961 . The depths of small shocks showed a systematic change before an earthquake of magnitude 6.2 in March 1962 much like those reported for a shock along the San Andreas fault [Bufe et al., 1974]. The mean computed depths were as follows: July to November $1961,4.5$ to $5.0 \mathrm{~km}$; December, $5.5 \mathrm{~km}$; January, $5.0 \mathrm{~km}$; February and March (before main shock), 6.0; April to July 1962, 4.0 $\mathrm{km}$. These variations in computed depth may represent real variations in depth of focus, or they may result from using the same velocity-depth model throughout the calculations when in fact a decrease in compressional velocity occurred before the large event and resulted in systematic errors in estimating focal depth.

\section{Periods of Low Seismic Activity Before Large Earlhquakes}

Chinese seismologists report several instances both from the historical record and from more recent instrumental examples of a period of lower than normal seismic activity before large earthquakes. Similar examples from the instrumental record have been reported in the USSR, Alaska, and New York. The examples from the Chinese historical catalog are important, since they indicate anomalously low activity for moderate-size events during a period of years to tens of years before several great earthquakes. These include magnitude 8 or greater shocks in Shensi Province in 1556, Shantung Province in 1668, and Kansu Province in 1920. Such quiet periods may be indicative of dilatancy hardening before the occurrence of large earthquakes. A period of low activity also occurred before the Hsinfengkiang earthquake of March 1962 Shen et al., $1974 \mid$ and the Hsingt'ai earthquake of June 6, 1974, which was mentioned above in the section on radon flux.

Chinese seismologists feel that the rupture zones of large earthquakes usually tend to fill seismic gaps; i.e., those parts of zones of historical activity that have not experienced large shocks for a relatively long period of time. A buildup in activity for moderate-size earthquakes occurred along the perimeters of the seismic gaps before several great historical earthquakes. Mogi describes similar increases in prior activity in Japan. The pattern of activity he reports resembles a donut, where the hole is the seismic gap which later becomes the rupture zone of the great shock. Activity in the immediate area of the Hsingt'ai earthquakes of 1966 was reported as low in the 20 years before the large shocks of 1966 but was higher than normal in the surrounding area during the same period.

\section{Changes in Water}

\section{Level in Wells}

Chinese scientists cited about 15 instances from 94 A.D. to 1973 of a rise or fall of centimeters to several meters in water level prior to earthquakes. In the Hsingt'ai area of the 1966 earthquakes, water level is being measured on a daily basis in about 70 shallow wells $10-20 \mathrm{~m}$ deep. We were shown maps of daily changes (indicated only as a rise, fall, or no change) in water level which are much like daily weather maps. Scientists at the Red Mountain Observatory believe that a coherent spatial pattern of changes occurred a few days to a few hours before several magnitude 4-5 shocks and that these patterns resulted from premonitory changes. A rise in water level of $10-20 \mathrm{~cm}$ occurred in two shallow wells at epicentral distances of 20 and $50 \mathrm{~km}$ before a swarm of earthquakes of which the largest shocks were of magnitude 5.0 and 5.2 .

Changes in water level are now being used for short-term prediction in this region but with mixed results. It was difficult for us to judge if these anomalies represent valid precursory changes or if they are only fluctuations of other origins that by chance appear to be associated in time with some earthquakes. The shallow wells in the Hsingt'ai area may be subject to considerable natural and man-induced fluctuations since they are used for water supply. Data from eight other wells 150 to $300 \mathrm{~m}$ deep, one of which is used only for scientific purposes, apparently have not yet been analyzed extensively. These data do not appear to track some of the anomalies reported using data from the shallow wells. Nevertheless, data from deep wells may eventually provide some of the crucial evidence needed to check the dilatancy-fluid diffusion model.

Scientists at the Tahuich'ang Crustal Deformation Station studied changes in water level in three wells in the Peking area which are about $50 \mathrm{~km}$ apart and $250-300 \mathrm{~m}$ deep. Changes in water level were found to have a high correlation between pairs of wells starting about 4.5 months before a shock of magnitude 4.5 on March 25, 1972, which was located about $40 \mathrm{~km}$ from the wells. This high correlation ceased before the earthquake much like the bay-shaped anomalies in $v_{p} / v_{s}$. This was the only instance of a large and persistent correlation in more than 3 years of observations.

The temperature of water in wells is also monitored for possible precursory changes in several places in China. Unusual physical characteristics of well water-such as bubbling, change in color, muddying, and unusual smellwere noticed a short time before several earthquakes.

\section{Acoustic Noise Before}

\section{Earthquakes}

A number of examples of the occurrence of sound and light before historic and recent earthquakes have been compiled by Chinese seismologists. They find that acoustic noise tends to occur most 
often in association with earth. quakes of very shallow depths and with competent bedrock or water in the epicentral area. No theory, however, was advanced to explain the origin of the noise, nor was information available about the reliability of acoustic noise as a warning of impending earthquakes.

In the eastern United States, small earthquakes of very shallow depth are heard frequently in regions where competent bedrock extends to the surface even in cases when they are not felt. The latter events tend to be very rich in high frequencies on seismograms recorded at close distances. Thus small events can be perceived by hearing the higher frequencies even when they cannot be perceived by feeling the lower-frequency part of the spectrum. The Chinese examples may have a similar explanation and hence may be associated with foreshocks.

\section{Anomalous Behavior of Animals}

This subject is most difficult to treat objectively but nevertheless is of considerable significance in China. In the three carefully documented examples of earthquakes predicted in advance of the event, unusual behavior of animals was listed as one of the principal bases for having made the prediction. The phenomenon does not readily yield to quantitative analysis, but some of the qualitative descriptions are striking. Rats are seen to leave the barns and houses and act somewhat irrationally. Snakes leave their holes in large numbers. Fowl refuse to go to roost in the evening. Dogs bark all day, and so on. The peasants take such observations seriously and report them to the seismological brigades along with observations from water wells. These data apparently serve to localize the prediction in space and time.

\section{Earthquake Predic'ion Policy}

Public warnings of forthcoming earthquakes have been issued on at least 11 occasions. The observations which led up to the predictions were made both by trained geophysicists using a variety of instrumental methods and by volunteer workers using the less sophisticated but more numerous measurements by indigenous methods. A more detailed evaluation of the results from these methods will follow. When anomalies in the measurements, having some empirically established premonitory character, are observed, scientists of the local and provincial seismological brigades are informed. The data from the stations of the local SSB brigades are reported to a central observatory in the province so that detailed inspection of these records for possible precursors takes place routinely. In the case histories described to us, anomalies in observational data of both volunteer workers and professionals were used to make predictions. If the professional workers agree that an earthquake is impending and are able to make an estimate of the time, location, and magnitude, the county officials are informed. If the magnitude predicted is large, say, $M$ $>$ 5.5, the SSB in Peking is in. formed before action is taken.

The measures taken involve principally evacuation of particularly hazardous structures in the case of smaller earthquakes. This action has been taken with the result that injuries have been avoided in the ensuing earthquake. The populace in seismically active areas are unusually well informed about earthquakes and their effects. The educational efforts are carried out by the local seismological brigades and include descriptions of possible precursors, the measures to be taken to minimize damage, and reinforcing methods for new construction.

\section{Discussion}

The scale of the Chinese effort to predict earthquakes is large in an absolute sense and relative to programs in other nations is very large indeed. Some 10,000 workers are involved, and although figures were not available, the number of untrained volunteers working on a part-time basis is probably as many. The reasons for investing such a large proportion of China's human and financial resources in this program were not discussed, but there are a couple of fairly obvious explanations. First, the Chinese believe that earthquakes are predictable, on the basis of past experience and that of other workers elsewhere. In their very well documented history of large earthquakes, examples of precursory phenomena are numerous, and certain of these recur. Peculiarities in the behavior of animals and anomalous changes in well water level or quality have been reported repeatedly. Therefore, at least empirically if not theoretically, the problem seems to be a soluble one. Second as was mentioned earlier, the prediction of a forthcoming great earthquake is presently the only practical way to avoid repetition of some of the terrible calamities of the past few hundred years. The loss of 820,00 lives in the Huahsien earthquake of 1556 near Sian was due almost entirely to the collapse of houses in the densely populated valley of the Wei and Huang rivers. The housing in the area at present is undoubtedly not greatly different in construction from that which collapsed or indeed from that in much of rural China. New construction, though of brick, is nevertheless liable to major damage in a great earthquake. To bring rural construction, which houses presently over 600 million Chinese, up to earthquake-resistant design standards would require an effort so immense that China's goal of industrial self-sufficiency would be drastically retarded. On the other hand, reconstruction in the limited regions which will suffer great earthquakes in the next 100 years would not be a burden on the economy, provided the inhabitants survive. Therefore if the great earthquakes can be predicted, the inhabitants' lives can be saved without having to resort to the Draconian solution of seriously modifying or rebuilding the $30 \%$ or so of the existing housing which occupies the earthquake-prone regions of China.

\section{Statistics, Models, and Theory}

\section{Long-Range Statistical \\ Prediction}

Long-range predictions are made by statistical analysis of the past history of earthquake activity in a 
given region. If a seismically active region is identified as dangerous, even at a relatively low level of probability of occurrence of a large shock, then the machinery of intermediate and short-range instrumental prediction techniques is activated for that region. Anomalous behavior observed with routine in. strumental observations may cause the intermediate and short-range programs to be activated without recourse to the long-range aspect of the program.

The program of long-range prediction using statistical methods is being carried out in at least seven areas: (1) the use of extreme value theory to estimate recurrence rates; (2) the analysis of the time series of earthquake occurrence in a search for periodicities; (3) studies of earthquakes as Markov processes to predict the time and location of future earthquakes; (4) the influence of orbital periodicities of astronomical bodies, such as the sun, moon, and other planets, on earthquake occurrence; (5) the study of the relation between the earth's rotation and polar drift on the one hand and the occurrence of large earthquakes on the other; (6) studies of the seismicity of the circum-Pacific belt to predict earthquakes on the Asiatic continent; and (7) studies of methods to evaluate the probability of occurrence of a predicted event, from the results of a number of independent experiments in the same region. Discussions took place in Peking on the first four of these topics.

1. The extreme value theory of Gumbel is applied to the identification of those geographical areas that are potentially dangerous. A distribution function for the largest earthquakes in a given period of time is derived for each of the 13 regions into which the seismically active parts of China are divided. If the number of shocks predicted in a certain number of years exceeds the number of shocks which actually occurred by one or more events, then the region is identified as dangerous at a $70 \%$ probability of occurrence; if this difference is 0.7 events, then the region is assessed as dangerous at the $50 \%$ probability level. In an example presented of 10 regions identified as dangerous by this procedure, an earthquake at the specified magnitude threshold occurred in eight cases; in the three regions considered nondangerous, one earthquake occurred. As was noted above, this technique is used to identify those regions that warrant further scrutiny by detailed investigations using intermediate and short-range forecasting procedures. Some of our group expressed concern regarding the statistical reliability of these methods of analysis of the seismic histories, since the extreme value model is unstable at the large-magnitude end of the calculation.

2. An analysis has been made of a long time series of earthquake events as a comb of delta functions. In a specific region, namely between the Fen and Wei rivers in Shansi Province, 23 earthquakes with $M \geqslant$ 6 and 90 earthquakes with $M \geqslant 4.6$ have occurred in the last 1500 years. The 23 shocks did not occur uniformly with time. Indeed the earthquakes seem to occur in only about 15 seismically active periods, which are clumps of 10-year inter. vals into which the 1500 -year span is divided. Dividing the time span into this number of time units suffices to eliminate aftershocks; if more than one event occurs in a time interval (10-30 years), it is counted as only one event. Har. monic analysis of the comb of delta functions ensues. To avoid the possibility of negative values of the sum of harmonics, the curve is constrained to have zero slope where no earthquakes occur. Using a fit with only six coefficients in the time series (three harmonics and phases), periodicities of 245,160 , and 130 years are obtained. Here the Chinese work has run into the same difficulty encountered elsewhere, namely, using counts of events as a measure of activity. If a shock rupture is stopped short by an asperity, then the magnitude of the event will be smaller, but a second or even third event of intermediate size will occur farther along a fault; if the asperity is absent, a single large shock will occur. This latter comment suggests that it is necessary to introduce physics into the model. A comparison model would be of value.

3. In an attempt to obtain short. er time and space range forecasting, a study of the occurrence of earthquakes in the north-south earthquake belt extending from Kansu to Yunnan has been made by considering the events as elements in a Markov process. The north-south belt is divided into five regions. By using a data set consisting of 92 shocks of $M \geqslant 5$ from 1950 to 1972 a calculation is made to assess the possibility of migration of earthquakes. The transition probabilities $P_{i j}$ and $P_{i j k}$ are calculated where the indices take on the values 1 to 5 . For example, the quantity $P_{i j k}$ is the probability that successive earthquakes in the north-south belt occurring in regions $i$ and $j$ will be followed by an earthquake in region $k$. The probability $m(k)$ that an earthquake will then occur in the $k$ th region is expressed as a linear combination of thẹse probabilities. The largest of the five numbers $m(k)$ is then taken to identify the region most likely to have the next occurrence, if the operation is calculated for the 2 most recent events. Some success is claimed for this method of identifying the region most likely to experience the next shock. Comparison with a random population would provide a useful test of the reality of this model.

4. The work on astronomical correlations with earthquake prediction was introduced with the historical commentary that 2000 years ago, astronomical phenomena were used to predict earthquakes. However, the antilegalistic policies of Confucianism interrupted this type of predictive work. A return has been made to astronomical correlative work in recent years. The underlying principle of this work is the postulate that periodicities in earthquake occurrence are real phenomena. From an analysis of four earthquakes migrating from Sian to Hsingt'ai, a time interval of 139 years is deduced. In Hopeh Province, the time interval of $M \geqslant$ 5.5 earthquakes is 11 years (using eight events). Harmonic analyses are reputed to show periodicities. Distributions in space show that earthquakes occur in sequence in 
parallelogram relationships; hence from three earthquakes, one can deduce where the fourth is likely to occur. The earthquake periodicities are proposed to be intimately related with astronomical periodicities, such as Chandler wobble, variations in the angular velocity of spin of the earth, and sunspot activity. The work involves the fit of about $80-100$ terms in a sum of sinusoids, each with a different period depending on the choice of astronomical correlates, to a comb of delta functions representing about 200 strong earthquakes in northern China. After adjusting the amplitude and phase of each of the terms in the sum, one can use the resulting series to predict future peaks in the magnitude-time curve. Of 31 shocks predicted in 1970-1972, 18 were accurately predicted, 7 were of questionable character, and 6 were wrong. The author concludes that earthquakes are correlated with the positions of other planets and cites Tamrazyan (this latter work was shown to be in error in the United States) and others in support of this position. No explanation was advanced as to what the influence of remote planetary objects on the earth might be.

Other work of a similar character is outlined in recent issues of Acla Geophysica Sinica. The character of this work is mainly curve fitting: in the case of the example of correlations with astronomical positions, 200 pieces of data are fit with a model having about 200 d.f. In the case of the analysis of the Chinese earthquake catalog, the desire to regionalize has forced the analysis into the use of small samples. The essential ingredient in this work which worries us has been the absence of the use of reference models for statistical comparisons: there does not seem to be any attempt to find out if the models used are any better than random (or any other model).

\section{Slatistics}

In China as in this country, statistical methods must be employed more widely in the design and evaluation of field experiments. It is to be hoped that in the future the statistical work will focus on more statistically valid procedures as well as on problems crucial to the rest of the program. For example, important questions which remain unanswered include the following topics:

1. How should statistical models for the assessment of failure of predictions be constructed? If earthquakes are predicted successfully $n$ times out of $m$ events and false alarms are given in $p$ cases, what is an overall measure of the success of prediction? This may be useful in devising strategies to decide whether to continue specific efforts at prediction.

2. How can the validity of certain field procedures be investigated? For example, is the construction of maps of regional rise (or fall) of water level, as in use at Hsingt'ai, a statistically sound procedure, or is it no better than a random predictor? Is the use of reporting of changes in resistivity, temperatures, etc., by amateurs any better than random? (To work on the latter problem, one must have the complete suite of data and not merely reports of anomalies.) The reliability of methods such as observations of anomalous animal behavior, resistivity, magnetic fluctuations, seismic velocity ratios, meteorological correlations, etc., can and should be investigated by reliable statistical procedures; this means that comparison populations should be constructed and variances estimated, etc. Answers to questions such as these may help to determine strategies for the field program.

3. The Chinese catalog of large earthquakes is the most important document of its kind in the world. Statistical tests should be made of the reliability of the catalog. Clearly, the older parts of the catalog are not as complete as the more recent portion. What is the date for which we can be sure, at let us say the $95 \%$ confidence level, that all earthquakes with $M \geqslant 6$ have been included in the catalog? Such information will allow geophysicists to assess the value of predictions made from interpretations of historical catalogs. For example, we can then determine the reliability of estimates of periodicities using the historical record.

\section{Model Building}

As is indicated elsewhere, the Chinese program seems to operate largely on an empirical (and pragmatic) philosophy. Thus there is little involvement with attempts to in. terpret observations in terms of models of behavior of materials in the vicinity of the focus. Hence during our visit although our Chinese hosts exhibited interest, there was little detailed discussion of models popular in the United States, such as the dilatancy model, or of models considered in the Soviet Union, such as the preferential growth of some cracks at the expense of others. We heard no discussion of the role of strengths, dynamical shear (frictional) stresses, creep and plas. ticity, etc., on the earthquake event; i.e., the properties of materials and their influence on the earthquake process have been little considered to date. Water as a significant factor in the fracture process, a model much espoused in the United States but not in the Soviet Union, has not been considered from the point of view of understanding processes at earthquake foci.

There are some hopeful signs, however, that dialogs can be developed along these lines in the future. Understanding the earthquake event in terms of the above topics depends strongly on a program of laboratory experimenta tion on the rheological and other physical properties of rocks. The level of interest of our Chinese colleagues in laboratory work in this area in the United States and intense questioning about such work during our visit lead us to suspect that some developments may be forthcoming in this direction.

In a different direction of activity, we heard contributions concerned with the resistivity cross section of the crust and upper mantle from magnetotelluric investigations. In one case, the Lanchow brigade has found that the resistivity cross section is correlated with the occurrence of earthquakes in the northsouth earthquake belt of China. In the region extending between latitudes $33^{\circ}$ and $39^{\circ} \mathrm{N}$ and longitudes $104^{\circ}$ and $107^{\circ} \mathrm{E}$, about 7 earthquakes of $8 \geqslant M \geqslant 7$ and 2 shocks of $M \geqslant 8$ have occurred in historical 
times. These shocks have occurred in a belt generally parallel to structural trends. Interpretation of magnetotelluric data has led to the conclusion that there is a lowresistivity layer at a depth of $20-30$ $\mathrm{km}$ which is also generally parallel to the seismic zones. There is also a low-resistivity layer at a depth of about $10-15 \mathrm{~km}$ below the surface, which also has regional characteristics, but it is not as well defined. The resistivity in the two low-resistivity layers is about $1 \Omega \mathrm{m}$. These two low-resistivity layers may all contain water and hence may give rise to earthquakes. The low-resistivity is caused by high heat flow at the contacts of major seismic blocks. The inversion of the data also gives a low-resistivity layer with resistivity about $5 \Omega \mathrm{m}$ or thereabouts at a depth of about 70 $\mathrm{km}$ in the upper mantle. This latter layer is shallower in the eastern part of the above regions and is deeper in the west.

At the Institute of Geology, a presentation was also made describ. ing resistivity cross sections in the vicinity of large earthquakes. As in the Lanchow case, a low-resistivity layer is found close to the surface in active areas; at a distance from the epicenter, say, more than $15 \mathrm{~km}$, the low-resistivity layer is much deeper or absent. In the case of the 1966 Hsingt'ai earthquake, the low $\rho$ layer ( 2 or $3 \Omega \mathrm{m}$ is found at a depth of $36 \mathrm{~km}$, and in the Lin-yi site (of the 1668 Shantung event) there is a low " layer with $4.7 \Omega \mathrm{m}$ resistivity at $17 \mathrm{~km}$ depth. These layers are from 3 to $5 \mathrm{~km}$ thick.

Since these data have yet to be interpreted by using modern inverse theory, a number of questions re. main to be answered concerning the uniqueness of the results and the role of noise level and its effect on the interpretation.

We were shown no crustal models obtained from seismic observations, either from earthquake or explosion work, which could be used to understand how hypocenters were located. However, recent papers in Acta Geophysica Sinica have reported crustal models in the Hsingt'ai area from deep seismic sounding, in the eastern Chaidam basin and south central Shansi
Province by methods of explosion seismology, and in the Lin Fen basin from reflections of shallow earthquakes. We understand that these crustal explorations will continue and the results will be coupled to the problems of hypocenter location. We were informed that large-scale or regional crustal or upper mantle studies were just getting started.

\section{Theory}

At the Institute of Geophysics a report was given of an attempt to fit the leveling observations for the Hsingt'ai earthquake by using a static elasticity model of an extended dislocation. In order to account for the two loci of subsidence, associated with the two shocks 60 $\mathrm{km}$ apart, an extended fault $60 \mathrm{~km}$ in length was proposed. The upper part of the fault was an inclined plane, itself divisible into two parts: on the upper of these, the motion was pure dip slip with a dislocation of about $80 \mathrm{~cm}$. On the lower part of the upper inclined section, the motion was both dip slip and strike slip. The lower part was vertical and the motion on it was a pure strike-slip dislocation of $160 \mathrm{~cm}$. There is a question about the uniqueness of the model from the point of view of inverse theory. The two shocks were modeled by one dislocation because the leveling data are only available for a time spanning both shocks.

Also at the Institute of Geophysics a report was given of a program to fit intensity distribution, obtained from isoseismals, to a focal mechanism. Since intensities are related to accelerations, the focal mechanisms considered are dynamical rupture mechanisms. Although some comments were made that intensity is affected by geological structure as well as by focal mechanism, it was not clear how geological effects were taken into account in reducing the observations. In one case an interpretation was given of a mechanism to describe isoseismals which followed a river bottom closely, although soil effects may be more important than the dislocation in determining isoseismals. In the case of the T'unghai earthquake (January 5, 1970, Yunnan), the dumbell-shaped isoseismals cannot be explained by geology.

The model has been applied to recent earthquakes (T'unghai, Hsingt'ai, and Luhuo in Szechuan, February 6,1973 ) as well as to ancient earthquakes. This therefore represents an attempt to recover ancient focal mechanisms.

The model combines the Haskell model, which is that of a moving fault of finite length, with the Aki (s) 2 frequency dependence. For bilateral faulting (rupture velocity $3.3 \mathrm{~km} / \mathrm{s}$ ), the three recent earthquakes can be given reasonable fits by using radiation from faults with a simplified focal mechanism. We were not informed how the rupture velocity was determined, whether the model is sensitive to the assumptions regarding the Haskell and Aki models, or how sensitive the model is to possible variations of dislocation with depth or variations in fault inclination.

This section has dealt rather superficially with the discussion of theory, since much that passes for theoretical work in the west is in fact the execution of the mathematics of a particular model. Thus discussions for models and theories are somewhat intertwined. However, a broad discussion of the development of the theoretical foundations of earthquake prediction research should be concerned with the level of understanding that the scientists themselves have of the fundamental physics of their research. Here the problems which may arise from the programatic aspects of earthquake prediction research become apparent. The program seems to have developed thus far by trying diverse experiments in the hope that some precursory correlation with earthquake events might be observed. Thus some experiments with what seems to some of us to have only a small chance of success have been incorporated into the program. Examples are the use of torsion balance gravitational measurements, soil surface temperature measurements, anomalous animal behavior, etc. However, we could be wrong, and we should not be against trying out long shots. Nevertheless, it seems to us that an expenditure of resources 
on aspects of science that have a slight probability of success needs better justification; the probabilities should be estimated by a study of the physical processes underlying the proposed experiments.

\section{Summary}

This section has begun with an attempt to understand the high level of concentration of effort in empiricism and the pragmatic approach to Chinese earthquake prediction. The present stages of the program are evidently devoted to finding a rapid solution to the problem. It is our feeling that the fine Chinese program would be even stronger if it were broadened into areas where the field programs are carefully selected and the observations evaluated using statistical methods, where physical models based on a program of laboratory experiments are constructed, and where the large-scale geophysical environment in which the earthquakes are imbedded is explored. The development of a theory or model for processes accompanying earthquake precursory phenomena would make the program more efficient. (For example, why should surface temperature be measured? If a physical reason cannot be given, or if the time series are no better than random, then the work should be discontinued.) It is to the credit of the Chinese program that long shots are encouraged, but they should have some basis in a possible physical mechanism.

\section{Rock Mechanics}

We visited two laboratories where experimental rock deformation is carried out, at the Institute of Geology, Peking, and in the Geology Department of Peking University. Both groups have only recently entered the field. While at Harbin, we heard for the first time of the Institute of Rock and Soil Mechanics at Wuhan. This is under the scientific guidance of T'an Chen-ko, who prior to 1958 was at the Institute of Engineering Mechanics (IEM), Harbin. We did not visit Wuhan but were told that the work there is on tunneling, excavation, slope stability, and rheology.
Both of the groups in Peking are quite new, with research programs closely related to earthquake mechanics. The Hsingt'ai earthquake of 1966 apparently was responsible for this new direction and perhaps for the existence of the laboratories as well. Little or nothing has yet been published from these groups, so that they may only have been in existence 2 or 3 years.

\section{Institute of Geology}

Rock mechanics is carried out in the Laboratory of High Pressure and Temperature under the general direction of Chang Wen-ya. Some of the younger people include C.L. Chou, K.C. Sun, and L.C. Shih.

The largest piece of equipment is a 1000 -ton press. At present it is used in a triaxial arrangement on approximately 6 -cm-diameter by 15-cm-long samples at confining pressure of 1-2 kbar. The $v_{p}$ in the axial direction and linear strains parallel and perpendicular to the axis are measured. Strain gages appeared to be wire and not foil; the velocity transducer was a ceramic. The $v_{s}$ was measured in uniaxial compression using the prism method. We also observed cube tests, unconfined, on 5-cm samples. We were shown what appeared to be vessels for smaller samples, capable of triaxial experiments in the 10 -kbar range, and solid medium hydrostatic equipment of the belt type. All equipment was said to be constructed for work in this laboratory.

Although all present work is at room temperature and low pressure, future plans include extension to high temperature and pressure in the 20 - to 60 -kbar range. They plan to study seismic forerunners, particularly seismic velocity and electrical resistivity.

During our visit a paper was presented by C.Y. P'an on the strains observed during uniaxial cube tests. Some attempt was made to interpret natural tilt and radon precursors in terms of fluctuations of strain observed in the postfailure region dur. ing these tests.

\section{Peking University}

A modest high-pressure laboratory exists at Peking University, operated by Chu Jen-yi, who is a teacher there but who in the late 1950's received graduate training in mechanical engineering in Poland. $\mathrm{He}$ has a new 100-ton China-built universal testing machine and a 10 . kbar pumping system on order. He has begun studies of electrical resistivity of saturated crystalline rocks (3- to 5 -cm sample size) and plans to extend this and the study of seismic velocity to high pressure. He has also begun the study of changes of resistivity and strain in a mine shaft and will attempt to relate changes to the increase in stress near the shaft as material is extracted from the mine.

In the laboratories both of the Institute of Geology and of Peking University the electronic equipment used for detection and amplification of strains, resistances, displacements, or velocities seemed adequate. We saw an eight-channel light beam oscillograph of fairly modern design, but $X-Y$ and digital recorders were not evident in these particular laboratories.

We had extensive discussions with members of the Institute of Geology and scientists at Peking University on the design of experiments, on promising areas of investigation, and on current work in the United States. Generally, the Chinese were quite up to date on U.S. work, having seen papers in two or three of our more prominent journals through 1973. They were aware of the dilatancy-diffusion hy. pothesis, for example, at least in its early development. They were very interested in current work in the United States.

It is difficult to predict how rapidly the Chinese will advance in rock mechanics. On the one hand, the subject is being pursued by a number of vigorous capable people with the same single-mindedness typical of Chinese research in earthquake prediction. Also, this field apparently has strong government support and is regarded as an essential element in a prediction program. On the other hand, there is no one in China who has had experience in high-pressure deformation studies. Probably, few people are being trained (considering among other things the abbreviated university training) with the right 
blend of physics, geophysics, applied mechanics, and petrology. The guiding philosophy to be followed in experimental studies does not seem to be well established yet. Will there be one or two central SSB-directed laboratories or a flurry of provincial centers all working independently? Will the Chinese program start with the existing state of the art, Russian, Japanese, or American, and break new ground? Or will the philosophy be to seek insights from very simple experiments, perhaps analogous to the 'indigenous' instruments developed for field use by amateurs for earthquake prediction? The one presentation we heard suggested the latter course, but this may reflect only a passing stage of development. A clearer appraisal may be possible in $2-3$ years.

\section{Soil Mechanics}

We visited only one soil mechanics laboratory, at the IEM at Harbin. Their specialty is soil dynamics, other work in soil mechanics being done at the Institute of Rock and Soil Mechanics at Wuhan with Tan Chen-ke and perhaps at other centers which we did not visit.

At Harbin, where the major efforts are earthquake-related, soil dynamics is studied principally in its relation to foundation design in seismic areas of China. Liu Ying seems to direct the laboratory of soil mechanics.

The laboratory has several triaxial machines and one dynamic direct shear test. The most elaborate triaxial device (closely resembling a Berkeley instrument) was built in 1966 and would accept an approximately $10 \cdot \mathrm{cm} \cdot$ diameter sample at a confining pressure of 5 bars at a maximum thrust of $600 \mathrm{~kg}$. Axial stress and confining pressure can be pulsed independently at $2 \mathrm{~Hz}$ at an amplitude of 2 bars. Modulus, shear strength, deformation, and damping were being studied under these conditions. Strip chart recordings were being made by a lightwriting oscillograph. Dynamic loads were applied through electrically operating valves using gas pressure. The entire machine was made in China and was of superior workmanship.
The two smaller triaxial machines were simpler variations of the large device. The direct shear device applied the same principles to the shearing of approximately 5cm-square samples. The shearing force could be pulsed to $2 \mathrm{~Hz}$ up to a stress of 1 bar.

Liu reported briefly some new work with fine sand. The transition to a state of liquefaction was evident after a number of cycles in direct shear. This transition is being studied as a function of frequency and normal load.

Our overall impression with soils work at Harbin was that the laboratory was reasonably up to date by U.S. standards. Virtually no current work from Harbin reaches open publication, but the results presented to us orally seemed of high quality. An exchange of publications with centers in the United States would seem highly appropriate.

\section{Earthquake Engineering in China}

\section{Introduction}

Responsibility for the earthquake engineering research program in China has been assigned to the IEM in Harbin. The IEM, the Institute of Geophysics, and the Institute of Geology are the principal operating units of the State Seismological Bureau. Essentially all earthquake engineering work in China is being done by the IEM; hence this report deals almost exclusively with its activities, as reported to the members of the U.S. Seismology Delegation who visited Harbin.

Upon our arrival in Harbin, we were briefed by Liu Hui-hsien, Vice Chairman of the Institute Revolutionary Committee, on the research topics being studied there. During the following 2 days, detailed reports on specific research projects were presented by the engineers in charge, and also tours were made through the research laboratories to observe the work being done. All of these reports and tours were extremely well planned and presented, making use of numerous wall charts labeled in English as well as Chinese. The presentations were greatly assisted by the excellent technical translations provided by Hu Yu-hsien, who seems to be Liu's principal assistant. He had done graduate studies and worked in the United States from 1947 to 1955 , and his familiarity with technical English was very helpful.

This report presents first a brief outline of the history and organization of the IEM, followed by short summaries of its principal research programs, where appropriate related work being done outside of the institute is also mentioned. Finally, some comments are made on the extent and quality of this research effort.

\section{History and Organization of the IEM}

The IEM was established in Harbin in 1954 as the Institute of Civil Engineering and Architecture under the direction of Liu Huihsien, the present director. At first its fields of research interest included engineering materials, soils, structures, and architecture. However, in the early 1960's it became desirable to transfer its architecture program to the Ministry of Construction and its soils and rock mechanics program to a new in. stitute in Wuhan. At that time its name was changed to the Institute of Engineering Mechanics.

The institute began working in the area of earthquake engineering as early as 1956 , and at the time of the 1966 Hsingt'ai earthquake when the government began a major effort toward the reduction of earthquake hazard, earthquake engineering research became the sole activity of the IEM. The primary purpose of the IEM is the prevention of losses of life and property due to earthquakes by making use of both modern and indigenous methods. At the present time it has about 300 scientific and technical personnel working in three laboratories (Laboratory of Strong Earthquake Motion, Laboratory of Earthquake Resistant Construction, Laboratory of Vibration Test Equipment) and in the instrumentation and machine shops. An important part of their work is carried out at the sites of strong earthquakes or where new structures are being built, working in cooperation with 
the local population, but its principal research programs are carried out in Harbin.

The principal areas of research interest of the IEM were listed by Liu Hui-hsien as follows: (1) investigation of damage at earthquake sites, (2) measurement and study of strong ground motions, (3) evaluation of local site effects on earthquake intensity, including soil and foundation problems, (4) design and analysis of earthquake-resistant structures, (5) development of improved construction codes, (6) evaluation and strengthening of existing structures, and (7) design and manufacture of earthquake engineering test equipment.

Detailed lectures were presented on most of these topics, and related work being done in the laboratories was demonstrated. A summary of data presented in the principal lectures and demonstrations follows, arranged in the sequence of presentation.

\section{Observation of Strong \\ Ground Motions}

Instruments. The principal strong motion seismograph in use in China is designated RDZ 1-12-66. This instrument was described in an earlier section. Experience with'its operation to date shows that it is effective and reliable and is well adapted to measurement of the earthquake response of important structures which require response measurements at many locations.

Network. At present there are 60 strong motion instruments installed in the field in China, and a few others are available as mobile units for aftershock measurements. Most of these stations were established by the IEM, but only 16 are operated by the IEM; the rest are under control of the local seismological brigades.

Most of the instruments in the network are 12 component RDZ 1-12-66 systems; thus a relatively large number of ground motion components are being monitored. In addition, a number of three-component seismographs designated QZY IV (reportedly based on the Japanese SMAC instrument, but made in Shanghai) are included in the network. Instruments of this type

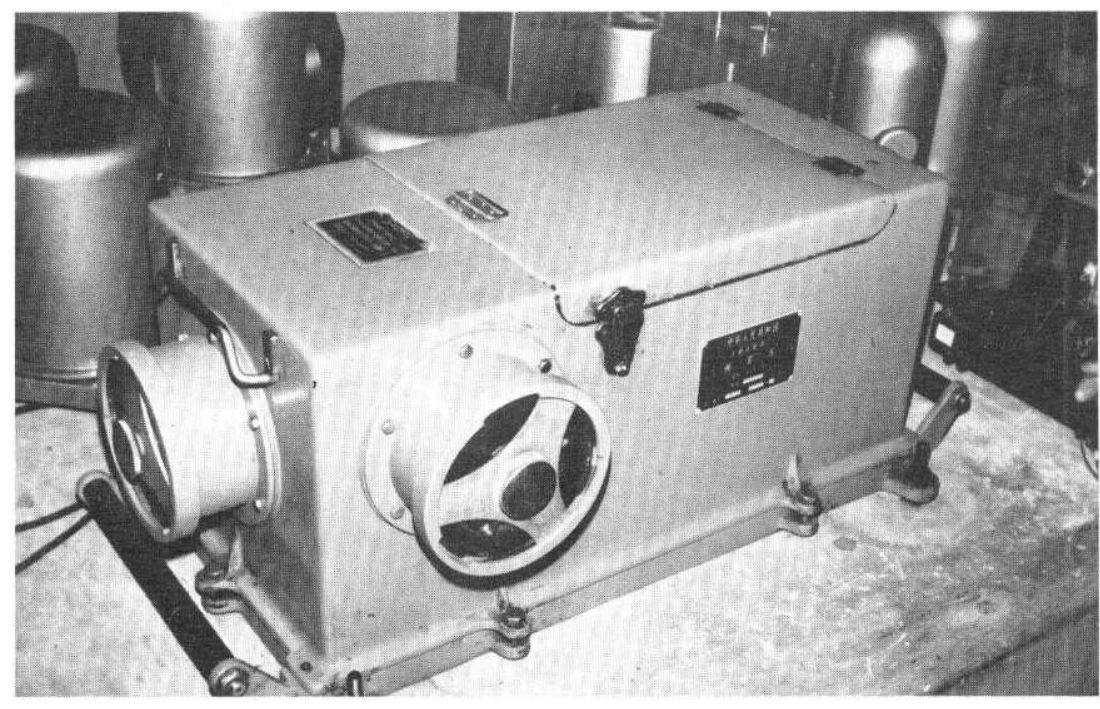

Fig. 8. Three-component strong motion seismographs, type QZY IV.

were seen in seismograph stations visited by the U.S. delegation near Peking and Kunming; one of these is shown in Figure 8.

Data processing. To date approximately 200-300 strong motion records have been obtained, most of them including 12 -component traces. Records which are considered to be of interest are digitized by means of a Japanese semiautomatic digitizer which produces a punched paper tape. This machine is shown in use in Figure 9. Analysis of the records is done by the digital computer of the institute. Typical processing includes making a base line correction, integration to obtain displacement records, and calculation of response and Fourier spectra.

\section{Site Effects on Ground \\ Motion Intensity}

Because few instrumental data have been obtained on variations of earthquake motion intensity as a result of soil or geologic conditions, a major effort is being made to evaluate these effects from observations of damage. Each major earthquake causes damage to large numbers of structures having rather similar construction, so the variations of damage can be interpreted in terms of intensity effects. For example, after the Hsingt'ai earthquake of 1966, all villages in which earthquake intensity was considered to be 8 or greater were studied in detail, a total of 1390 villages in all. A damage index, ranging from 0 (no damage) to 1 (collapse), was assigned to each structure, and then damage index contours were sketched so that variations of damage could be correlated with local soil conditions.

The principal conclusions drawn from such studies are that soil conditions can affect the damage index in two ways: (1) soil failures, such as liquefaction or instability, which should be avoided by proper foundation design or site selection, and (2) change of period of vibration of the ground motion, which can be considered in the seismic design code. Many of the field observations have been verified by finite element computer studies or by laboratory experiments on soil behavior.

\section{Evaluation of Structural Behavior During Earthquakes}

A large part of the research effort of the IEM is devoted to predicting the earthquake performance of various types of structures. Where possible such predictions are based on observed performance in past earthquakes. For structural types with which there has been extensive earthquake experience, such as the typical two- to six-story brick apartment houses, considerable effort has been devoted to development of empirical design rules and of analytical models which reproduce the observed behavior. Similar 


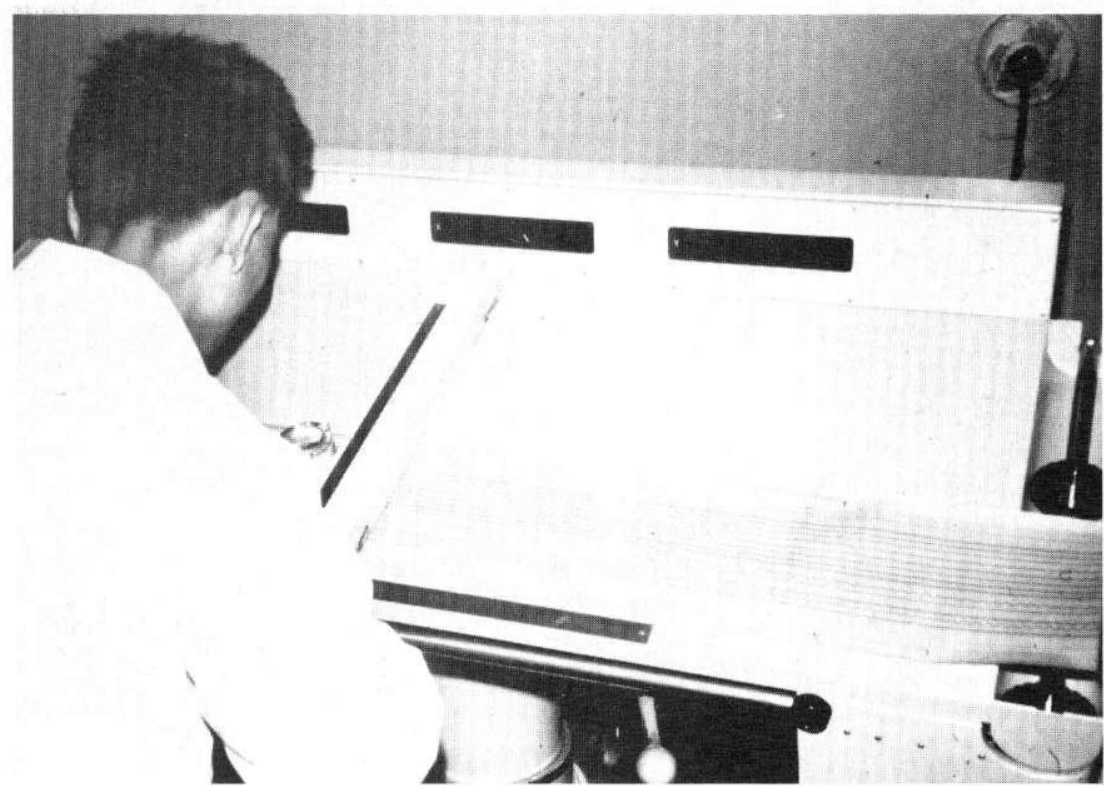

Fig. 9. Digitizing a strong motion record at IEM.

detailed investigations have been made of a wide range of industrial 'mill' buildings, including field measurements of their vibration properties. These have led to empirical vibration formulas which are now included in the design code.

Multistory reinforced concrete frame buildings also are being studied extensively, with the following principal topics of interest: (1) three-dimensional behavior of frames, taking account of floor diaphragm flexibility as well as torsional response, (2) action of frames with masonry infilling (these have

been studied experimentally at reduced scale to develop analytical models, and also by field vibration measurements conducted on fullscale structures during the infilling process), (3) lateral strength of precast frames, by full-scale test of a two-story structure (it was concluded that the joints can be designed to develop full strength and ductility of all members), and (4) interaction of shear walls and frames, studied mainly by model test.

All of these experimental studies had been completed prior to our

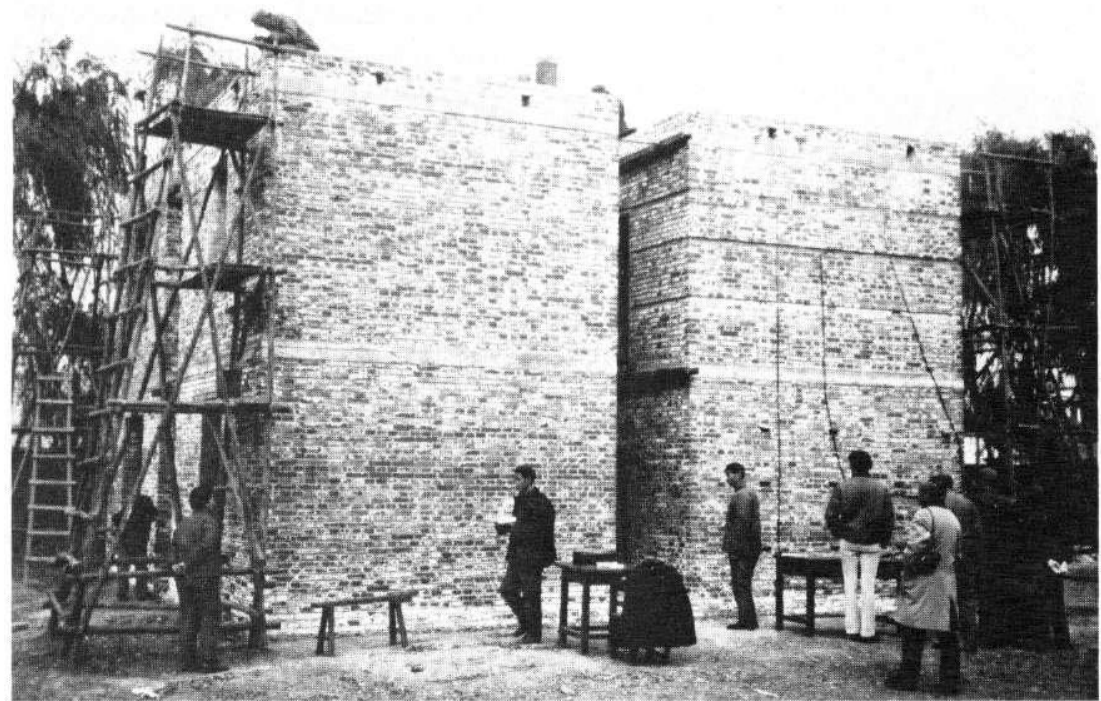

Fig. 10. Group of four brick structures during test at IEM. visit, so we were only told about the end results. The most important fact learned about the analytical investigations performed in support of experiments is that the analyses were based on linear elastic models. The need for nonlinear analyses to correlate with experimental results is recognized, but this analytical capability has not yet been developed.

A major experimental study which was in progress during our visit was a test program on a group of two-story box-type masonry buildings. Four buildings of similar square plan dimensions were erected in a square arrangement, with about $1 \mathrm{~m}$ of space between them on adjacent sides. A view of the test structures during testing is shown in Figure 10. Different window and door openings were built into each structure and also different reinforcing bar arrangements so that a range of results can be obtained by testing the group of four buildings. Horizontal test loads were being applied by means of hydraulic jacks acting between adjacent pairs of buildings. Loadings along the perpendicular axes could be applied by jacking between the pairs taken in the other direction. The test was being carried out in three stages: (1) in the elastic range to obtain linear material properties, (2) to the initial crack level, for defining the elastic limit, and (3) to the ultimate load capacity. The test appeared to be well planned and conducted, and it is expected that it will yield valuable information on Chinese masonry behavior; however, the strength of the Chinese materials is considerably less than that of those used in the United States, so the results would be only of qualitative value here.

Another important part of the structural research program concerns the earthquake engineering resistance of highway and railway bridges. Again, the principal data for these studies have been obtained by field observations of earthquake damages and by field measurements of the structural vibration properties. The vibration measurements have been made on 12 bridges of multiple simply supported spans by using vibration generators; the 
principal conclusion is that the superstructure causes little coupling between the tranverse pier vibrations but that the coupling in the longitudinal direction is great. A second type of bridge of considerable current interest in China is the double curvature arch. In this system, the main arch ribs are connected by precast concrete elements which arch in the transverse direction. Such structures can be assembled with little heavy equipment and have performed well in past earthquakes, so they are expected to be used extensively in the future. A model of a double curvature arch being used for vibration tests in the IEM laboratory is shown in Figure 11.

\section{Dynamic Behavior of Soils}

Many soil and foundation failures have occurred in China due to liquefaction caused by earthquakes. At the Hsingt'ai earthquake, for example, hundreds of sand blows were observed over a large area, each involving a sizable volume of sand. Studies of the phenomenon have been made in the field, attempting to obtain empirical relationships between penetration test data and liquefaction, and results derived from Chinese earthquakes appear to correspond well with the average of results reported by Japanese authors.

In addition, extensive dynamic laboratory tests are being made of soil samples. Several dynamic test devices, designed and built in the IEM shops, are in operation. The largest of three dynamic triaxial test machines can apply $600-\mathrm{kg}$ vertical dynamic load and $5 \mathrm{~kg} / \mathrm{cm}^{2}$ dynamic pressure each being cycled independently. It is operated by air pressure and was being used to study a clay sample during our visit. The light beam oscillograph used for recording pore pressure, lateral pressure, and axial load and displacement is similar to units in use in the United States. A dynamic direct shear test machine was also being used to evaluate the shear strength of clay samples.

\section{Building Code Development}

The first seismic building code provisions were proposed on a tenta-

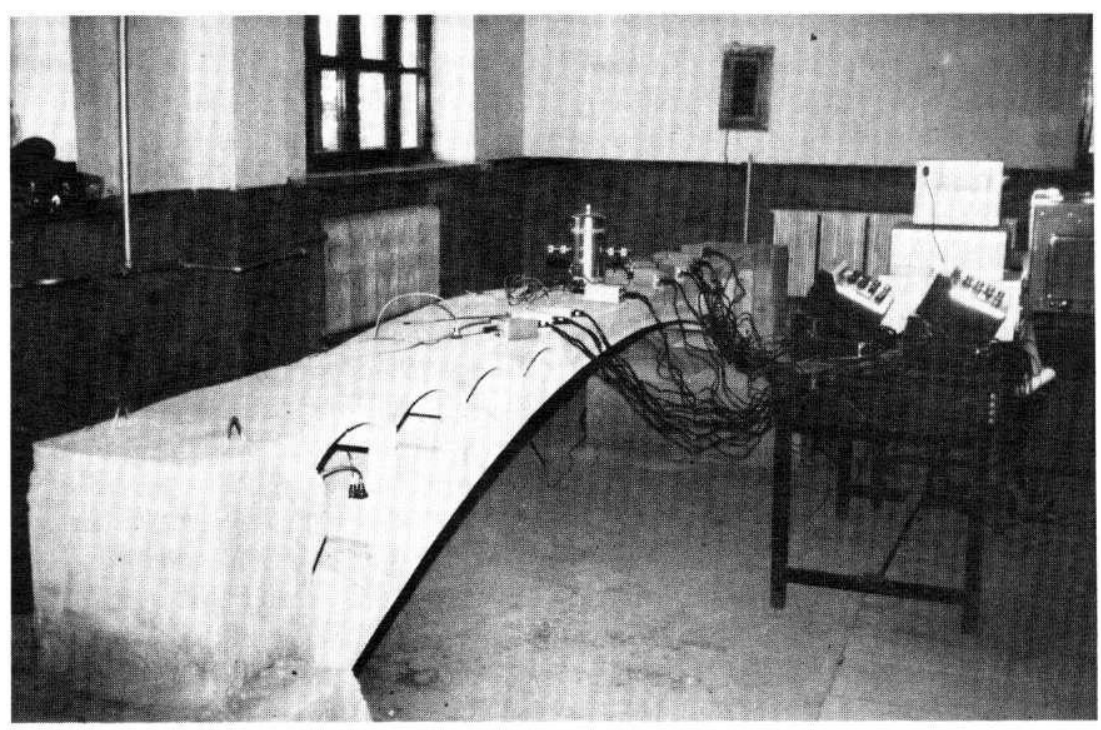

Fig. 11. Vibration tests of model of double curvature arch bridge.

tive basis in China in 1959 and were revised extensively in 1964 . In addition, a local code was developed for the Peking-Tientsin area in 1969. However, none of these codes had any legal status; they were considered only as guides for the designer. On the basis of experience with these code recommendations in a number of damaging earthquakes, it was decided in 1972 that it was time to formulate a new code, which would be adopted as a legal document. Thus the Ministry of Construction assembled a group of experts from design offices and the

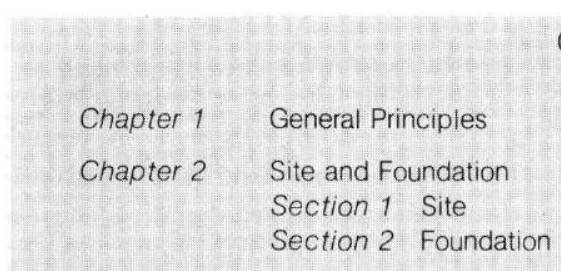

Chapter 3 Earthquake Loads and Check on the Earthquake-Resistant Strength of Structures

Section 1 Earthquake Loads

Section 2 Principles of Load Combinations and Check on Strength

Chapter 4 Measures on Earthquake-Resistant Construction

Section 1 Multistory Brick Buildings and Multistory Reinforced Concrete Inner-Frame Buildings

Section 2 Brick Buildings With Few Inner Walls and Single-Story Mill Buildings With Brick Columns

Section 3 Single-Story Reinforced Concrete Factories

Section 4 Multistory Reinforced Concrete Frame Buildings

Section 5 Buildings With Load-Bearing Wood Columns

Section 6 Buildings With Load-Bearing Walls of Lime-Earth

Section 7 Brick Chimneys and Water Towers

Appendix 1 General Method for Computing Earthquake Loads and Interna Forces

Appendix 2 Approximate Formulas for Fundamental Periods

Appendix 3 Assessment of Earthquake Loads for Single-Story Mill Buildings With Reinforced Concrete Roofs Considered as Space Structures

Fig. 12. Design code for earthquake-resistant industrial and public structures. Appendices $4,5,6$, and 7 are omitted. 
construction ministry, as well as from the universities and the IEM, to draft the new code. The first part of this code, dealing with industrial and civil buildings, was completed in summer 1974 and was being printed at the time of our visit. The second part, which treats dams and bridges, is expected to be completed before summer 1975. The code is divided into four chapters and seven appendices (Figure 12).

The general philosophy of this code is that safety of human lives and important equipment should come first and that the building should be in a repairable condition after the earthquake. It is applicable in any part of China which falls in earthquake intensity zone 7 or higher.

The seismic forces are specified by this code in terms of a base shear force which is distributed over the building height in a manner similar to our Uniform Building Code (UBC). The base shear $Q_{0}$ is given by the product of the building weight $W$, a building type factor $C$, and a seismic coefficient $\alpha$; i.e., $Q_{0}$ $=W C \alpha$. The seismic coefficient depends on the zone design intensity, on the type of soil, and on the period of vibration of the building. Three soil types are identified: I, bed rock; II, loose soft soil; and III, any other type. A different seismic coefficient curve is provided for each type of soil, as shown in Figure 13. Also shown are the building type factors and the design intensity values.

In general, the code seems quite comprehensive and represents a major development effort. However, although it differs in many respects from the UBC, it does not appear to include any major conceptual differences. It does not appear to deal explicitly with ductility in the structural system, which is a major concern of our code planning at present.

\section{Study of Hsinfengkiang Dam}

One of the principal earthquake engineering investigations in China, not done within the IEM, has been the investigation of earthquakes induced by filling the reservoir behind Hsinfengkiang Dam. This structure, located about $160 \mathrm{~km}$ northeast of Canton, was built in 1958-1960 in the form of a diamond head buttress dam with a height of $105 \mathrm{~m}$. Soon after impounding was started, a series of earthquakes began occurring in the vicinity, and because the dam was originally planned for only small seismic input, it was strengthened in 1961. Then in March 1962 an earthquake of mag. nitude 6.1 occurred in the reservoir region which caused horizontal cracking on both faces of the dam on both sides of the central spillway.

Following this event, extensive geological and seismological investigations were carried out to evaluate the seismicity of the region, strong motion instruments were installed to measure aftershock ground mo- tions, and detailed analyses were made of the dynamic response of the structure to determine further strengthening requirements. On the basis of these studies, the dam was strengthened by filling with concrete in the spaces between the buttresses and adding more concrete on the downstream face. Thus the modified structure is now essentially a gravity dam. This comprehensive study of the cause and correction of the earthquake problem at Hsinfengkiang Dam is an outstanding piece of earthquake engineering. It was carried out by cooperative efforts of members of the Ministry of Water Conservancy and Electric Power, of the Kwang.
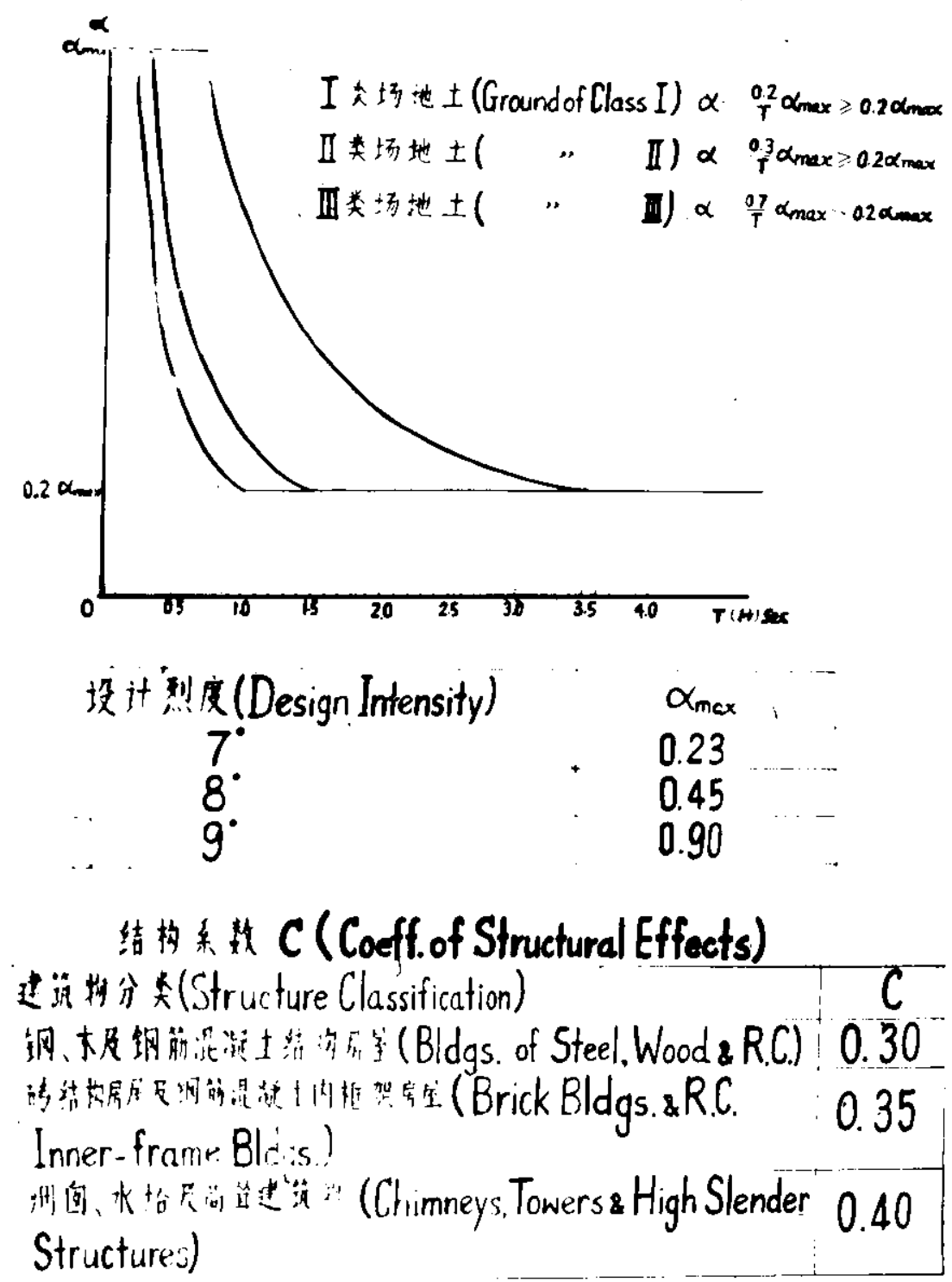

Fig. 13. Variation of seismic coefficient with building period $T$ (for three types of soil conditions). 
tung Bureau of Science and Technology, and of the IEM. It is in teresting to note that a paper on the Hsinfengkiang Dam investigation was presented at the Ninth International Congress on Large Dams in Madrid, June 1973 lsee Shen ef al., 1974l.

\section{Concluding Remarks}

The principal impression we received from our brief visit to the IEM was of a good professional organization, well managed, with a solid research program. They have identified objectives which are important to them and are within their technical capabilities, and they are working effectively toward these ends. Much of the credit for the good work of the IEM appears to be at tributable to $\mathrm{Liu}$ and $\mathrm{Hu}$; they are providing excellent technical direction.

The time allocated to this visit was far too short to permit a complete evaluation of all the work being done by the IEM. However, it is clear that the scope and quality of their research program warrants further study, and it is recommended that plans be made for the future exchange of earthquake engineering delegations between the United States and China. It is expected that each delegation would derive considerable immediate benefit for such an exchange, and it would make possible continued communication in many areas of common concern.

\section{History and Politics of Chinese Earthquake Studies}

\section{China's Earthquake \\ Prediction Program}

The Chinese earthquake prediction program, which we investigated for 1 month in October and November of 1974 , is at the same time a microcosm of Chinese science in general and a test case of the limits of innovation within the Chinese system of scientific administration. The program represents part of an ever-expanding effort in science and technology, an effort that has received growing in. vestment in manpower and appropriations despite recent reforms.
Like other specialties the earth sciences underwent considerable rationalization during the recent Cultural Revolution from 1966 to 1969 , including simplification of administration at the top, reduction of the scale of theoretical as opposed to applied effort, and extensive devolution of authority and manpower from the central to the regional and provincial levels. Earth science research now seems more highly focused than before on a topic of immediate national significance, the prediction of earthquakes, in much the same way as other fields such as biochemistry and medicine have been reoriented toward quick breakthroughs. Finally, the earthquake program has not escaped the general tendency toward the popularization of science, in which scientists are not only required to make their work and findings understandable to the people but are encouraged actively to seek inputs from 'the broad masses of the people.'

But despite these evident parallels with other scientific fields, earthquake studies will probably continue to play a unique role in Chinese science. Unlike Chinese work in atomic energy, or the synthesis of organic molecules, the earthquake prediction effort does not have clear models of foreign success to follow and so may require greater innovative effort than other highly publicized fields. This effort will demand a long-term commitment to pure research which administrators have been unable or unwilling to supply to other fields. The earthquake prediction program emerged from the lucky confluence of scientific and political interest at the end of the Cultural Revolution, and the question is, can this delicately balanced and so far highly productive alliance last the term required to make a major breakthrough?

The earthquake forecasting effort is the newest in a long series of high-priority drives in Chinese science, from the attack on schistosomiasis in the mid-fifties to the nuclear physics drive of the early sixties to the efforts of com. puting technology of the mid to late sixties. It remains something of a puzzle why earthquake studies should have become a major priority. Certainly Chinese leaders are concerned about reducing the damage done by all kinds of natural disasters, since these damages take their toll not only upon the people affected but on the greater national effort of economic development. The program got its start in the wake of the great Hsingt'ai earthquake of March 1966, a disaster that may have killed tens of thousands of people and required a massive relief program. Hsingt'ai is close enough to Peking that several major national political leaders could visit and see with their own eyes the extent of suffering. A government which is determined to lift China by its bootstraps could not sit idly by and wait for the occurrence of the next shock. So when Chou En-lai said, 'We must predict earthquakes,' on his return from Hsingt'ai, the stage was set for the present large-scale drive.

But there was a 5-year hiatus between Chou's expression of interest and the beginning of the earthquake studies program in earnest in 1971, which hints at a second reason for the priority of the new program. During that 5-year period, Chinese science and technology fell subject to the turbulence of the Cultural Revolution. The Academy of Sciences, the holding company for several of the research institutes in the earth sciences came under serious attack from leftist groups for their harboring of 'bourgeois' scientists and their failure to do research which would benefit the 'masses' in any direct way. The earthquake program may have emerged from this turmoil in part because it offered the academy and scientists a convenient vehicle for countering these charges. The discovery of accurate forecasting techniques for earthquakes will save many lives and much property damage, so the research has an obvious payoff. A proper earthquake program will require extensive manpower to man the networks, some imagination in the design of instrumentation, and extensive field observations of various geological surface phenomena. Hence earthquake scientists, unlike nu. 
clear physicists, can claim a direct 'reliance on the masses' in their research. Finally, the earthquake program is one of the few sciences where the Cultural Revolution demand for decentralization of research effort makes excellent sense. China's seismic zonation is rather well defined, and regional institutes specializing in regional conditions may be a much more effective type of research organization than the top-heavy centralization of the early 1960's. The decision to decentralize science makes earthquake studies more, not less, feasible.

There is a third element in the choice of earthquake prediction that is peculiar to the international development of this field of research. Chinese interest in this subject coincides with a blossoming of Western and Soviet interest and indeed with a series of major breakthroughs in prediction techniques outside of China. Chinese scientists since the 1950's have been seeking areas in which they can reach what they call 'the inter. national level' to demonstrate Chinese competence and naturally find earthquake prediction a tantalizing prospect. The uniqueness of China's seismological conditions-short recurrence periods, extensive intraplate seismicity, and the extensive historical record of earthquakes-automatically would place China at the forefront of an international effort. If satisfactory results can be produced, earthquake predic. tion could become one of the major showpieces of high science which Chinese scientific and technical people have been hoping for over the decades. Whichever of these explanations of the earthquake program is most valid, it is clear that earthquake study in China is, to echo the name of a current American National Science Foundation program, 'research applied to a national need.'

\section{Administration of the \\ Earth Program}

The new priority programs of the 1970 's are built squarely on programs and administrative structures built since 1949. Chinese science is presently in a fifth stage of transformation at the end of a quarter century of effort. Since present-day work takes its inspiration and draws its lessons from past experiences, we must briefly review the preceding four stages.

Between 1949 and roughly 1954, Chinese science, still suffering from the ravages of civil warfare and internal political dissention, underwent a consolidation under the new Communist regime. The older central academies, the Academia Sinica and the Peking Academy of Sciences, were amalgamated into the new Chinese Academy of Sciences. The older academic societies, numbering in the dozens, were allowed to flourish while being kept under the watchful eye of the party's cadres in charge of mass organizations. Professional educa. tion up to and including the gradu. ate level enjoyed a growing share of the budget and growing allocations of skilled manpower. During this consolidation phase the groundwork was laid for construction in the mid-1950's of an extensive bureaucratic hierarchy devoted to science and technology and headed by the Chinese Academy of Sci. ences.

During the second stage between 1954 and 1958, Chinese science modeled itself closely on the scientific establishment of the Soviet Union, relying heavily on the Soviet pattern of an academy of experts which harbored a large number of specialized research institutes in which most major scientific research was concentrated to the virtual exclusion of the universities. Thousands of Soviet scientific ex. perts in virtually every field spent time in China setting up programs, monitoring the installation of Russian instrumentation, and advising the Chinese about their research priorities. But though the Russian influence in Chinese scientific circles continued to early 1960 , when the Russians and Chinese suddenly broke off all collaborative contact, already in 1956 there were clear signs that Chinese politicians were dissatisfied with the Soviet model of science administration. During the 'Hundred Flowers' period of late 1956 to mid-1957, many prominent scientists trained before 1949 largely in Europe and America became openly critical of party con. trols in science and scholarship and in turn underwent large-scale criticism as the party launched its counterattack. The attacks on scientists for their political deviations coin. cided with increased demands that scientific and technological work link itself more directly to satisfying the quotas of the new first 5 year plan (1953-1957) and to the new 12-year scientific plan (19551967). Chinese scientists were given the task of reaching the international level' by the end of their 12 . year plan.

The third stage, from 1958 to 1965 , saw the increasing politicization and militarization of science administration. This stage began with the call in 1958 for a 'Great Leap Forward' in science to parallel that being demanded in industry and agriculture. Scientists and technicians were given of ten unreasonable quantified targets for their scholarly output and were subject to even closer controls by nonscientific administrators than in the past. The Academy of Science structure was modified and placed under a newly created Commission of Science and Technology, headed by a military man, under the State Council, or cabinet. During this stage, many of the larger scientific research institutes were broken up and their personnel distributed into the research branches of working productive ministries, notably the Ministry of Defense.

During the fourth stage, which coincides with the larger phenomenon known as the 'Great Proletarian Cultural Revolution,' scientific work for a period of several years ground to a halt for all practical purposes. (On this event, which began as a drive to reform cultural and educational work and ended with the extended involvement of the army in civilian affairs, see, e.g., Karnow [1972].) Scientific publications ceased (Acta Geophysica Sinica was silent from the second issue of 1966 to the first issue of 1973). The scientific and technical commission came under sharp attack from radical Red Guard groups on the left who eventually managed 
to purge two of the deputy chairmen of the commission and ultimately to abolish the commission itself in sweeping reforms of the ministries under the State Council which followed. The Academy of Sciences, under sharp attack for its harboring of 'bourgeois' scientists who refused to obey Chairman Mao Tse-tung's instruction to 'serve the people' found itself cut back from more than a hundred specialized research institutes in 1965 to somewhere between 20 and 30 such institutes in Peking.

Work in the earth sciences and geophysics has shown the effect of this stage by stage general development of Chinese science. Geology was one of the more well developed specialties in China before 1949 under the leadership until his death in 1936 of V.K. Ting, the founder of the Geological Survey of China. Already in 1949 this survey, established in 1916, had eight research laboratories with 30 senior scientists and 200 technical specialists. The survey along with the pre-1949 Academia Sinica and the National Academy of Peking became the core of the new Chinese Academy of Sciences formed in November of 1949 .

During the consolidation period to 1954 in which the new academy attracted to itself nearly 1000 scientists at home and abroad, earth scientists played a leading role. Indeed, the major scientific effort of the period went into large-scale nationwide surveys of resources in which the biologists and especially the geologists did most of the work. By 1954 the number of geologists and earth science technicians had reached 900 , and during the great expansion of work in the 5-year plan that followed that number increased to some 21,000 by 1960 . By the late 1950's the two institutes in earth sciences under the academy in 1950 had expanded to more than 14 central level institutes of which the Institute of Geology and the Institute of Geophysics were the most prominent.

By the early 1960's the earth sciences could claim two of the six deputy directors of the Academy of Sciences, the meteorologist $\mathrm{Chu}$ K'o-chen and Li Ssu-kuang (J.S.
Lee). The remaining four included only one other natural scientist, $\mathrm{Wu}$ Yu-hsun (Woo Yui-hsun, our delegation's host at the main banquet in Peking).

During the drive to expand scientific and technological work in the first 5-year plan along Soviet lines of organization the close connection between earth science surveys and production received official recognition. In 1952 the State Council established a Ministry of Geology under J.S. Lee, which in turn built a geological administration in virtually every region of China. This ministry led the crash program of resource surveys which produced major results, such as the Outline of Geotectonics of China, published with an associated map in 1959 .

Throughout most of the 1950's the study of earthquakes in particular and geophysics in general did not receive major attention. There were only two seismographic stations operating in China in 1949 , and though the Institute of Geophysics under the Academy was born in 1950 from the amalgamation of the Meteorological Institute and two other institutes, its work was given relatively low priority by the academy. Geophysics received its greatest boost during the 1950's from the planning for Chinese participation in the International Geophysical Year. China joined the IGY preparations in 1955 (formal approval of the State Council came in August 1955) on the stipulation that the rival Academia Sinica of Taiwan would not be permitted to take part as an independent country. In fact Taiwan had been invited in 1952 but had never replied to the invitation. A Chinese delegation attended the East European Regional Conference for the IGY in Moscow in August of 1956, the Barcelona meeting in September of 1956, and the West Pacific Regional Conference in Tokyo in February and March of 1957 on this understanding. By June of 1957, China's geophysicists had prepared seven seismological observatories using 'equipment of the latest type produced by China on the basis of technical data from the Academy of Sciences of the USSR.' But in late June the IGY special committee, on an appeal from Taipei, decided to admit the Republic of China scientists under the name of Chinese IGY Committee: Taipei. Chu K'o-chen formally protested, saying China had been drawn into a trap, and refused China's further participation.

But despite this diplomatic break, geophysical work got a tremendous boost from the IGY preparations. The first geomagnetic observatory in Tibet was established in January of 1957 followed by the seismological instrumentation a few months later. Geomagnetic observatories were set up in Sheshan (Kiangsu), Peking, and Canton. Sunspots were studied at Nanking, Sheshan, Kunming, and Peking, and cosmic rays at Peking and Tungkwan. The basic seismological network grew from the two observatories in Peking and Shanghai to seven at Peking, Shanghai, Lanchow, Nanking, Sheshan, Kunming, and Canton, and thus the foundation was laid for the 'standard station network' of which we heard much in 1974.

Despite this burst of energy in 1957, earthquake studies remained only a small part of the greater geophysical effort. Our hosts in 1974 made it clear that the Institute of Geophysics as late as 1971 was still responsible for it. Occupied with much more than just earthquake studies, the institute until the late 1960's always bore the English name Institute of Geophysics and Meteorology (though in Chinese the meteorology part was left out). But in the 1960's, at least the Institute of Geophysics began to concentrate its efforts more on pure scientific questions than had been the case in the 1950's. Though the Great Leap Forward reforms of scientific administration aimed at increasing the productive value of scientific work, they included secondary commitment to stepped up basic research which benefited academic institutes such as the Institute of Geophysics. Though the academic societies-the loose organizations of professional workers in each scien. tific field drawn from institutes, universities, and enterprises-underwent extensive criticism during the 'Rectification Campaign' of mid-1957, their publishing ac- 
tivities continued unabated to 1965 , and the contents of Acta Geophysica Sinica over this period reveal an increasing concern with theoretical work and a declining responsibility for direct productive functions such as mineral prospecting. The growth of an extensive meteorological program under the State Meteorological Bureau served to relieve the institute of many of its earlier functions. Already by the mid-1960's the great majority of articles in Acta Geophysica Sinica concerned seismology and geomagnetic studies, the main themes of work of the institute today.

The Cultural Revolution after 1966 brought a halt to much of earthquake work. The Institute of Geology suffered considerably from internal dissention and rivalry. Indeed, at the high point of 1967 , 'revolutionary rebel groups' within the institute launched a veiled attack, published in Red Guard newspapers in Canton, on elements within the top political leadership in Peking. We got the impression in 1974 that the dissention within the Institute of Geology had not yet settled down from the Cultural Revolu. tion period of unrest.

During the 5-year period between 1965 and 1971 earthquake prediction work, though given the blessing of central authorities such as Chou En-lai, lacked central organizational leadership. That leadership has been provided since 1971 by the State Seismological Bureau, now a direct subsidary of the Academy of Sciences, and the lead organization over the Institute of Geophysics, the Institute of Geology, the IEM, and the Geodetic Survey Brigade in Tientsin.

\section{Administrative Organization}

The administrative structure within which the earthquake science program grew in the late 1960's still resembles its Soviet counterpart in many ways despite the reforms of the Cultural Revolution. As in the Soviet Union, science in China is centrally administered, subject to the constraints of nationwide planning, and concentrated largely in research institutes underneath an Academy of Sciences rather than in universities. Broadly speaking, science administration remains divided into four major segments which since 1950 have waxed and waned with respect to one another beneath the leadership of the State Council, the Chinese council of ministers. These four segments are the productive ministries, the Academy of Sciences and its related research institutes, the scientific and professional societies, and the universities and other higher educational institutions.

Over the years since 1949 the supervision of scientific and technical work and the coordination of these four broad structures has fallen to a changing set of leading science organs. During the first 5 year plan from early 1954 to early 1956 the secretariat of the Academy of Sciences began to coordinate scientific work within the academy as well as without. Following Soviet practice, beneath this secretariat of the academy four or five 'academic departments' existed, with dozens of China's most prominent scientists as members. Each of the institutes beneath the academy was likewise assigned academic committees composed of members of the related profession drawn from both inside and outside the institute. The Institute of Geophysics, for example, had a science committee of ten members in addition to its director, Chao Chiu-chang, and three deputy directors including $\mathrm{Ku} \mathrm{Kung-hsu.}$ Though neither the academic department (in this case, the Department of Earth Sciences) nor the scientific committees were mentioned on our trip in 1974 , the institute is still located in the building adjoining the headquarters of the Academy of Sciences.

In the mid-1950's a new device for cross-sector coordination emerged in the form of a Science Planning Committee (SPC) established in March 1956 directly under the State Council and chaired initially by Vice Premier Ch'en Yi. This committee was in charge of working out the 12-year plan for science. Part of this plan involved the strengthening of nonacademy sectors of the science system, namely, the universities and colleges and to some degree the ministries. The SPC, which in November 1958 merged with the State Technological Commission to form the State Scientific and Technological Commission, consisted entirely of nonscientists and presided over the strong reorientation of science away from 'bourgeois' attitudes during the Great Leap Forward (Figure 14). Its chairman, Marshal Nieh Jung-chen, remained China's major scientific leader until the commission disappeared in the turmoil of the Cultural Revolution in 1966.

The shape of administration after that turmoil is yet to be revealed, but in place of the old SPC is now a group with even broader responsibilities not only for science and technology but also for the entire educational system. This organization, called the Science and Educa. tion Group of the State Council, is now headed by a former deputy chairman of the SPC. (Note added in proof: It now appears that this group may have been disbanded shortly after our departure.) Thus structural reform from 1949 to the present has confirmed the Chinese commitment to making organized science subservient to changing national priorities.

The great bulk of technological work and much scientific work is carried out not in institutes or universities but in working governmental bureaucratic organizations also under the State Council. Indeed, a major effort of the academy in the 1950 's went into proving that scientific research would help the productive departments working on fulfilling the national economic plan. Throughout the 1950's, productive ministries steadily ate into the manpower and resource pool which the academy had squirreled away in its early years, and by the mid-1960's, earthquake-related research, for example, was being carried out in at least four of the seventy-odd ministries under the State Council. It was not until the formation of the State Seismological Bureau in 1971 that this outflow was to some extent reversed.

The professional societies, largely composed of older scientists, many trained outside of China, remain a stronghold of expertise, though they no longer perform their former public roles. In the early 1950's, 


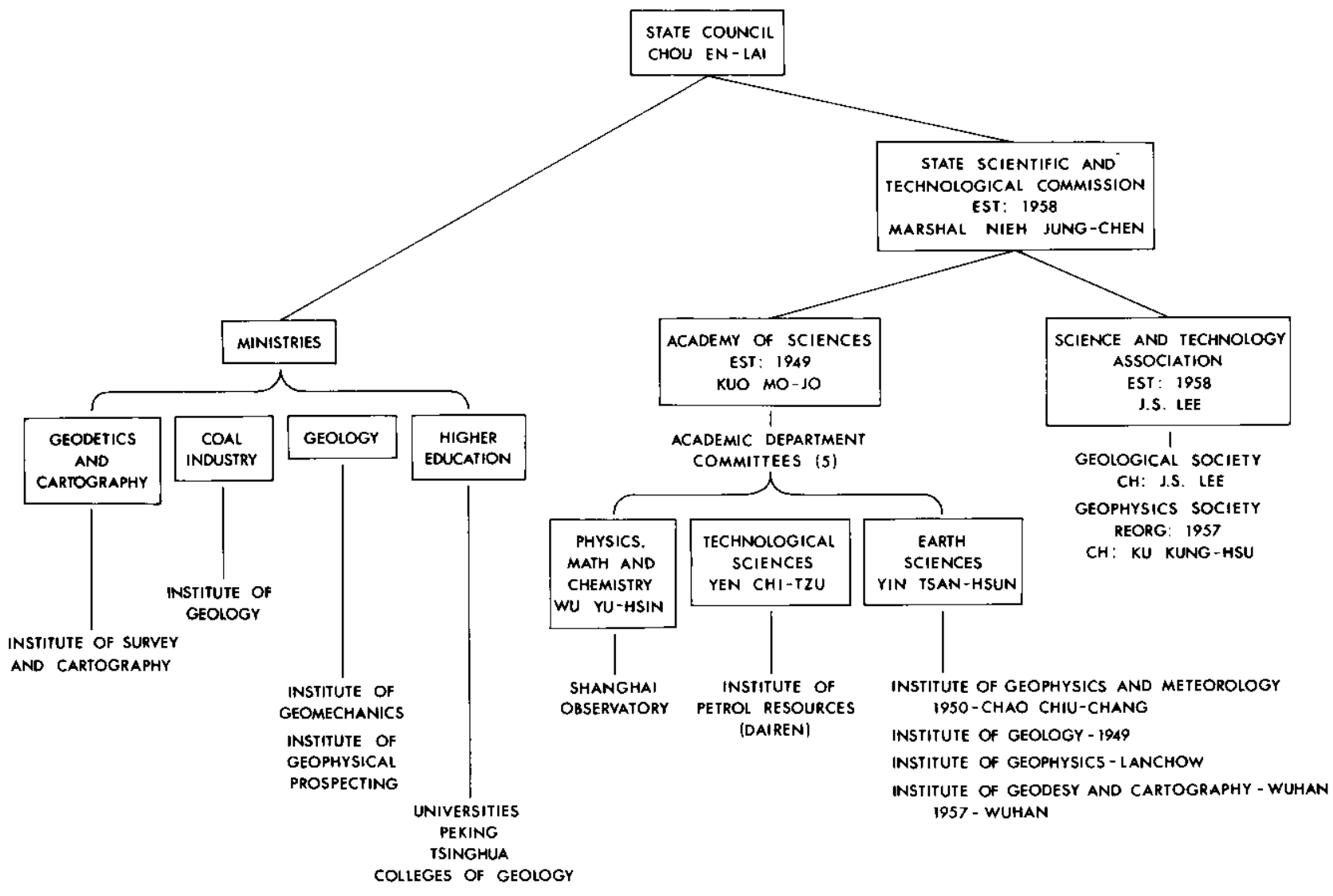

Fig. 14. Chinese earthquake science organization, 1965.

dozens of professional associations like the Geological Society and the Geophysical Society of China flourished and for some time held a monopoly of scientific talent. Representing the government in directing the affairs of these associations was an all-China Federation of Scien. tific Societies, an organization of government cadres whose job it was to coordinate the finances, guide the political behavior, and manage the foreign contacts of each of the individual societies. This organization, when combined in February 1958 with a popularizing unit known as the All-China Society for the Dissemination of Scientific Knowledge, became the Science and Technology Association of China (S\&T Association). This association now assumes responsibility for hosting international visitors such as ourselves.

Earthquake science is thus a part of the 'science and technology system' (k'o-chi hsi-t'ung), an enormous nationwide network which includes top scientists down to provin- cial technical administrators. If we include local workers in counties and communes in our accounting, this system may include several hundred thousand or even several million workers. The earthquake program thus can draw upon an enormous manpower pool. The leadership of science and technology ( $S \& T$ ) is, however, in the hands of a small number of party 'responsible persons' (the Central Committee office in charge of managing S\&T work has not yet been indentified) who closely supervise the day-to-day work of the 'Science and Education Group' under the State Council. Our delegation saw nothing of this august group (though the visiting American university presidents did meet with their representative). Beneath the capital group are the operating organs of $\mathrm{S} \& \mathrm{~T}$ at the central level, divided into two sets: research organizations and 'mass organizations.' The Chinese Academy of Sciences is at the pinnacle of the research pyramid, and the $S \& T$
Association heads the other. Many of us got the impression that association cadres were somehow more powerful and important than workers in the academy. But their prominence in our eyes may have been due to the fact that we, as scientists from a noncountry where only people-to-people contacts with China are allowed, could not deal directly with the administrative authorities at the academy. (Our hosts in Peking, even when they held academy posts, as did $\mathrm{Wu} \mathrm{Yu}$ hsun, a vice president of the academy, announced themselves as S\&T Association officers for this reason. On one occasion, a cadre mistakenly spoke in the name of the academy, only to have his translator, without blinking an eye, correct his error in the English version.) The S\&T system is sufficiently unified to maintain its own 'May 7th Cadre School,' a large spread in Ch'uehshan county, Honan, for the benefit of all high-level members. Cadres and scientists alike, whether from association or academy, attend 


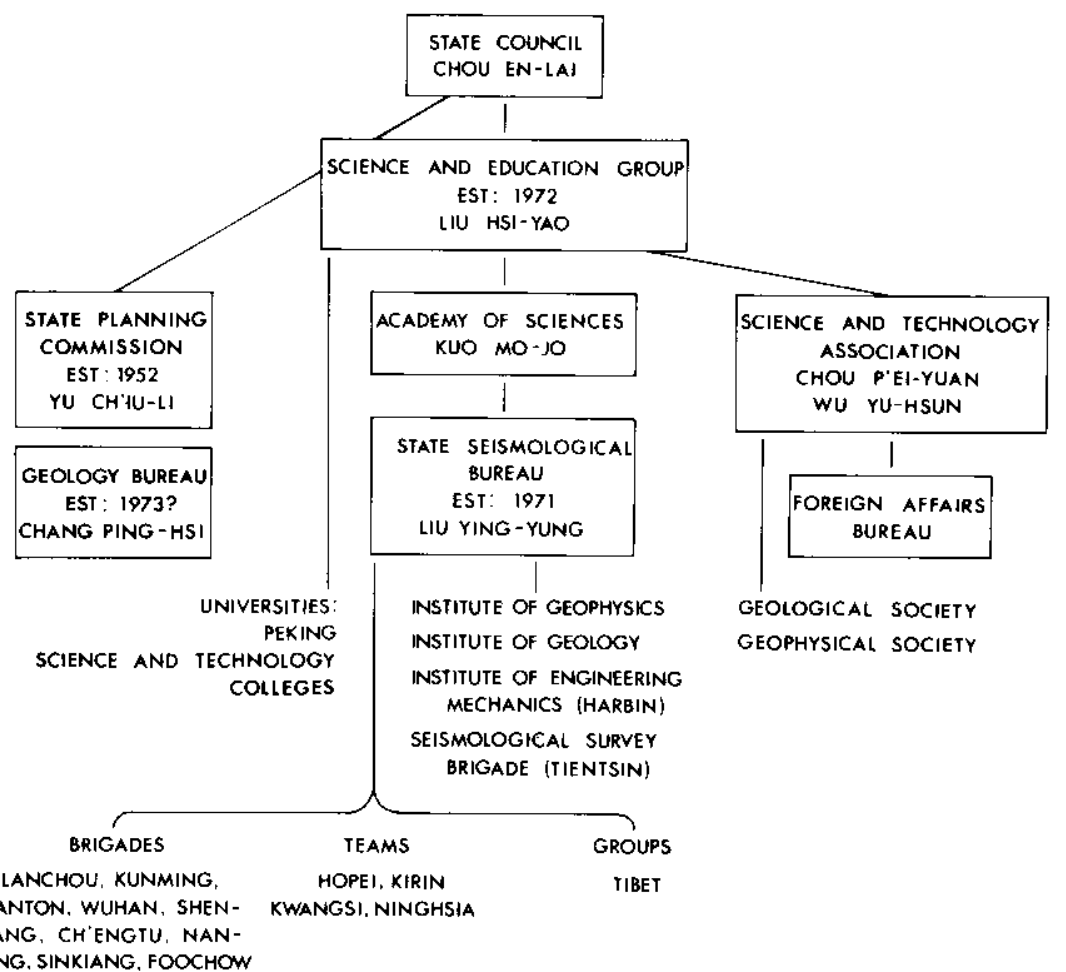

Fig. 15. Chinese earthquake science organization, 1974.

this same school for periods of up to 1 year. Earthquake scientists thus play their role as part of a much larger bureaucratic system.

The rapid expansion of the earthquake program has brought a flood of new S\&T workers under the State Seismological Bureau. As the seismological net expanded from 2 stations in 1949 to 7 in 1958 to 15 in 1971 and presently to 17 (standard stations), so the bureau has established contacts with scientific workers in virtually every province. And as the number of nonstandard stations has grown from 150 in 1971 to 250 this year, there has been considerable expansion in the average size of each provincial effort (see Table 2).

The bureau presently makes a distinction between three different types of provincial level earthquake organizations: the brigades, teams, and groups. Only 9 of the nearly 30 provinces have brigades (see Figure 15). Though we were told that rela. tive seismicity determines the location of brigades within the earthquake system, in fact seismically active Tibet has been assigned only a group, and several brigades are located in relatively quiet but large capitals such as Wuhan and Nanking. The selection of the location of brigades therefore appears to be a mix between considerations of relative seismic risk and considerations of existing administrative and scientific capability. Seven of the nine brigades are located at sites chosen for the first seismological installations during the IGY period. Some brigades clearly exercise an

TABLE 2. Scope of the Earthquake Studies Effort

\begin{tabular}{lcc}
\hline \multicolumn{1}{c}{ Province } & Technical Workers & $\begin{array}{c}\text { Stations } \\
\text { (Nonstandard) }\end{array}$ \\
\hline Kwangtung & 400 & 20 \\
Kansu & 400 & 20 \\
Ninghsia & $40-50$ & $7-8$ \\
Yunnan & 500 & 16 \\
& $1,200^{*}$ & $300^{*}$ \\
All China & 10,000 & 250
\end{tabular}

Statistics are only partial.

*Amateur effort only.

administrative function that extends to their surrounding provincial teams. Indeed, there were indications that in late 1971 the brigade located at Canton served as the Central South Earthquake Brigade, indicating its administrative responsibility for Kwangsi and perhaps Hunan provinces as well as Kwangtung.

The relationship between brigades or teams and their local governments was a subject of much discussion during our trip. An important result of the Cultural Revolution has been the decentralization of administrative institutions of all types. Even the Academy of Sciences has lost a number of its institutes to the control of regional authorities. The operative slogan of the day was 'Dual Level Leadership, With the Locality in Charge.' This slogan, apparently the instruction of Chairman Mao himself, suggests perhaps more direct control over brigades and teams by provincial political authorities than is in fact the case. We were told that the Revolutionary Committee had the power to recommend answers to such questions as which station to make the standard station in a province or even what topics to research. But this sort of answer would have to be approved (k'en ting) by the State Seismological Bureau. Plans are laid by the province with respect to research planning expenditures and appropriations of material, but once again the State Seismological Bureau makes the final decision (ch'ueh ting) about the plans. The local authority of the Revolutionary Committee over the brigade appears to be most extensive in personnel hiring. Here all the national bureau does is to provide the number of slots to be filled in the science and technical fields, a number based on a rational calculation of need. But the local Revolutionary Committee selects the people according to its own dictates. Even here it was clear that local authorities, particularly for the higher ranking jobs, would rely heavily on the recommendations of the central leaders of the program. While the province after the Cultural Revolution may be held responsible for paying the salaries, 
providing the office space, and maintaining a personnel sur. veillance of local seismological workers, it was clear that their professional work (yeh-wu kungtso) linked them in a direct way to the State Seismological Bureau.

\section{Earthquake Prediction for the \\ People: Role of the Masses}

Earthquake science, like every other activity in China, is expected to observe Chairman Mao's dictum to 'serve the people.' Other observers have reported on how Chinese scientists, particularly since the Cultural Revolution, are expected to adhere closely to the correct political line, to overcome their 'bourgeois elitist tendencies,' and to develop a respect for the strength of the masses. Earthquake scientists are no exception to these rules, and indeed a good portion of our briefings dealt with the political frame. work for scientific work. Many times we were told that Chinese earthquake scientists draw heavily on the 'broad masses of the laboring people' who have a 'rich experience of long struggle against earthquakes.' Earthquake science, to the degree that it can reduce losses from natural disasters, actively serves the people by improving economic construction and national defense. Earthquake scientists are constantly urged to improve their professional work by maintaining close contact with the people affected by earthquakes. The slogan most often heard during our trip set the political tone for our hosts' presentations: 'Under unified leadership of the party, take prevention first, combine professional and amateur efforts, mix modern and in. digenous methods, wage a people's war.'

Even though our hosts agreed on the goal of serving the people, the means to that goal seemed often to us subject to differing interpretations. Will a crash program to predict disasters really work? 'Some comrades doubt that we can predict earthquakes,' we were told in our first briefing. This skepticism, our hosts assured us, is erroneous, since Chairman Mao Tse-tung has told the nation, 'We can predict earthquakes.' The very mention of doubt, however, suggests the continued existence of opposition to that view.

If prediction is to be the policy, who should do the work-the experts or the masses? The answer, a combination of the two, begs the question of the proper mix. A vast army of amateurs man more than 5000 observation and prediction points (ts'e-pao-tien) scattered around the countryside. Village schoolteachers encourage classes to run long-term ambitious projects using simple locally built instrumentation. All over China, particularly in earthquake-prone regions, farmers are encouraged to make daily observations of water well levels and to report any curious behavior of farm animals by telephone to the nearest authorities. Taken together, these activities demonstrate that China has made earthquake prediction into a mass campaign far more extensive than that anywhere else in the world. Are these mass activities the most promising approach to the problem?

There may indeed be many good scientific justifications for taking the art of prediction out of the hands of the experts in this way. The water well program alone may make the 'mass observation, mass prevention' policy worthwhile. Rural labor to man the seismological network makes good economic sense. Local experimentation helps build a sense of technical competence as, for example, scarcely literate farmers learn through it the elements of basic electronics or graphic presentation. A village schoolteacher may not successfully predict an earthquake alone and save the lives of inhabitants, but he can surely make villagers aware of the physical processes that cause earthquakes and of the dangers of faulty construction. Finally, in a country where tradition has always identified the occurrence of natural disaster with political incompetence of its ruling elite, the earthquake prediction mass campaign can be used to demonstrate the activist concern of the present government. Any or all of these considerations may help us explain why earth. quake prediction has become a mass campaign of the type and scope of earlier campaigns against schis- tosomiasis or against typhoons, tornadoes, and other meteorological disasters.

Yet with all the important stress on mass work, it is clear that the experts in this field have their protagonists. How else can we explain expensive centrally financed construction of a number of regional seismic stations in recent years or the financial and bureaucratic energy spent in building the State Seismological Bureau described in an earlier chapter? While political leaders, such as one prominent provincial revolutionary committee member, may chide their expert comrades with making a number of false predictions in a row, the leadership realizes that China will have to 'study the advanced experiences' of other nations such as the United States and that this study must be conducted by specially trained technicians. The government sends its earthquake experts abroad, subscribes to an im. pressive range of foreign publications, and to a degree protects its scientists from excessive disruption during political campaigns. In these and other ways the People's Republic is showing its commitment to attacking the scourge of earthquakes by 'walking on two legs'-by depending on the masses and the scientific experts.

\section{The State of the Art:}

\section{A Balance Sheet}

What do our observations tell us about the strengths and weaknesses of this new program in China? The earthquake program began with the advantages of a relatively strong background in basic geological research laid down in previous decades. It has obtained an apparently reliable commitment from high authority to a level of investment in funds and manpower that makes it presently one of the priority sciences in China. The effort over the last 5 years has built a steadily growing momentum, easily seen in the expanding personnel and budget allocations as well as in the enthusiastic high spirits of the earthquake scientists we met. Even with the pinch on education of the Cultural Revolution a broad base of talent has been brought 
together from various quarters, talent which is at least in many ways competent if not yet indisputably brilliant. American seis mologists are confident that much more will be heard from the Chinese as the world gropes toward a solution to the problem of earthquake prediction.

We emerged from China less concerned about the obvious skills and high motivation of our scientific counterparts than about the future development of Chinese society in general. The Chinese view science as but one small part of a major process of transforming Chinese society. Whether by demanding in the 1950's that scientists abandon their independent 'bourgeois' views of science as an international apolitical process or by insisting that theoretical projects be abandoned in favor of direct contributions to production or more recently by effecting a nearly universal ban on research for a 3-year period in order to stage a 'Cultural Revolution,' the Chinese leadership has demonstrated that it will insist on subordination of scientific improvement to more general social and political policies. (For an accurate echo of the recent line on science policy by a visiting American team with an admitted 'clear political bias,' see Science for the People [1974|.) There is no reason at this point to suspect that the earthquake program will be singled out and drastically cut in the future. But neither is there assurance that the hesitations, uncertainties, and shifting priorities of China's leadership will always leave a place for the earthquake prediction program. The future success of the earthquake program may depend on how these leaders handle three major problems of scientific and technical development: improvement of quality, training, and leadership.

Improvement of quality. Scientific presentations, papers, and conversations all reveal a great variety in the backgrounds, training, and sophistication of the workers we met. A number of Chinese earthquake scientists are clearly in an international class and will have much to contribute. Earthquake studies require a rare mar- riage between such outstanding scientists and an extensive technologically trained infrastructure of technical personnel. Not just in geophysics but in most areas, China is still in a phase of being more concerned about popularization of existing standards rather than their improvement in level.

Perhaps some of the uncritical tolerance for less fruitful work that we observed is the result of the present stage of development. Chinese presently see their problem as one of raising the entire Chinese society by its bootstraps rather than permitting individual portions of the society to rise above others. After the Cultural Revolution, scientists who rise above others to the extent of making extensive criticism, boasting about their own achievements, or looking down their noses at less well endowed students or colleagues are all violating the recent mood. We are now in a phase, we were told often, of "the most widespread experimentation possible.' Students and technical workers are encouraged to undertake projects with only minimum likelihood of success on the general principle that anything can and should be tried at least once. While this quest for experience in quantity is impressive, it will sooner or later have to yield to a consolidation phase in which the better and more suc. cessful results and experiments are selected out and made the basis for new speculation and investigation.

Training. The difficulty of expanding earthquake studies as the country emerges from the Cultural Revolution is most apparent in the area of 'bringing along new cadres.' The department of geophysics at Peking University this year kept on only three students for education beyond the $3^{1 / 2}$ year course. Each institute we visited complained that the planning authorities were una. ble to assign them as many technical workers as they needed. Cultural Revolution reforms make extensive graduate training in the universities virtually impossible, and so in. stitutes and ministries have taken to bootlegging graduate education within their institutions. Under the State Seismological Bureau this was done largely by assigning young recruits from the universities or elsewhere experimental tasks designed to train them upon their first arrival at their new place of work. These young recruits may establish a relationship with an older professor who has trained graduate students in past decades. Young trainees therefore learn by doing rather than by reading, and their theoretical or interdisciplinary understanding must be developed as a sideline. We remain uncertain how adequate the new onthe-job training system is for China's ambitious earthquake program.

Leadership for scientific development. Any scientific field demands a degree of coordination of effort When the Soviets introduced the concept of scientific planning in the late 1920's, there were those who scoffed and claimed that science could not be planned. Chinese efforts in several important fields have proved to themselves what the Soviets have also learned, that without a certain degree of thinking ahead and administrative preparation large-scale scientific progress is unlikely. The SPC under the State Council still does lay down elements of the scientific plan even though the '12-year plan for science' ended many years ago. The planning organs are particularly active in determining where the meager output of trained university graduates will be placed as well as in shaping the distribution of the national budget. But beyond these research and development allocation functions, the work of scientific leadership must be provided if the earthquake program is to move toward success.

Quality control, rewards, and training in the best methods are part of this leadership that is required. So are channels of communication across regions and between regions and the center, the editorial function of the boards of the central journals, and review procedures for approval or disapproval of various research topics. In many ways the State Seismological Bureau is in an excellent position to coordinate these functions, and there is some evidence it has done so without much fanfare. (For exam- 
ple, the predictions of the recent (February 4, 1975) Liaoning earthquake apparently were coordinated at two meetings of the SSB in June 1974 and again in January 1975.)

The earthquake program we observed is groping toward an answer for these uncertainties. In many ways its hesitancy is a mirror of the uncertainty about most aspects of Chinese society today. Many would like to see the program move to raise standards of achievement, to increase the level of training, to strengthen the discipline of leadership at the national level. But many others seem unconvinced that the time has come, and the words 'grop. ing' and 'experimentation' came often to the lips of our hosts, as though to say the final decisions are yet to be made. Whether the Chinese will be the first nation in the world to predict earthquakes on a large scale successfully may hinge directly on the outcome of this discussion.

\section{Acknowledgments}

Members of the American Seismology Delegation were Frank Press, Chairman;
Clarence R. Allen, Vice-Chairman; Manuel G. Bonilla, William F. Brace, Carl Kisslinger, Robert M. Hamilton, C. Barry Raleigh, Ray W. Clough, Lynn R. Sykes, Leon Knopoff, Roy Hofheinz, Jr., Peter G. Smith, and Mary Bullock. Although the Committee on Scholarly Communication with the People's Republic of China sponsored the visit of the delegation, this report does not necessarily reflect its viewpoint or the viewpoints of its sponsors.

\section{References}

Ambraseys, N.N., Maximum intensity of ground movements caused by faulting, paper presented at Fourth World Conference on Earthquake Engineering, Santiago, Chile, Jan. 13-18, 1969.

Bolt, B.A., Earthquake studies in the People's Republic of China, Eos Trans. $A G U, 55(3), 108-117,1974$.

Bufe, C.G., J.H. Pfluke, and R.L. Wesson, Premonitory vertical migration of microearthquakes in Central Califor nia-Evidence of dilatancy biasing?, Geophys. Res. Lett., 1, 221-224, 1974.

Feng, T.-Y., Anomalies of amplitude ratio and $\bar{S}$ and $\bar{P}$ waves from near earthquakes and earthquake predic. tion (in Chinese with English abstract), Acta Geophys. Acad. Sinica, $17,140-154,1974$.

Feng, T.-Y., A.-N. Tan, and K.-F. Wang, Velocity anomalies of seismic waves from near earthquakes and earthquake prediction (in Chinese with English abstract), Acta Geophys. Acad. Sinica, 17, 84-98, 1974.

Heim, A., Earthquake region of Taofu, Geol. Soc. Amer. Bull., 45, 1035-1049, 1934.

Karnow, S., Mao and China: From Revolution to Revolution, 592 pp., Viking, New York, 1972.

Scholz, C.H., L.R. Sykes, and Y.P. Aggarwal, Earthquake prediction: A physical basis, Science, 181, 830-810, 1973.

Science for the People, China: Science Walks on Two Legs, 316 pp., Avon, New York, 1974

Shen, C., H. Chen, C. Chang, L. Huang, T. Li, C. Yang, T. Wang, and H. Lo, Earthquakes induced by reservoir impounding and their effect on Hsinfengkiang Dam, Sci. Sinica, 17, 2, 239, 1974.

Shih, C.L., W.L. Huan, H. Wu, and H.L. Tsao, On the intensive seismic activity in China and its relation to plate tectonics, Sci. Geol. Sinica, 281-292, 1973. (English translation by E.C.T. Chao, Amer. J. Sci., John Rogers vol., in press, 1975.)

Shih, C.L., W.L. Huan, K.K. Yao, and Y.T. Hsieh, On the fracture zones of Changma earthquake of 1932 and their causes, Acta Geophys. Sinica, 17(4), 272-287, $1974 a$.

Shih, C.L., W.L. Huan, H.L. Tsao, H.Y. Wu, Y.P. Liu, and W.K. Huang, Some characteristics of seismic activity in China, Acta Geophys. Sinica, 17(1), $1-13,1974 b$.

\section{Abstract Deadline}

\section{January 13,1976}

